IS-T-579

\title{
DROP SHAPES AND INTERNAL FLOW PATTERNS BY NUMERICAL SOLUTION OF THE NAVIER-STOKES EQUATIONS
}

\author{
Ph.D. Thesis Submitted lo lowa State University, \\ May 1973
}

T. D. Sandry

Ames Laboratory, USAEC lowa State University

Ames, lowa 50010

\begin{abstract}
This report was prepared as an account of work sponsored by the United States Government. Neither the United States nor the United States Atomic Energy Commission, nor any of their employees, nor any of thein cunliaclurs, subcontractors, or their employees, makes any warranty, express or implied, or assumes any legal liability or responsibility for the accuracy, completeness or usefulness of any information, apparatus, product or process disclosed, or represents that its use would not infringe privately owned rights.
\end{abstract}

Date of Manuscript: May 1973 


\section{DISCLAIMER}

This report was prepared as an account of work sponsored by an agency of the United States Government. Neither the United States Government nor any agency Thereof, nor any of their employees, makes any warranty, express or implied, or assumes any legal liability or responsibility for the accuracy, completeness, or usefulness of any information, apparatus, product, or process disclosed, or represents that its use would not infringe privately owned rights. Reference herein to any specific commercial product, process, or service by trade name, trademark, manufacturer, or otherwise does not necessarily constitute or imply its endorsement, recommendation, or favoring by the United States Government or any agency thereof. The views and opinions of authors expressed herein do not necessarily state or reflect those of the United States Government or any agency thereof. 


\section{DISCLAIMER}

Portions of this document may be illegible in electronic image products. Images are produced from the best available original document. 
NOTICE

This report was prepared as an account of work sponsored by the United States Government. Neither the United States nor the United States Atomic Energy Commission, nor any of their employees, nor any of their contractors, subcontractors, or their employees, makes any warranty, express or implied, or assumes any legal liability or responsibility for the accuracy, completeness or usefulness of any information, apparatus, product or process disclosed, or represents that its use would not infringe privately owned rights.

Available from: National Technical Information Service Department $A$

Springfield, VA 22151

Price: Microfiche $\$ 0.95$ 
Drop shapes and internal flow patterns

by numerical solution of the Navier-stokes equations

by

Thomas Denniston Sandry

A Dissertation Subritted to the

Graduate Paculty in Partial Fulfillment of

The Requireaents for the Degree of

DOCTOR OF PHILOSOPHY

Major: Chemical Engineering

Approved:

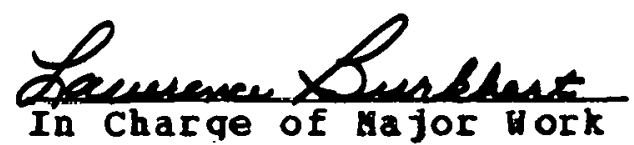

Henournet

For the Major Department

$\frac{\text { Chanlott Ehodeneh }}{\text { For the Graduate College }}$

Iowa State University

Ames, Iowa

1973 
TABLE OF CONTENTS

Page

ABSTRACT

INTRODUCTION :

LITERATURE REVIEH ! ! 14

Experimental observations $\quad 14$

Numerical Simulation 27

TEEORY . . 36

The Differential Model $\quad 37$

The Finite Difference Approximation 46

The Computation schere $\quad 59$

Stability and Accuracy . 64

Recent Hodifications $\quad 67$

RESOLTS 76

Drop Hodifications $\quad 76$

The Falling Drop Problem 99

The Forced Internal Circulation Drop Problem 121

CONCLUSIONS AND BBCOHERDATIONS 150

Conclusions $\quad 150$

Recommendations $\quad 150$

NOMENCLATURE $\quad 152$

ACKNORLEDGEHERTS $\quad 155$

BIBLIOGRAPHY $\quad 156$ 


\section{ABSTRACT}

The shape of and flov patterns uithin a hypothetical separating drop were determined by numerical solution of the Navier-stokes equations. The drop uas hypothetical in the sense that it separated because the surface tension force restraining it was reduced at the start of calculation. Houever, the velocity distributions and shape of the drop resemble those of an actual drop as it separates. Considerable surface stretch was observed at the sides of the drop and very little at the apex. The flow pattern within the drop was found to approach plug flow in the direction of qravity when the drop began to stretch out. These results vere also observed when a surface tension force was applied at the interface.

The flow patterns within a constant volume forced internal circulation drop were also determined numerically for various flow rates and viscosities. Increasing the viscosity while holding flow rate constant caused a transition in flow pattern from rotating to non-rotating flow. A similar change in flov pattern was observed when viscosity was held constant and flow rate decreased. However, a complete lack of rotation was not reached in this manner. Very little mixing was observed even at the highest velocity (1 centimeter per second) and lowest viscosity ( 1 centipoise). These flow patterns indicate that a penetration theory mass transfer model 
vi

would be appropriate for this system.

Several modifications to the un method are also pro-

vented. Host of the modifications deal with the location at which the tree surface pressure boundary conditions are applied. but some changes were also necessary in the method of surface tension force calculation, and in velocity extrapolatron at the free surface. Without all of these modifications it would not have been possible to simulate drop motions using the Mac method. 
IATRODOCTION

In most liquid extraction processes, drops forn, separate, and travel through a continuous nedium exchanging mass. monentur and energy. However, the mechanisms of these exchanges are not well anderstood, except during the travel period. This is because drops may form and separate so rapidly that the flows can be observed only by high speed photoqraphy, as illustrated in Fig. 1. On the other hand, during the rise or fall of a separated drop motion is usually steady and perhaps several orders of magnitude slover than formation and separation. Thus it is more easily observed, analyzed and modelled.

since the steady travel of drops has received uch attention, the transport mechanisms are fairly vell known, and the circulation patterns predictable (27). Yet ass transfer. calculations based on steady travel do not successfully account for all the material transferred during a drop's lifetime (27). Obviously, solute is being transferred during the formation and separation periods. But the velocity and pressure distributions ithin forming and separating drops are as yet unknown, consequently mass transfer mechanisms must be based on speculation about the nature of the flow patterns. The simplest flow models, hovever, do not successfully predict mass transfer during formation. Thus a means 
THIS PAGE

WAS INTENTIONALLY

LEFT BLANK 
Piqure 1. Photographs of a uater drop separating in air, taken at 400 frames per second by Halligan (26). Gravity acts in the downuard direction, and the screw has 52 threads per inch for scaling purposes. The seguence of the photographs is from top to botton beginning on the left. The relative times are 0.0,0.025, 0.050,0.0625, 0.065, and 0.075 sec onds. 

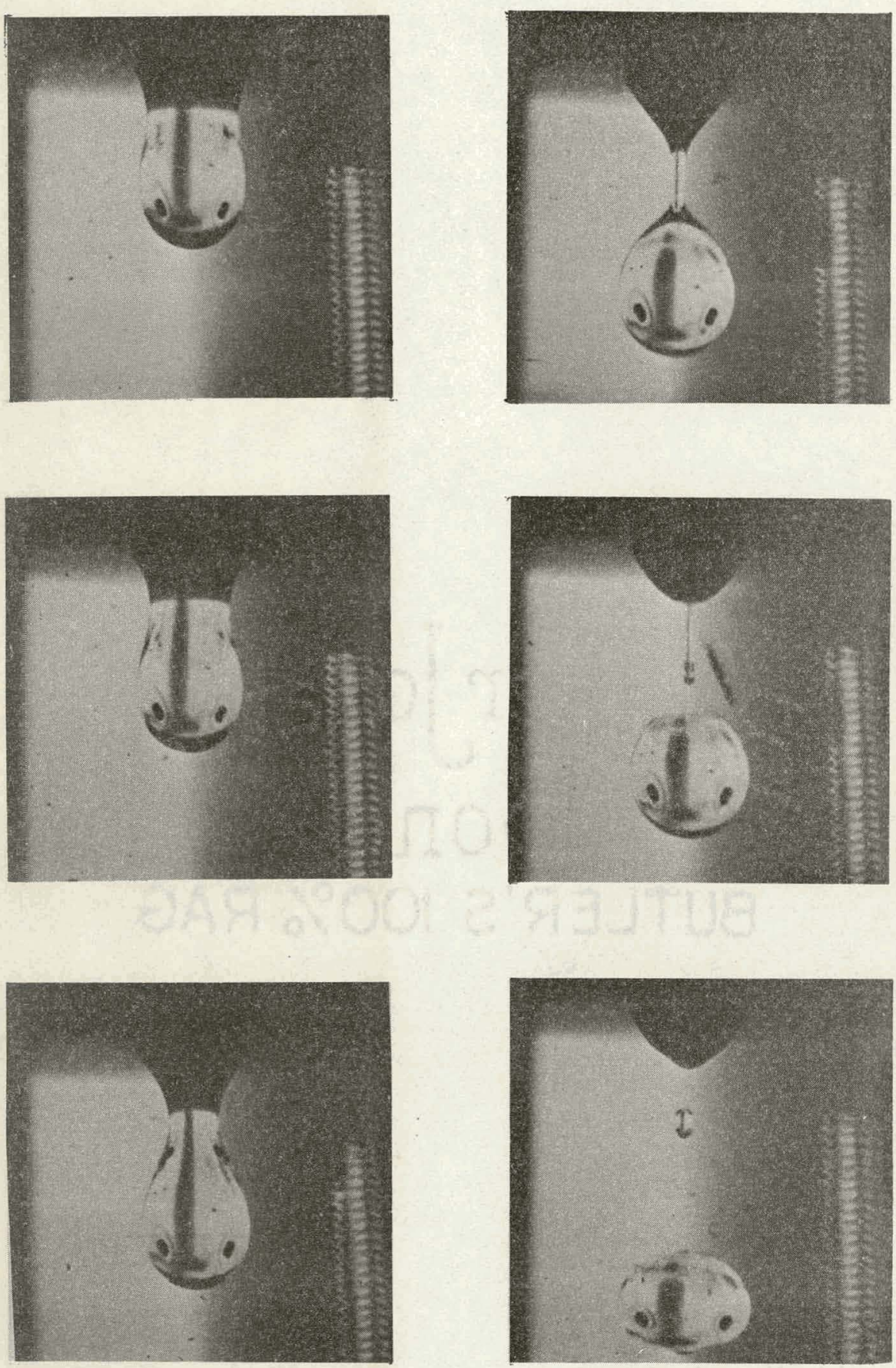
of analysis is needed wich will predict flow patterns, velocities and pressures, in order to predict mass transfer results more accurately.

It vas found during the course of this work that the combined processes of drop formation and separation are too complex to be analyzed as a single problem. Accordingly. formation and separation are dealt with as separate parts of the same problem. While it has not been possible to synthesize a complete picture of all the flous which go on during the combined processes, a clearer picture of the separate flows has been gained.

It is necessary to distinguish betreen two types of flow which will be considered. The first is the steady notion of a fluid circulating within a drop wose volume is maintained by addition and withdrawal of fluid at the same rate. This type of flow has been used in previously published mass transfer experiments $(22,52)$, and approxinates the flov vithin growing drops which have fluid added but not withdrawn.

The second type of flow is that of a drop which has underqone a sudden reduction in surface tension. This flow is somewhat like that which takes place vithin a drop during the separation process. These tuo types of motion, while only approximations, simulate the dominant wodes of flow during the formation and separation processes. 
The geometry of a drop of constant volune with forced internal circulation is seen in Fig. 2. The drop is composed of a material nore dense than the mediug around it and so qravity acts in the dounward direction, which is opposite to the direction of positive density difference. (In this study it was also necessary to restrict consideration to a continuous mediun of negligible inertial effect.). This situation is a particular form of Rayleigh-Taylor instability in which the interface is curved, and interfacial tension and qravity oppose one another. other forces acting on the drop are fluid pressure and acceleration. Gravity acts uniforaly over the entire drop. while surface tension creates a force which acts normal to the surface at each point, opposing the fluid pressure. Fluid within the drop ast conserve volume, but may be in motion. In general, fluid will enter through the orifice and leave through the annulus, producing the type of motion seen in Pig. 2.

Deformation of the drop will result if its restraining force, surface tension, is suddenly decreased or elininated. This type of flow, referred to as the falling drop problem, approximates the flow within a separating drop. Orice unrestrained flow begins, the fluid experiences locally high velocities and rapid acceleration in the direction of qravity. as illustrated in Rig. 3. Gravity acts in the downward direction, and watever surface tension force 
RADIAL DISTANCE, R

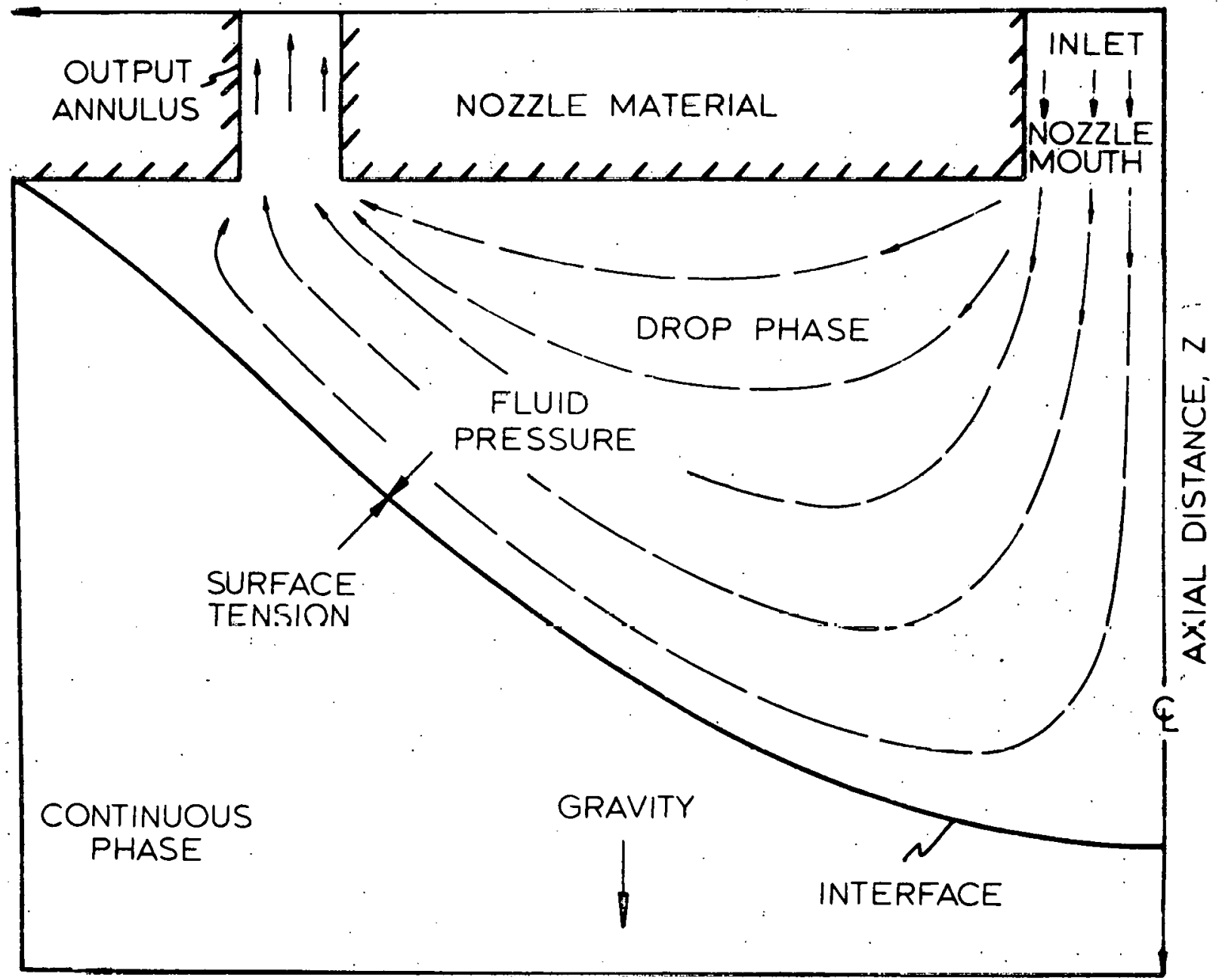

Figure 2. A typical drop with forced internal circulation showing particie paths and forces acting on the drop. 
RADIAL DISTANCE, $\mathrm{R}$

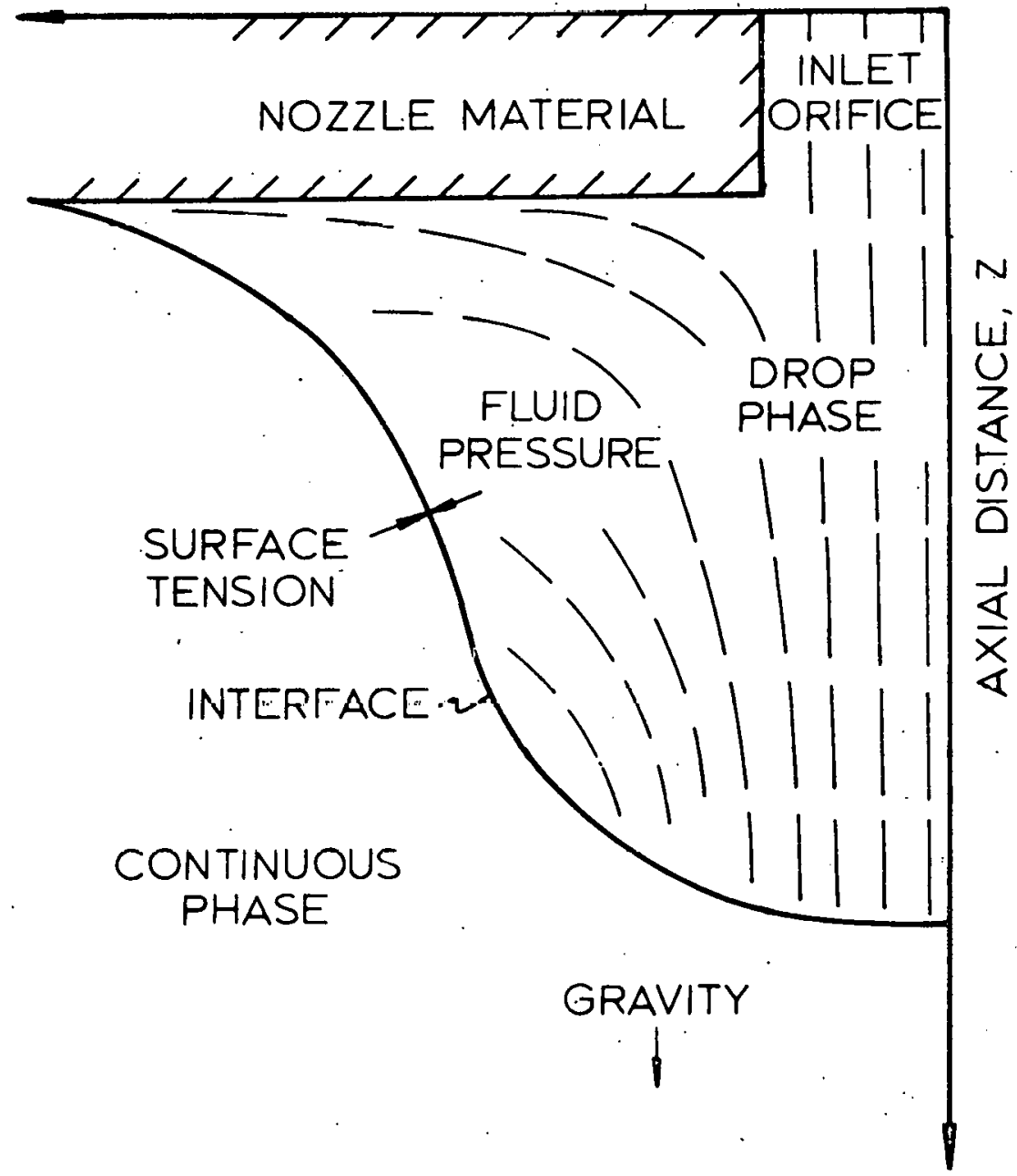

Fiqure 3. A typical falling drop shape shoving its relation to the cylindrically symmetric coordinate system. The dashed lines indicate particle paths and the forces acting on the drop are indicated by arrous. 
remains acts in the direction of the surface noral at every point of the surface, opposing fluid pressure. In this situation, the motion is predominantly vertical, with some horizontal flow near the base, as required by conservation of volume, but there is no rotation.

The complete analysis of floy during droplet formation and separation, by experimental determination of relocity and pressure distributions, is not presently feasible for several reasons. First the experimentally observed viscous, surface tension and buoyancy effects are difficult to separate from one another. They are also difficult to measure accurately. Furthermore, such data must be gathered by laboriously analvsing large volumes of high speed photographic film. making the experimental process tedious at best. Surface tension forces may be estimated from drop shapes, and accelerations from the movement of particles of aluminum or qlass suspended in the fluid, but no direct measure of pressure is yet póssible.

second, there is no guarantee of consistent or accurate results from one experimental run to the next due to the high sensitivity of surface tension to the presence of impurities. sliqht changes in surface tension produce changes in the pressure and velocity distributions. which makes accurate comparison of subsequent runs difficult. In the case of opaque substances, direct observation is not possible. Therefore, a 
technique is necessary which will allow the study of individual effects of the fluid parameters and provide time dependent information about the drop. without heavi reliance on experimental data.

In order to account for all the desired effects. without depending on experiaental data it is necessary to use a mathematical. model as a substitute for real fluid. The model nust be subject to the same restrictions as the real fluid and must provide enough detailed information about the fluid to allow prediction of flow patterns, changes in interfacial area and shape, as well as velocity and pressure distributions. By obtaining solutions to the mathematical model and comparing then with a limited number of experimental observations it should be possible to separate the effects of the individual fluid parameters and to determine the effects of those variables for which experimental measurements cannot be made. Of course the accuracy of the results obtained by mathematical modelling depend directly on the accuracy of the model. Thus accurate simulation of flow during drop formation and separation reduces to finding a sufficiently detailed model of the flow and an accurate method of solving the model.

The most accurate nathematical model of fluid motion, the equations of wotion, has been knoun for many years, and was derived by Navier in a restricted form in 1822. These 
equations are found in Bird. Stewart and Lightfoot (4), Aris (2) and Landau and Lifschitz (39). who discuss in detail the development of the equations and the restrictions which wust be observed in solving then. These equations are presented later in the Theory section: Conveniently, Bird, stewart and Iiqhtfoot (4) present them in a form wich is directig applicable to the problem at hand.

These equations represent the momentum conservation relationships, in differential form, of a Nevtonian. incompressible fluid of constant density. The equations used are also restricted to isothermal, non-turbulent flow conditions. The fluids and flow regimes that it is desired to study comply with these restrictions. Othervise auch are complicated models would be necessary. and the Navier-stokes equations are themselves a formidable challenge.

Analytical solutions to the equations of motion are known only for certain tppes of fluid flowing in containers having simple geometry. Because of the non-linearity of the equations, previous information about the form of the solution is usually incorporated into the solution technique, thus allowing some terms of the equations to be dropped. However, wen the flows are not known in advance, no reconmendation can be made to siaplify the problew. Such is the case for forming and separating droplets. Thus the technique used must be capable of handing the complete equations of 
motion.

accurate solutions to the equations of motion have been obtained by numerical techniques. Hovever, each numerical technique wust be tailored to cope with the specific problems it will be nsed to solve. Then, within the accuracy of the technique, an approxinate solution is guaranteed.

As indicated by Harlow (29) there are many numerical techniques arailable for solving the Navier-stokes equations. Each method has limitations on the types of flows to which it is best suited, the types of boundary conditions wich it can accept and the type of fluid it can simulate. Methods for solving viscous incompressible flow problems began to appear in 1965 and their accuracy has improved steadily with modification.

One such method is the rarker and Cell (AAC) method. which has been used to solve several Rayleigh-Taylor instability problens. The MAC method is a numerical technique which uses a finite difference approximation to the equations of motion. This is done by fixing the region in which flow is to be observed and dividing it up into a grid of small rectangles or cells. Within the cells, the primary variables (pressure and the velocity components) are located, and the finite difference aproximations are made. Fiuid is represented by massless marker particles which are independent of the grid and move about at the local fluid relocity. 
Thus the name, Marker and cell method.

The MAC method allows flow visualization because the movement of fluid is seen as movenent of the particles. The method also conserves mass because of its particular choice of finite difference approximation, thus satisfying the nost stringent restriction on the method. Also, the flow may be expressed quantitatively at any grid point, in teras of the primary variables. Thus the MaC method also satisfies most of the basic requirements of the droplet flor problen. However, as with any technique, it has its drawbacks, and any. of them appear when one attempts to adapt the method to the calculation of droplet flow patterns.

The basic drawback of the MAC nethod is the maner in which the boundary conditions at the free surface are handled. Producing the necessary modifications to the MAC method constituted a major portion of this project. Hoverer. the flexibility of the method, and its proven capabilities provided the inpetus to attempt the needed modifications.

It is the purpose of this research to present the modifications to the MAC method which were needed, their effects on the solutions, and the initial surface shapes and velocity distributions within forming and separating drops, calculated by the modified method. It is also the purpose of this research to determine the effects of viscosity and inlet velocity upon the flov patterns within drops with forced in- 
ternal circulation. It has been found that drops with forced internal circulation have tuo basic flov regimes, rotating and non-rotating. The effects of viscosity and inlet velocity on the occurrence of rotating flow have been investiqated over a range of values. Also a general picture of the combined processes of drop formation and separation has been qained from the investiqation of the falling drop problem, which was conducted vith varying reductions in surface tension. Comparison of the solutions of the falling drop problem and the forced internal circulation drop problem inplies that there is ret another transition from circulating flow to plug flow in the direction of gravity, occurring in the combined processes of drop formation and separation. This corresponds with the experimental observations of Wea thers (56). 


\section{LITERATORE REVIEN}

The literature related to this study is conveniently di- . vided into two groups, 1) experimental observations and 2) numerical simulation. The first group of articles, provide a brief history of the many approaches that have been taken toward understanding droplet phenomena. In this group there are two cateqories of articles, those which refer to the conbined processes of formation and separation, and those which refer to the process of circulation within a forming drop. They serve to introduce the phenomena physically, to explain the need for increasingly complex models, and to show the trend in droplet simulation leading to the use of the Navierstokes equations for dynamic simulation of droplet flous.

The second group of articles provides a parallel history of the development of the nac method, the conputing technique used in this study. They introduce the conputing rethod. some problems it has been used to solve, and the changes that have been made in the method in the search for increased accuracy.

\section{Experimental Observations}

In the first category of articles the approaches range from straight forward empiricism to differential models of the dynamics of formation and separation. The emergence of the more mathematically sophisticated models can be folloved 
with time, and it might be added, parallels the development of the modern computer.

Since about 1965 there has been a rapid proliferation of articles in the chemical engineering literature concerning drops. The level of interest in the area of drop phenomena is indicated by the number of recent reviev articles which include this area, or are devoted to it entirely $116,18,19$, 20. 50; 53). Of the experimental approaches, by far the majority are concerned with the transport processes going on during the travel (rise or fall) portion of a drop's iifetime. This is reflected in the fact that of the approximately 600 total related drop phenomena articles (16) published between 1965 and 1969, more than half vere concerned with steady motion. also, the majority of the articles relied on some form of dimensional analysis to correlate the transport data. As explained by lagarvey and laclatchy (4.1).

Since the wathematical complexities arising from the nonlinear terms in the Navier-stokes equations admit almost no relevant solutions to the problems associated with velocities and drop sizes normally encountered in chenical enqineerinq operations, most of the information has been the result of empirical and semi-empirical approaches to these flou problems. It would seen that the flow fields about all but the smallest drops are more or less unknown, and the experimental data specific to each problem offer little in the way of generalization.

Faced with the problem of correlating a property of drops forming in air and the fluid parameters. Freud and Harkins (14) in 1929 chose detached droplet weight as the 
most easily neasured flow parameter. They observed that the drop weight could be empirically correlated with boundary geometry and surface tension, but only crudely. While their work was mainly concerned with the determination of surface tension. they did consider the problem of droplet formation and separation, and concluded.

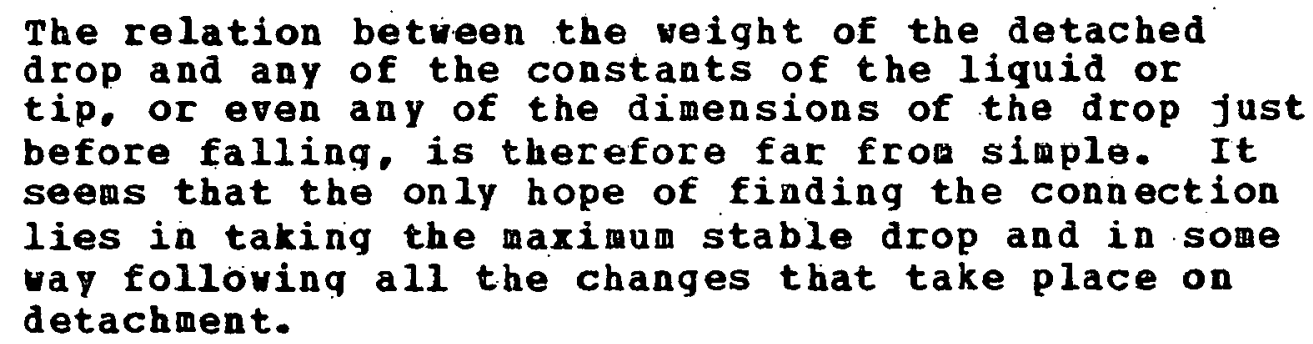

Hayvorth and Trepbal (33) in 1950, chose droplet volume as the wost significant variable they could measure in liquid-liquid systens and that to which other practically important variables could be related. But rather than follow all the changes during droplet formation and separation, as sugqested by freud and Harkins (14), they chose to urite a force balance and accept the correlation it gave between drop volume and the fluid parameters. Osing dimensional analysis they correlated their volume prediction equation and experimental data, varying the single free parameter in their model. Thus by studying the overall effects of surface tension, nozzle velocity, density and viscosity, they were able to produce an equation for the prediction of drop volumes accurate to within. $7.5 \%$ average error. 
In 1958 Null and Johnson (47) introduced the idea of a simplified geometric model of drops undergoing formation and separation. By combining cones, spheres and cylinders they were able to sinulate the shape of a drop in various stages of formation and separation. The volumes they obtained in this manner correlated with their experimental observations vithin $20 \%$ average error.

In 1966 uanfre (43) analyzed the drop formation and separation process, treating the drop as a boundary condition in a pressure balance. His analysis employs the Hagenpoiseuille relationship betueen pressure and volumetric flowrate, and results in a first order ordinary differential equation relating the change in droplet volume with tine. The analysis is unfortunately restricted to low Reynolds number flous as Manfre was primarily concerned with the extrusion of glasses and other highly viscous materials. His equation correlates his data vithin $8 \%$ average error.

During the same year Bao, Kumar, and Kuloor (49) presented several refinements to Hayrorth and Treybal's (33) oriqinal analysis. By using a more complicated force balance and a model with more free parameters, they were able to predict droplet volumes to within 6.8\% average error. This fiqure is sonethat deceiving, howerer, in that they minimize the number of maximu deviations of the model from the data, while Hayworth and Tregbal (33) do not. 
The force balance analysis was used successfully by Griqar, Jaroslay, and Landau (21) in 1970 to predict the loss in pressure across an orifice with a detaching drop. Their results vere accurate to vithin 4.68 average error when the flow was laminar.

Also during 1970 karaganan, Basu, and Roy (45) reported a simple dimensional analysis which results in an equation for the prediction of drop dianeters, that is accurate to within 108 average error. In 1971 kumar (37) proposed another force balance model valid for both bubbles and drops. It is one of the most complicated yet proposed, giring rise to a second order ordinary differential equation, but which only predicts droplet volumes to within 158 average error.

The previous authors have taken broad approaches and found the overall effects of the fluid parameters on one variable. drop volume. But recognizing that other useful information such as surface area, rate of area production. circulation rates and mass transfer rates must be related to the drop volume if this approach is to be used, it is doubtful that accurate values can be calculated due to the errors in predicting the volume. Thus it is necessary to find a means of relating these variables directly to the fluid paraneters.

In order to describe the profiles of forming and separating drops Halligan and Burkbart (23) in 1968 attribut- 
ed the change in interfacial shape to a linear pressure variation which they added to the equation of Laplace (40). By varying the radius of curvature at the origin (or apex) of the drop and also the paraneter multiplying the added linear tern, they vere able to produce droplet profiles in very good agreement with those observed experimentally. However, their model is valid only up to that time in the droplet's lifetime when it begins to mneck in" or derelop a minimum in its profile. They rere also able to nodel successfully the qrowth of a droplet with flow in through its base (25), but aqain only up to the point of "necking in". Halligan and Burkhart (24) in 1969 further observed the motion of small qlass spheres suspended vithin forming drops and found that the bulk velocity of the fluid in the separating portion of the droplet could be approximated by an exponential fnnction of time. It was also observed that viscosity retarded the motion of the particles relative to the apex of the drop. seemann (51) in 1970 observed the formation and separation of drops particularly frow the tiae of "necking in" on to separation. His observàtions confira by pressure balance analysis, that the non-linear interaction of velocities within the drop strongly affect the profile once "necking in" has occurred. Hear "necking in" the pressure distribution begins to shov a large departure from the linear assumption of Halliqan and Burkhart $(25,23)$. The maximua pressure devi- 
ation from linearity occurs where the fluid velocity is qreatest, suggesting that vere the velocity and pressure distributions more accurately known, improvenents in the prediction of droplet profiles might be made.

The second category of articles in the experimental qroup provides a history of observations about drops with internal circulation, primarily from a mass transfer point of view. This brief history also shous the need for nore sophisticated models of the circulation process, because existing mathematical treatments are very limited in scope and applicability.

In 1950, Dixon and Russell (13) found that, contrary to the assumptions of previous workers, the rate of gas absorption of a drop during the period of formation may be very hiqh, especially when the time of formation is short. They found that the mass transfer coefficient was inversely proportional to the time of formation and concluded,

It seens clear that the very high absorption values of drops having short formation times is due mainly to the turbulence produced within the drop by the jet of liguid from the capillary, which reduces the resistance to diffusion at the surface. It would be advantageous if in the matheratical treatment the degree of turbulence could be expressed quantitatively.

Hovever, they ade no attempt to predict the flou patterns within forming drops, and noted that unless the shapes of the drops observed vere more or less uniform it could not be assumed that the flou patterns induced by the jet rould be 
similar.

Garner and skelland (17) in 1951, observed that during the formation of a droplet the internal circulation was similar to that within a droplet in free fall. The found that liquid travelled from the nozzle along the central axis of the drop and returned along the interface to the base on which the drop rested, giving internal circulation. Increased rates of feed through the nozzle increased the rate of circulation and decreased the time of formation. They concluded.

Our experiments show that circulation during drop formation must be the chief reason for the large proportion of extraction during drop formation as compared to extraction during fall. Rapid formation of droplets gives increased mass transfer through more rapid circulation, but the work lof the authors) does not prove that this persists during the period of fall.

This work and that of Dixon and Russell (13) indicate the siqnificance of the circulation of fluid within forming drops, and sheds some light on the types of flow patterns which wight be expected.

In 1945, Groothuis and Kramers (22) observed considerable increase in the absorption rate for drops formed at short times (one second or less) compared with drops formed over longer periods. and attributed it to the mixing produced by the fet of fluid entering the drop. They also observed that while the rate of absorption was higher for the shorter times of formation, the total amount absorbed vas less than 
that for drops formed more slowly. In addition it uas found that the fet of liquid pronoted absorption aore in the initial stages of formation than in the latter stages. This was believed to be due to some daming effect of drop separation. Damping of circulation in high viscosity drops was credited vith decreasing the total absorption, even at high flov rates through the nozzle. They formulated a criterion for the point at wich jet action within the drop becones inportant. A Reyolds nuber characterizing the bulk flov was calculated based on the nozzle dianeter, the average jet velocity, and the density and viscosity of the drop. When this Reynolds nuaber was in the range 40-50 the rate of absorption began to increase due to jet action.

Harsh and Heideger (44) in 1965, observed a 14-fold decrease in the rate of mass transfer during the first second after drop formation. This was attributed to the decay of internal circulation. Hovever, the rate of decay in separating or separated drops was not as rapid as they had expected. As they had observed no oscillations of the drops iminediately after separation, they concluded that the persistent high mass transfer rates resulted from intense circulation within the drop. As the y explain.

The standard criterion for circulation predicts a stagnant drop during the transition from forming to separated drops and beyond. Thus one would expect that internal circulation vould decay early in the life of the drop. Motion pictures vere taken of drops containing degreased aluminum parti- 
cles in an effort to verify this assumption. From the filw it was concluded that internal circulation was indeed present during and immediately after formation and that this motion did appear to be rapidly damped during the first second of detached drop life. However; it has not been possible to detect an ordered circulation pattern vithin the drop. Because of the large transfer during formation the high transfer rate after separation cannot be attributed solely to the high concentration gradients of initial contact which would be obtained even in a stagnant syster. Bather, internal circulation ust sustain these gradients in spite of transfer out of the drop.

They also reported that the amounts of mass transferred during the three phases of a drop's life, formation, one second after formation, and thereafter, were approximately equal. These results indicate that the circulation that develops within drops during fornation is a persistent phenomenon wich way extend well into the separation stage. Panno and Calvert (48) in 1965, stated that one of the principal probleas in studying the effects of internal circulation has been the difficalty of isolating. initiating and maintaining internal circulation for an extended period. Consequently. they adopted the technigue of constan and Calvert (8) which consists of suspending a drop from two concentric nozzles in an atmosphere of the gas to be absorbed. Internal circulation was initiated by. injecting liquid into the center nozzle while sidultaneously withdrawing an equal amount from the outer annulus. It was noted that for the same drop size and flow rate, tho smaller the nozzle the greater the rate of absorption. This effect 
indicated the dependency of the absorption rate on the nozzle velocity.

visual observation of the flow pattern was made in a large scale model consisting of a nozzle inserted into a larqe test tube to provide a henispherical flow region. Some of the liquid in the anaiog drop vas observed to recirculate. After a matheratical analysis of the flov characteristics of a submerged jet impinging on the drop interface was made, it was concluded that the flow down the interface could be described as bulk flow with a boundary layer near the interface. It was also concluded that the boundary layer of the drop could be charactorized by a Begnolds number based on the nozzle diameter and relocity, and the drop density and viscosity.

Empirical correlations of the sherwood number la neasure of mass transfer) with the Repnolds number revealed that the mass transfer rate increases significantly with increasing Reynolds numbers while the Reynolds number is less than 120. For Reynolds numbers in the range $120-1200$ the mass transfer rate did not increase significantly. but was found to be proportional to the square root of the Reynolds number. They also found that for Reynolds numbers less than 120 the transfer rate is not defined by boundary layer theory, and it is possible that at these lov velocities recirculation occurs. Recirculation would tend to decrease the hass transfer rate 
by lowering the concentration gradient between the drop and the surrounding atmosphere, because absorbed material vould be retained in the drop.

Meathers (56) in 1970, observed that viscosity had a pronounced effect on the internal circulation within drops, and quantitatively described this effect. He also found that if the drop viscosity were sufficiently great circulation could be damed altogether. His observations agree with the fact that reduced mass transfer is found in high viscosity systens.

His high speed photographic analysis of the circulation patterns also revealed that circulation could extend vell into the separation period for relatively lov viscosities or hiqb flow rates. His presentation of photographs of particle paths, taken by time exposure, reveal the types of circulation patterns which can be expected in drops of high and lov'viscosity at the same flov rate. Comparison of the circulation patterns for drops with and withont withdrawal during formation revealed that the two flow patterns did not differ appreciably. In his correlation of "per cent circulation" with viscosity he observed a transition flow pattern uhich occurred at Reynolds numbers in the range 29-41. This corresponds with the range in which Groothuis and Kramers (22) found increased mass transfer rates for drops with internal circulation. 
Sharer (52) in 1972, confirmed the analysis of Heathers (56) in a mass transfer experiment involving drops uith forced internal circulation. He found that the flov regines which corresponded to the lovest circulation rates also produced the lowest rates of nass transfer, and a corresponding result for high circulation rates. He concluded that there are three distinct mass transfer regimes which correspond to the flow regimes in the drop. In addition to the high and Low mass transfer regines uentioned above he found a transition regime which corresponded to the flow transition regime of Heathers (56).

As can be seen from the compressed history of droplet flow simulation and experimentation just presented, flow models have developed to a point just short of detailed solution of the davier-stokes equations. clearly. this is the next logical step in the process of droplet floy modelling, as the machinery for solving the Navier-stokes equations is noy well developed.

About 1969 the dynamic modelling of drops vas considered. It had been noticed by many authors that surface tension played a large role in droplet phenomena, and that it vas most sensitive to the presence of impurities. Thus a means of eliminating this sensitivity was needed. It was also clear that iaproved accuracy in the modelining of aroplet behaviour beyond "critical volume" or with large volumetric 
flov rates, would have to include the effects of internal fluid velocity. Since the flow was very difficult to obtain experimentally. numerical simulation became a realistic possibilty. Numerical simulation

As a possible approach to the problem of determining dynamic drop profiles the numerical procedure known as the HaC nethod, originated by delch, Harlow, Shannon, and Daly (57) in 1965, and also described by Harlow and Melch (31) . was considered.

This technique assumes as its basis the complete Navierstokes equations with some slightly restricted boundary ánd initial conditions. The equations are approximated by Taylor series expansions truncated after the first fey terms. Basically the method steps through time obtaining approxinate solutions at each step, which are used as initial conditions to advance another time step. The technique is generally applicable to any flow problem for which the the Navier-stokes equations are a valid model and an Eulerian or fixed laboratory reference frame is desirable.

Within the laboratory reference frame marker particles are moved to follow the motion of the fluid and indicate the position of any interfaces, and for these reasons, the aAc method is highly qualified as a scheme for modelling drop formation and separation. The MAC method is known to be 
quite stable with respect to long tera instabilities because of a corrective procedure which keeps the errors aade in the conservation of mass at one tine step from accululating over the length of the problem.

An example of the free surface capabilities of the MaC method is the study of larqe amplitude free surface waves by Harlov and Welch (32). In this 1966 study the surface of an initially quiescent liguid is inpulsively perturbed by a sinusoidal pressure variation. After the initial inpulse no. pressure is applied to the free surface, which points out a drauback of the oriqinal MaC method. As formulated, the MAC method does not allow accurate application of time varying pressure boundary conditions at the free surface. This study was successful because accurate application of initial conditions at the free surface is possible. Thus the resulting flov behaves much like a forming drop, particulariy in the initial stages. The results vere found to agree quite well with available theoretical and experimental "bubblen or "spike" speeds and interface shapes.

In 1967. Harlow and Shannon (30) simulated the deformation of an initially spherical liquid drop just after it had inpacted either a solid surface, a deep pool, or a shallow pool. The resulting output vividly portrays the actual fluid motion, agrees fairly vell vith the available experimental data, and reveals some flow patterns not previ- 
ously observed. The article clearly indicates the potential of the Mac nethod for handing the types of flows expected in a forming and separating droplet.

Due to the iaportance of the free surface both as a source of boundary conditions and as an experinentaliy convenient reference surface, it is necessary to have the best possible boundary information arailable. As mentioned earlier, the original aic nethod has several shortcoaings in this regard. Hoverer, they have not gone unnoticed. In their 1968 article concerning the free surface stress conditions. Hirt and Shannon (36) point out the effects of viscosity on the transport of both normal and tangential nomentua at the interface. They choose the example of a viscous bore and illustrate the separate effects of including the nornal and tangential stresses at the interface.

Their results are an improvenent on the original MaC calculations, compared with the theoretical bore height and speed. Hoverer, they do not attempt any detailed resolution of the free surface position, but rather make approximations to the stress conditions, which largely take care of the errors in the viscous bore problem.

Although their study is restricted to inviscid flow and no time varying surface pressure is reported. Chan and street (7) in 1970 took up the problem of improving the resolution of the free surface, in order to accurately locate pressure 
boundary conditions. While they do not say so explicitly, the order of the ercor they point out in the original MAC method nay be as large as the value of the pressure itself, i.e. $0(1)$. Their technique for lowering the errors incurred at the free surface is a considerable improvement orer the oriqinal kac treatment; The resulting study of the runup and amplitude of water waves striking a bulkhead showed excellent reproducibility not possible using the original ac nethod, and also excellent agreement with theory and experimental results.

Nichols and Hirt (46) in a subsequent paper (1971) incorporated the actual free surface position into their calculations and have also included the viscous stress terms discussed by Hirt and shannon (36). Howerer, their nain modifications to the $M A C$ technique are in the application of boundary pressure data more nearly at the free surface (though there is some doubt as to the generality of their technique). and the inclusion of viscous stress terms in the pressure boundary condition of the free surface. Their technique provides an alternative to that of chan and street (7) if viscous effects are deternined to be important, in aroplet calculations.

viecelli (55) in 1969, considered the problem of incorporating arbitrarily curved boundaries in unc calculations. His approach is to treat curved boundaries as though 
they were free surfaces with an applied pressure which causes the fluid to flow tangential to then. The schene involves replacing the MAC technique for pressure iteration with one which simultaneously relaxes the pressure and velocity fields. No advantage is gained unless there are curved boundaries. Then this form allous the application of a corrective pressure force at the wall which conserves rolume. To use this technique in forced internal circulation droplet flous one has only to apply a corrective pressure at the free surface at each iteration and allow the flou to proceed to steady state. The corrective pressure term vanishes at steady state as it is proportional to the scalar product of the local fluid velocity and the surface normal, and these two vectors are orthogonal at steady state.

viecelii (54) in 1970, also considered the problen of arbitrarily curved boundaries which nove vith time. This technique is a variation of his previous work (55) which allows the boundary to respond to fluid pressure and rotion, while still requiring the flow to be tangential to it. While this approach vas not used in droplet calculations, it merits further investigation. One serious drawback of the technique is the requirement that the velocities and pressures be iterated simultaneously. This procedure is very tine consuming. and may ultimately linit the length of a fiou simulation in teris of computer time. 
Also of considerable importance in any numerical scheme are the measures of accuracy and nunerical stability. In general the techniques used for stability analysis of linear partial differential equations simply will not work when applied to non-linear equations, Hovever, Hirt (35) has provided a guideline for approaching the stability analysis of aAC type probleas. He compares the original partial differential equation with that which produced the finite difference approximation, including the low order error teras. The discrepancies between the original equation and the Taylor series approximation provide the stability conditions direct1y. Results identical with a Fourier stability analysis are produced for linear equations, and those for the equations of motion agree vell with observations about the stability of the waC method gained from experience.

In 1968 Hirt and Harlow (34) generalized the analysis of the corrective procedure used in the original MAC nethod and in so doing nore clearly stated its principles. The procedure is qenerally applicable to the solution of initial value problems, and in particular it is the reason for the stability of long running ac problems. This procedure also introduces considerable efficiency into the iterative procedure by allowing some error to occur within an iteration, but no accumulation of error from one iteration to the next. 
The final area particularly germane to this study is the calculation of fluid dynamics problems affected by interfacial tension. In order to add the ability to handle surface tension related phenomena to the unc method, Daly (12) in 1969 proposed that the interface be designated by specific particles originally laid out on the free surface and interpolated by cubic splines at each iteration. This technique allows direct computation of the forces acting on the free surface from the relation between the radius of curvature and the interface position function. It allows for considerable complexity in the curve describing the interface, but requires an equally complex algorithm for the force computation due to the parameterization he has chosen for the interface. The accuracy of the procedure is not discussed but a detailed description of the entire algorithm and some sugqestions for initial particle layouts are provided. Daly (10) has used the MAC technique to study the effects of tro material flovs where the fluid is divided into immiscible hodogeneous regions, with constant properties throughout each region. His study of this type of RayleighTaylor instability agrees well with the theoretical work of Chandrasekhar (6) in predicting the grouth rate of "spikes" of heary fluid and "bubbles" of light fluid. The study produced detailed information about the interface characteristics as a function of the density ratios of the two fluids, 
in the absence of viscosity. Also an expression is derired. which correlates the observed "spike" and "bubble" speeds over a longer interval than the linear theory and is reasonably justifiable on the basis of the fluid's resistance to motion. This article also serves to illustrate the potential applicability of the MAC method to two fluid problems such as the forming and separating drop in a liquid-liquid systen.

In a subsequent paper, Daly and pracht (11). investigated density current surges or flows which result from small differences in the densities of two fluids. In this presentation the inclusion of surface tension is discussed as vell as solute transport and the numerical stability of the technique. The method presented previously (12) was used to incorporate the interfacial tension force, and the method of Hirt (35) was used to deduce the stability criteria. solute transport was accomplished by incorporating a Boussinesq approximation into single fluid computations. Both the single fluid and full two fluid computations were used to compare the effects of density. geometry, viscosity and surface tension on interface shape and motion. Excellent agreement with experimental results is reported and the conputed results have permitted the developont of simplified models of initiating and steady flow which also agree vell with experiments. The effects of surface tension vere observed to be a smoothing and a slowing of the interface, but the 
results vere linited to a single computation.

In another publication Daly (9) has investigated the effects of surface tension on the Rayleigh-Taylor instability previously covered. In general the effect of surface tension vas found to be a "squeezing" of the interface uhich enhances the "spike" breakup, or the formation of a separated drop. Surface tension is also found to retard the grovth of short wavelength surface instabilities and to produce smooth interface profiles. Good agreement was obtained with the theoretical vork of Chandrasekhar (6) vho predicted the initial grovth rates of such instabilities by linear analysis.

In conclusion it should be reiterated that the uAC method and its variations reported here comprise but a small portion of the total breadth of numerical fluid dyamics techniques. Harlow (29) has compiled an annotated bibliography of these technigues which includes representative proqrams that have been used. The MAC method is only one of the available techniques. which range from Lagrangian methods for hiqh speed flows, to transient creep flows by a variant of the MAC method, through many constitutive equations, boundary and initial conditions, and yeometry capabilities. 


\section{THEOR Y}

Before the detailed mathematical analysis of flow uithin drops can be begun, more specific statements of the physical problems to be investiqated are necessary. It is desired. for the purpose of eventual mass transfer calculations, to study the hydrodynamic behavior of liquid drops formed at an orifice through which fluid may enter. The drops may be of two types: pendant drops which undergo a step change in surface tension initially, as illustrated in pig. 3, or, pendant drops of constant volume and shape which have forced internal circulation, as illustrated in Fig.2. It is of interest to determine the general flow patterns, the velocity and pressure distributions, and the independent effects of viscosity, density and surface tension, upon such drops. From the above variables are sought their independent effects on the formation and separation processes and such related variables as the interface shape and the rate of surface area production.

In order to limit this study to a differential model which is known to be solvable, the fluid is idealized to have constant density and viscosity throughout its homogeneous portions. It is further restricted to be incompressible, or volume conserving, and without mass transfer or buoyancy effects. In addition to easing the mathematical burden these 
approximations are known to be valid for the liquids which it is desired to study. The velocity distributions sought nust also be non-turbulent. Further, the flows mut be axially symetric with no angular relocity component, and as flows within the interface do not exist, the interface ay be treated as a matheratical surface of revolution.

The Differential godel

Figure 4 serves to illustrate the general arrangenent of the free surface, the orifice, the interface and the coordinate system in cross-section. The droplet is taken to be the volume formed by revolving the curve about the z-aris, and its surface to be the surface of revolution. This surface is also the boundary between the fluid and a region of negligible inertial effect, the atmospherè.

The differential model of both the falling arop problem and the forced internal circulation drop problem will be taken as the full Navier-stokes equations of notion, derived in Bird, Stewart, and lightfoot (4). In cylindrical coordinate component form, for a Newtonian fluid with constant density. $\rho$. and kinematic viscosity. $\nu$. the equations are r-component $\frac{\partial V_{r}}{\partial r}+\frac{\partial V_{r}}{\partial r}+\frac{V_{0}}{r} \frac{\partial V_{r}}{\partial \theta}-\frac{V_{e}^{2}}{r}+V \frac{\partial V_{r}}{\partial z}=$

$$
-\frac{1}{\rho} \frac{\partial \mathrm{P}}{\partial r}+\nu\left[\frac{\partial}{\partial}\left(\frac{1}{\partial}(r)\right)+\frac{1}{r^{2}} \frac{\partial^{2} V_{r}}{\partial \theta^{2}}-\frac{2}{r^{2}} \frac{\partial V_{\theta}}{\partial \theta}+\frac{\partial^{2} V_{r}}{\partial z^{2}}\right]+g_{r}
$$




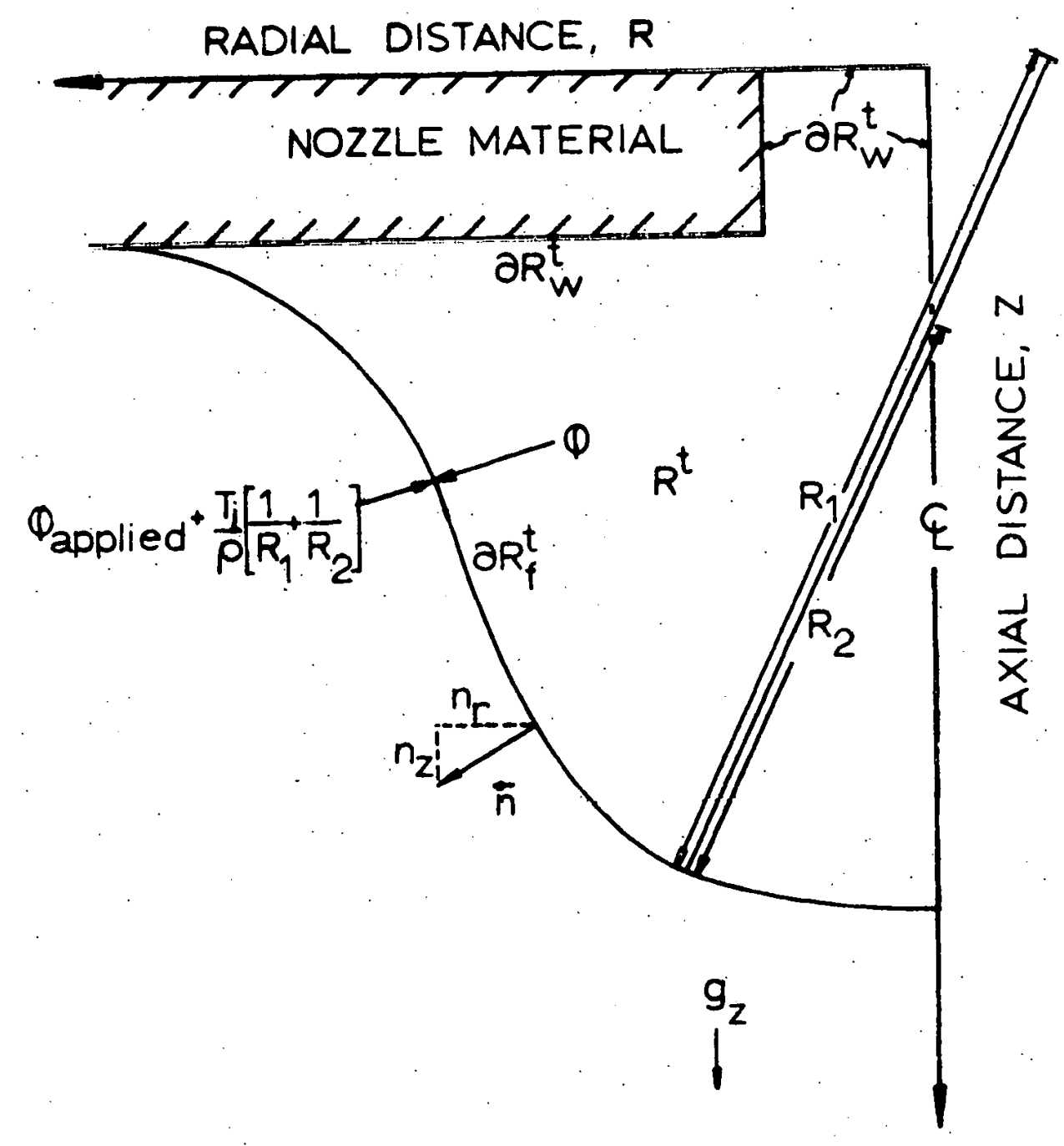

Piqure 4. a typical falling drop shoring the definitions of the fluid region and its boundaries. Also indicated are the relation of the surface normal vector to the interface, the radii of curvature and the lines of action of the normal stresses. 
e-component $\frac{\partial V_{\theta}}{\partial t}+V_{r} \frac{\partial V_{\theta}}{\partial r}+\frac{V_{\theta}}{r} \frac{\partial V_{\theta}}{\partial \theta}+\frac{V_{r} V_{\theta}}{r}+V_{z} \frac{\partial V_{\theta}}{\partial Z}=$

$$
-\frac{1}{\rho} \frac{\partial P}{\partial \theta}+\nu\left[\frac{\partial}{\partial r}\left(\frac{1}{r} \frac{\partial}{\partial r}\left(r V_{\theta}\right)\right)+\frac{1}{r^{2}} \frac{\partial^{2} V_{\theta}}{\partial \theta^{2}}+\frac{2}{r^{2}} \frac{\partial V_{r}}{\partial \theta}+\frac{\partial^{2} V_{\theta}}{\partial Z^{2}}\right]+g_{\theta}
$$

z-component $\frac{\partial V_{z}}{\partial t}+V_{r} \frac{\partial V_{Z}}{\partial r}+\frac{V_{\theta}}{r} \frac{\partial V_{Z}}{\partial \theta}+V_{z} \frac{\partial V_{Z}}{\partial Z}=$

$$
-\frac{1}{\rho} \frac{\partial P}{\partial z}+\nu\left[\frac{1}{r} \frac{\partial}{\partial r}\left(r \frac{\partial V_{z}}{\partial r}\right)+\frac{1}{r^{2}} \frac{\partial^{2} V_{z}}{\partial \theta^{2}}+\frac{\partial^{2} V_{z}}{\partial z^{2}}\right]+g_{z}
$$

continuity

$$
\frac{1}{r} \frac{\partial\left(r V_{r}\right)}{\partial r}+\frac{1}{r} \frac{\partial V_{\theta}}{\partial \theta}+\frac{\partial V_{z}}{\partial Z}=0
$$

By assuming that the flow will be cylindrically symetric, the number of equations and independent variables may both be reduced by one. Setting, $\nabla_{\theta}=0$ and letting $u=v_{r}, v=v_{2}$ and $\phi=p / p$. Eqs. $(1,3,4)$ become

$$
\begin{gathered}
\frac{\partial U}{\partial t}+u \frac{\partial U}{\partial r}+v \frac{\partial U}{\partial z}=-\frac{\partial \phi}{\partial r}+v\left[\frac{\partial}{\partial r}\left(\frac{1}{r} \frac{\partial(r u)}{\partial r}\right)+\frac{\partial^{2} u}{\partial Z^{2}}\right]+g_{r} \\
\frac{\partial V}{\partial t}+u \frac{\partial V}{\partial r}+v \frac{\partial V}{\partial z}=-\frac{\partial \phi}{\partial Z}+v\left[\frac{1}{r} \frac{\partial}{\partial r}\left(r \frac{\partial V}{\partial r}\right)+\frac{\partial^{2} V}{\partial z^{2}}\right]+g_{z} \\
\frac{1}{r} \frac{\partial(r u)}{\partial r}+\frac{\partial V}{\partial z}=0
\end{gathered}
$$

These equations may be subsequently rearranged into a form which conserves momentum over an arbitrary volume by using the continuity equation.

$$
\frac{\partial U}{\partial t}+\frac{1}{r} \frac{\partial\left(r u^{2}\right)}{\partial r}+\frac{\partial(u V)}{\partial Z}=-\frac{\partial \phi}{\partial r}+\nu \frac{\partial}{\partial Z}\left[\frac{\partial U}{\partial z}-\frac{\partial V}{\partial r}\right]+g_{r}
$$




$$
\frac{\partial V}{\partial t}+\frac{1}{r} \frac{\partial(r u V)}{\partial r}+\frac{\partial\left(V^{2}\right)}{\partial z}=-\frac{\partial \phi}{\partial z}-\frac{\nu}{r} \frac{\partial}{\partial r}\left[r\left(\frac{\partial U}{\partial z}-\frac{\partial V}{\partial r}\right)\right]+g_{z}
$$

Equations (7-9) are the equations on which the uac uethod is based.

In order to complete the problem statement it is necessary to furnish initial and boundary conditions uhich the solutions $u(r, z, t), v(r, z, t)$ and $\phi(r, z, t)$ must satisfy in addition to satisfyinq Bgs. (7-9). At walls and lines of symnetry the boundary conditions are easily specified. The normal component of velocity must vanish, in any case, and the tanqential component, or its derivative in the normal direction must ranish also. Strictly speaking, both the normal and tangential velocities wust vanish at solid yalls, in order to satisfy the no slip condition observed in nature: Hoverer, forcing the tangential velocity to vanish in sinulations can qive the solutions so obtained the appearance of having excessive drag at these surfaces. This is because in ail numerical solutions of this type there is a linit to the resolntion of the fluid motion which may be obtained. consequently boundary conditions ay excessively influence the solution a few units into the computation grid instead of acting only along the line to which they apply. This effect is overcone in the wac method by allowing the normal derivative of the tangential velocity to vanish instead of the velocity itself. Thus. the tangential velocity may not be 
zero at a wall as expected. but this condition may be at least partly justified on numerical grounds $(57,46)$.

The normal derivative of pressure is thus also specified, because the fluid must satisfy the equations of motion at the walls and lines of symmetry, and the velocities and their derivatives are specified for all time at these boundaries. The boundary conditions at walls and lines of symetry are shown below.

Free slip condition:

No slip condition:

$$
\frac{\partial V_{T}}{\partial \eta}=0 ; \quad V_{\eta}=0 ; \frac{\partial \phi}{\partial \eta}=g_{\eta}
$$

$$
v_{\tau}=0 ; \quad v_{\eta}=0 ; \quad \frac{\partial \phi}{\partial \eta}=f\left(\frac{\partial v_{\eta}}{\partial \eta}, \frac{\partial^{2} v_{\eta}}{\partial \eta^{2}}\right)+g \eta
$$

Where subscript $\eta$ denotes the normal direction and subscript $\tau$ the tangential direction. For example, at a vertical line of spmetry or free slip wall, $\eta$ becomes the radial direction $r$, and $\tau$ becomes the axial direction. $z$. Thus,

$$
\frac{\partial v}{\partial r}=0 ; u=0 ; \frac{\partial \phi}{\partial r}=0
$$

and in the same geometry as above, but at a no silp wall

$$
v=0 ; u=0 ; \frac{\partial \phi}{\partial r}=\frac{\partial}{\partial r}\left(\frac{1}{r} \frac{\partial(r u)}{\partial r}\right)+g_{r}
$$

The most difficult boundary conditions to specify are those at the free surface. At the free surface, in order to conserve momentum and volume, the continuity equation. Eq. (7). must be satisfied within the fluid. From the stress tensor one finds that $\phi=\phi_{\text {applied }}+2 \nu\left[n_{r}^{2} \frac{\partial u}{\partial r}+n_{r} n_{z}\left(\frac{\partial U}{\partial z}+\frac{\partial V}{\partial r}\right)+n_{z}^{2} \frac{\partial V}{\partial z}\right]+\frac{T_{i}}{\rho} K_{(12)}$ 
and

$$
\nu\left[2 n_{r} n_{z} \frac{\partial u}{\partial r}+\left(n_{z}^{2}-n_{r}^{2}\right)\left(\frac{\partial u}{\partial z}+\frac{\partial y}{\partial r}\right)-2 n_{r} n_{z} \frac{\partial v}{\partial z}\right]=0
$$

as qiven by Hirt and Shannon (36), and Landau and Lifschitz (39). Here $\phi$ is the pressure to density ratio used in Eq's. (8) and (9). $\mathrm{T}_{j}$ is the surface tension coefficient and $\mathrm{K}$ is the curvature. Thus.

$$
K=\left(\frac{1}{R_{1}}+\frac{1}{R_{2}}\right)
$$

where $R_{1}$ and $R_{2}$ are the principal radil of curvature. Clearly. if the fluid is either motionless $(u=v=0)$ or inviscid $(\nu=0)$. Eq. (12) becomes Laplace's (40) capillary equation.

Equation (12) as written is the dynanic pressure boundary condition and is one of the most difficult conditions to simulate. Weither the velocity gradients nor the curvature of the surface can be specified a priori, if the drop changes shape with time. Thus, this boundary condition must be sinulated and in general cannot be accurately applied. Fortunately. the curvature term and the applied pressure terms are reasonably easy to specify and they tend to dominate the term containing the velocity derivatives in the problems to be solved. Thus, for convenience this boundary condition is reduced to

$$
\phi=\phi_{\text {applied }}+\frac{T}{\rho}\left(\frac{1}{R_{1}}+\frac{1}{R_{2}}\right)
$$


As wight be expected, Eq. (13) is even more difficult to approximate than Eq: (12) . as it involves more unknown derivatives. Consequently Eg. (13) is ignored as a boundary condition on this problem, but Eq. (7), continuity, is enforced. Thus, wile these conditions are not the correct boundary conditions, they are those uhich can be most accurately simulated. and are a reasonable approximation to the correct boundary conditions.

This is a much simplified set of boundary conditions, but one uhich is reasonably accurate for the types of systems that it is desired to study. For those fluids in which the full stress boundary conditions are important, some approximations may be used wich will allow partial incorporation of Eqs. (12) and (13) as boundary conditions.

The initial conditions to which the fluid is subjected are in general easily specified. The velocities must be consistent with the above boundary conditions and satisfy the equations of motion. In general, these restrictions are satisfied by, the conditions u=constant, v=constant which is a useful starting condition. No initial condition is needed on pressure, becanse it may be solved for by inserting the initial velocity conditions into the equations of motion, and inteqrating. Also, the initial velocities must satisfy the continuity equation, which constant velocities do. Hovever, more complicated initial conditions may be used provided they 
satisfy continuity, the equations of motion, and the boundary conditions. Their general for is indicated by

$$
u=f(r, z) ; v=g(r, z)
$$

The problea can now be more coapactly stated if the followinq conventions are adopted. Defining $R^{\dagger}$ as the spacial reqion occupied by fluid at any time $t$ and $\partial R^{\dagger}$ as its boundary (rigid valls, free surfaces, lines of symetry, etc.), it is clear that Egs. (7-9) must be satisfied for all $R^{\dagger}+\partial R^{\dagger}$ and for all times t $\geq 0$. The solution wist also reduce to Eq. (16) at $t=0$, on $R^{\circ}+\partial R^{\circ}$, and wust satisfy. Egs. (10) and (11) at valls and lines of symmetry, $\partial R_{w^{\prime}}^{\dagger}$ and Bgs. (7) and. (15) at the free surface, $\partial R_{f}^{\dagger}$, for all $t>0$. Here ve take $\partial R^{\dagger}=\partial R_{w}^{\dagger}+\partial R_{f}^{\dagger}$. A typical fluid configuration, such as that in Pig. 4, will help define some of the terms used in the preceding equations. The definitions of all the terms used in the above equations way be found in the section entitied Nomenclature.

Since there are three equations, Eqs. $(7)-(9)$ and three dependent variables, pressure, and the two velocity components, the above set of equations may in principle be solved for tho dependent variables. Hovever, the pressure $\phi$ is implicit in the expressions for the accelerations. Thus it is necessary to differentiate Eq. (8) with respect to $r$ and $\mathrm{Eq}$. (9) with respect to $z$ and combine the differentiated forns in order to produce an equation explicit in $\phi$. Thus. 
45

$$
\begin{aligned}
\frac{1}{r} \frac{\partial}{\partial r}\left(r \frac{\partial U}{\partial t}\right) & =\frac{1}{r} \frac{\partial}{\partial r}\left\{r\left[-\frac{1}{r} \frac{\partial\left(r u^{2}\right)}{\partial r}-\frac{\partial(u V}{\partial Z}-\frac{\partial \phi}{\partial r}+\nu \frac{\partial}{\partial Z}\left(\frac{\partial U}{\partial Z}-\frac{\partial V}{\partial r}\right)+g_{r}\right]\right\} \\
& \left.=-\frac{1}{r} \frac{\partial^{2}\left(r u^{2}\right)}{\partial r^{2}}-\frac{1}{r} \frac{\partial}{\partial r}\left(r \frac{\partial(u V)}{\partial Z}\right)-\frac{1}{r} \frac{\partial}{\partial r}\left(r \frac{\partial \phi}{\partial r}\right)+\frac{\nu}{r} \frac{\partial^{2}}{\partial r} \frac{\partial U}{\partial Z}-\frac{\partial V}{\partial r}\right) \\
\frac{\partial}{\partial Z}\left(\frac{\partial V}{\partial t}\right) & =\frac{\partial}{\partial Z}\left\{-\frac{1}{r} \frac{\partial(r u V)}{\partial r}-\frac{\partial\left(V^{2}\right)}{\partial Z}-\frac{\partial \phi}{\partial Z}-\frac{\nu}{r} \frac{\partial}{\partial r}\left[r\left(\frac{\partial U}{\partial Z}-\frac{\partial V}{\partial r}\right)\right]+g_{z}\right\} \\
& =-\frac{1}{r} \frac{\partial^{2}(r u V)}{\partial r \partial Z}-\frac{\partial^{2}\left(V^{2}\right)}{\partial Z^{2}}-\frac{\partial^{2} \phi}{\partial Z^{2}}-\frac{\nu}{r} \frac{\partial^{2}}{\partial r \partial Z}\left[r\left(\frac{\partial U}{\partial Z}-\frac{\partial V}{\partial r}\right)\right]
\end{aligned}
$$

These equations may be combined in the following manner,

$$
\begin{aligned}
& \frac{1}{r} \frac{\partial}{\partial r}\left(r \frac{\partial U}{\partial t}\right)+\frac{\partial}{\partial Z}\left(\frac{\partial V}{\partial t}\right)=\frac{\partial}{\partial r}\left(\frac{\partial U}{\partial t}\right)+\frac{1}{r} \frac{\partial U}{\partial t}+\frac{\partial}{\partial Z}\left(\frac{\partial V}{\partial t}\right) \\
& =\frac{\partial}{\partial t}\left(\frac{1}{r} \frac{\partial(r u)}{\partial r}+\frac{\partial V}{\partial Z}\right) \\
& =\frac{\partial}{\partial t}(\nabla \cdot \vec{u}) \\
& =-\frac{1}{r} \frac{\partial^{2}\left(r u^{2}\right)}{\partial r^{2}}-\frac{2}{r} \frac{\partial}{\partial r}\left(r \frac{\partial(u v)}{\partial Z}\right)-\frac{\partial^{2}\left(v^{2}\right)}{\partial Z^{2}}-\frac{1}{r} \frac{\partial}{\partial r}\left(r \frac{\partial \phi}{\partial r}\right)-\frac{\partial^{2} \phi}{\partial Z^{2}}
\end{aligned}
$$

Which is the desired relation between the pressure and velocity distributions. Identifying the divergence of $\vec{u}$ by D. the above form becomes,

$$
\frac{\partial D}{\partial t}=-\frac{1}{r} \frac{\partial^{2}\left(r u^{2}\right)}{\partial r^{2}}-\frac{2}{r} \frac{\partial}{\partial r}\left(r \frac{\partial(u V)}{\partial Z}\right)-\frac{\partial^{2}\left(V^{2}\right)}{\partial Z^{2}}-\frac{1}{r} \frac{\partial}{\partial r}\left(r \frac{\partial \phi}{\partial r}\right)-\frac{\partial^{2} \phi}{\partial Z^{2}}
$$

or, recognizing the cylindrical coordinate for of the $\nabla^{2}$ operato,

$$
\nabla^{2} \phi=-Q-\frac{\partial D}{\partial t}
$$

where

$$
Q=\frac{1}{r} \frac{\partial^{2}\left(r u^{2}\right)}{\partial r^{2}}+\frac{2}{r} \frac{\partial^{2}(r u V)}{\partial r \partial Z}+\frac{\partial^{2}\left(V^{2}\right)}{\partial Z^{2}}
$$

Equation (19) provides a means of finding the pressure dis- 
tribution associated vith a qiven velocity distribution. Now the differential model is completely specified by Egs.

(7) - (9) (19) and the boundary and initial conditions, Bqs. (10). (11). (15) and (16).

The Finite Difference Approximation

The eventual finite difference for mulations depend on the choice of the locations of the dependent variables, or, the grid. Since there are any possible choices of grids, some experimenting is necessary to deternine which arrangements are feasible. The choice of the grid shape and size and the relative location of the variables was determined by Helch, et al. (57) after many different schemes vere tried. Their trial and error approach led thes to the conclusion that the conservation of mass within the systen was nost important. This further led then to locate the velocities u and $\nabla$ at the edges of the computation cells and pressure and other variables at the cell centers; as illustrated in Fiq. 5. In this anner mass could be rigorously conserved by the finite difference representations of the velocity equations. This can be demonstrated by the integration of the difference forw of the velocity equations over a fixed control volume.

There are actually two interlaced couputing weshes then, one for velocity and one for pressure and divergence. The velocity grid is made up of points that bisect the borders of 


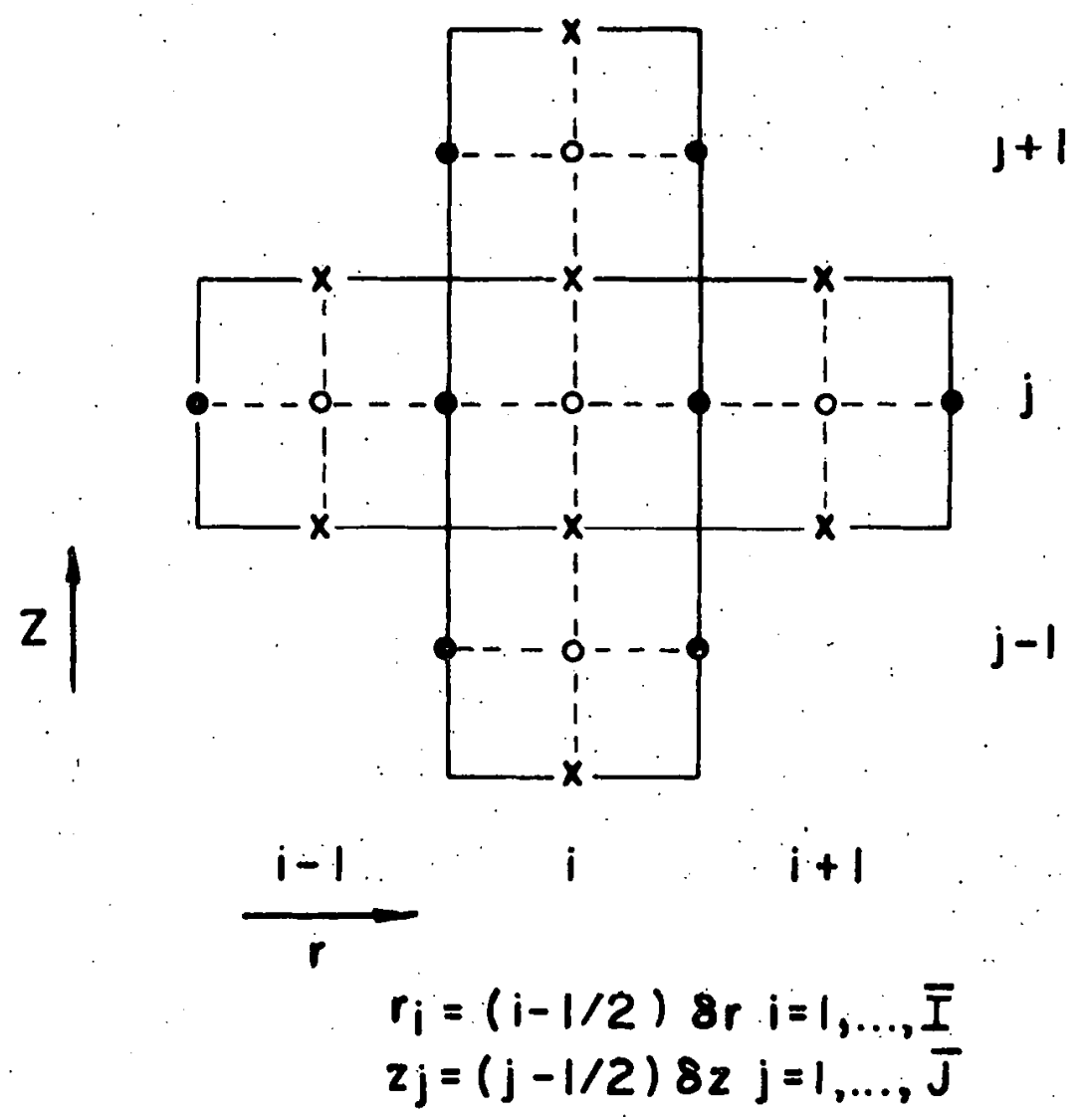

- U VELOCITY
$\times \checkmark$ VELOCITY
- CELL CENTER, $\phi, Q, D$

Figure 5. Illustration of the interlaced computing grids, the locations of the velocities and the distance indices $i$ and $i$. 
the cells. The pressure grid is made up of the cell centers. The idea of this interlaced grid structure probably oriqinated vith fromm (15). who used it in a stream functionvorticity solution of the problem of incompressible flow a round an obstacle.

The MaC method uses another grid besides those for velocity and pressure, and that is the marker particles. The particles are spread over the region containing fluid and desiqnate which cells require the. free surface boundary conditions. This grid also allows the resolution of the fluid's position to be greatly increased provided the spacing betueen particles is made less than a cell width.

The arrangement of velocities is naturally suited to incorporate normal velocity boundary information at vertical and horizontal walls and lines of symmetry, and was found to be superior to all other variable arrangements tried (57). Piqure 6 illustrates that this choice of $u$ and. $v$ locations also leads to the minimum error term associated with the calculation of the divergence $D_{i j}$ for a cell with four bordering velocities. Expansion in a Taylor series about the point $r_{i}=(i-1 / 2) \delta r, z_{j}=(j-1 / 2) \delta z$ referred to as $i j$ leads to

$$
D_{i j}=\frac{1}{r_{i} \&}\left(r_{i+\frac{1}{2}} u_{i+\frac{1}{2} j}-r_{i-\frac{1}{2}} u_{i-\frac{1}{2} j}\right)+\frac{1}{\delta 2}\left(v_{i j+\frac{1}{2}}-v_{i j-\frac{1}{2}}\right)
$$

the finite difference approrimation to Eq. (7). This result means that accurate values of $D_{i j}$ will be available at the 


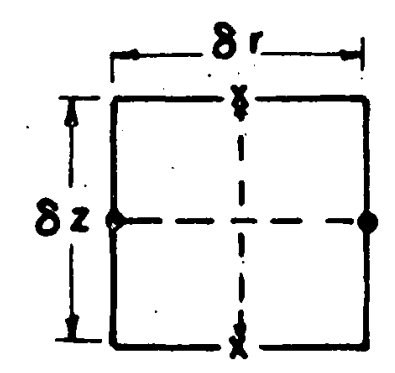

$$
\begin{aligned}
& u_{i+1 / 2 j}=u_{i j}+\left.(8 r / 2) \frac{\partial u}{\partial r}\right|_{i j}+\left.\frac{(8 r / 2)^{2}}{2} \frac{8^{2} u}{\partial r^{2}}\right|_{i j}+\cdots \\
& u_{i-1 / 2 j}=u_{i j}-\left.(8 r / 2) \frac{\partial u}{\partial r}\right|_{i j}+\left.\frac{(8 r / 2)^{2}}{2} \frac{\partial^{2} u}{\partial r^{2}}\right|_{i j}+\cdots \\
& v_{i j+1 / 2}=v_{i j}+\left.(8 z / 2) \frac{\partial v}{\partial z}\right|_{i j}+\left.\frac{(8 z / 2)^{2}}{2} \frac{\partial^{2} v}{\partial z^{2}}\right|_{i j}+\cdots \\
& v_{i j-1 / z}=v_{i j}-\left.(8 z / 2) \frac{\partial v}{\partial z}\right|_{i j}+\left.\frac{(8 z / 2)^{2}}{2} \frac{\partial^{2} v}{\partial z^{2}}\right|_{i j}+\cdots
\end{aligned}
$$

TAKING LINEAR COMBINATIONS OF THE ABOVE,

$$
D_{i j}=\left\{\frac{1}{r} \frac{\partial(r u)}{\partial r}+\frac{\partial v}{\partial z}\right\}_{i j}
$$

MAY BE APPROXIMATED BY

$$
\begin{gathered}
D_{i j}=\frac{r_{i+1 / 2} U_{i+1 / 2 j}-r_{i-1 / 2} U_{i-1 / 2 j}}{r_{i} 8 r}+\frac{V_{i j+1 / 2}-V_{i j-1 / 2}}{8 z}+ \\
+0\left(\frac{8 r^{2}}{r_{i}}, 8 z^{2}\right)
\end{gathered}
$$

Pigure 6. The arcangement of u and $v$ shown above results in the minimum truncation error in the calculation of $D$. 
cell centers ij. The importance of this result will be seen when the difference forms relating pressure and the velocities are presented.

As a cunsequence of the availability of accurate values of $D_{i j}$ at the cell centers, and the need for accurate derivatives of $\phi$ at the borders of the cells, it is natural to locate $\phi$ at the cell centers. This means that the approximation of Eq. (18) could be based on Taylor series expansions about a cell center ijo However, instead of writing the approximation for Eq. (18) and then forcing the velocity equations to be alqebraically consistent, the derivation is begun with the velocity equations. Because of the linearity of the finite difference approximations, the same result would be obtained if the derivation were started from finite difference approximations of Eq. (18) directly, but the manner in wich algebraic consistency is forced is then lost. This point is important when the approximation of Eq. (18) is modified to handle unequally spaced data as seen in the Results section.

With the establishment of the locations of the variables relative to the coordinate system, it is possible to display the finite difference approximations to Eqs. (8) and (9). To approximate Eq. (8), all needed Taylor series are expanded about point $i+1 / 2 i$ at time $n \delta t$, where superscript $n$ is implied if none appears. 


$$
\begin{aligned}
\frac{1}{\delta t}\left(u_{i+\frac{1}{2} j}^{n+1}-u_{i+\frac{1}{2} j}\right) & =\frac{1}{r_{i+\frac{1}{2}} \delta r}\left[\left(r \cdot u^{2}\right)_{i j}-\left(r u^{2}\right)_{i+1 j}\right] \\
& +\frac{1}{\delta z}\left[\left(u v_{i+\frac{1}{2} j-\frac{1}{2}}-\left(u v_{i+\frac{1}{2} j+\frac{1}{2}}\right]+\frac{1}{\delta r}\left(\phi_{i j}-\phi_{i+1 j}\right)\right.\right. \\
& +v\left\{\frac{1}{\delta z^{2}}\left(u_{i+\frac{1}{2} j+1}+u_{i+\frac{1}{2} j-1}-2 u_{i+\frac{1}{2} j}\right)\right. \\
& \left.+\frac{1}{\delta r \delta z}\left[v_{i+1 j+\frac{1}{2}}-v_{i+1 j+\frac{1}{2}}+v_{i j-\frac{1}{2}}+v_{i j+\frac{1}{2}}\right]\right\}+g_{r}
\end{aligned}
$$

Equation (9) is approximated by expansion about point $i f+1 / 2$ at time nst.

$$
\begin{aligned}
\frac{1}{\delta f}\left(v_{i j+\frac{1}{2}}^{n+1}\right. & \left.-v_{i j+\frac{1}{2}}\right)=\frac{1}{r_{i} \delta r}\left[(r u v)_{i-\frac{1}{2} j+\frac{1}{2}}-\left(r u v_{i+\frac{1}{2} j+\frac{1}{2}}\right]\right. \\
& +\frac{1}{\delta z}\left[v_{i j}^{2}-v_{i j+1}^{2}\right]+\frac{1}{\delta z}\left[\phi_{i j}-\phi_{i j+1}\right] \\
& +\frac{v}{r_{i} \delta r}\left[r_{i-\frac{1}{2}}\left(\frac{u_{i-\frac{1}{2} j+1}-u_{i-\frac{1}{2} j}}{\delta z}-\frac{v_{i j+\frac{1}{2}}-v_{i-1 j+\frac{1}{2}}}{\delta r}\right)\right. \\
& \left.-r_{i-\frac{1}{2}}\left(\frac{u_{i+\frac{1}{2} j+1}-u_{i+\frac{1}{2} j}}{\delta z}-\frac{v_{i+1 j+\frac{1}{2}}-v_{i j+\frac{1}{2}}}{\delta r}\right)\right]+g_{z}
\end{aligned}
$$

A check of the locations of all these variables reveals that they lie on a diamond consisting of nine pointa centered on the position of the velocity being evaluated.

$$
\text { Because of the linearity of the finite difference ap- }
$$
proximations, it is possible to combine the difference forms for the velocities to produce the difference form of the Poisson's equation relating pressure and the velocities. Eq. (18). By combining velocity equations, from points $i+1 / 2 j$. 
52

$i j+1 / 2, i-1 / 2 j$, and $i j-1 / 2$ it can be seen that

$$
\begin{aligned}
& \frac{1}{\delta t}\left\{\left(\frac{r_{i+\frac{1}{2}} u_{i+\frac{1}{1} j}^{n+1}-r_{i-\frac{1}{2}} u_{i-\frac{1}{2} j}^{n+1}}{r_{i} \delta r}+\frac{v_{i j+\frac{1}{2}}^{n+1}-v_{i j-\frac{1}{2}}^{n+1}}{\delta z}\right)\right. \\
& \left.-\left(\frac{r_{i+\frac{1}{2}} u_{i+\frac{1}{2} j}-r_{i-\frac{1}{2}} u_{i-\frac{1}{2} j}}{r_{i} \delta r}+\frac{v_{i j+\frac{1}{2}}-v_{i j-\frac{1}{2}}}{\delta z}\right)\right\}= \\
& =\frac{D_{i j}^{n+1}-D_{i j}}{81}=\frac{r_{i+\frac{1}{2}}\left(\phi_{i j}-\phi_{i+1 j}\right)-r_{i-\frac{1}{2}}\left(\phi_{i-1 j}-\phi_{i j}\right)}{r_{i} \delta r^{2}} \\
& +\frac{2 \phi_{i j}-\phi_{i j+1}-\phi_{i j-1}}{8 z^{2}}+\frac{2\left(r u^{2}\right)_{i j}-\left(r u^{2}\right)_{i+1 j}-\left(r u^{2}\right)_{i-1 j}}{r_{i} \delta r^{2}} \\
& +\frac{2 v_{i j}^{2}-v_{i j+1}^{2}-v_{i j-1}^{2}}{8 z^{2}}+\frac{2}{r_{i} 8 r \delta z}\left[(r u v)_{i-\frac{1}{j} j+\frac{1}{z}}+\left(r u v_{i+\frac{1}{2 j}-\frac{1}{2}}\right.\right. \\
& \left.-(\text { rue })_{i+\frac{1}{2} j+\frac{1}{2}}-(\text { rue })_{i-\frac{1}{2} j-\frac{1}{2}}\right]
\end{aligned}
$$

$$
\begin{aligned}
Q_{i j} & =\frac{1}{r_{i} \delta r^{2}}\left[\left(r u^{2}\right)_{i+1 j}+\left(r u^{2}\right)_{i-1 j}-2\left(r u^{2}\right)_{i j}\right] \\
& +\frac{1}{\delta z^{2}}\left[v_{i j+1}^{2}+v_{i j-1}^{2}-2 v_{i j}^{2}\right]+\frac{2}{r_{i} \delta r \delta z}\left[(r u v)_{i-\frac{1}{2} j+\frac{1}{2}}\right. \\
& \left.+(r u v)_{i+\frac{1}{2} j-\frac{1}{2}}-(r u v)_{i+\frac{1}{2} j+\frac{1}{2}}-(r u v)_{i-\frac{1}{z} j-\frac{1}{2}}\right]
\end{aligned}
$$

Eq. (18) is approximated by

$$
\begin{aligned}
\frac{D_{i j}^{n+1}-D_{i j}}{81}= & -Q_{i j}+\frac{r_{i+\frac{1}{2}}\left(\phi_{i j}-\phi_{i+1 j}\right)-r_{i+\frac{1}{g}}\left(\phi_{i-1 j}-\phi_{i j}\right)}{r_{i} \delta r^{2}} \\
& +\frac{2 \phi_{i j}-\phi_{i j+1}-\phi_{i j-1}}{\delta z^{2}}
\end{aligned}
$$

Nov it is appropriate to introduce the error correction scheme that makes the MAC method so successful. Since it is 
desired that the solutions obtained satisfy $D=0$ for all $t$ ime.

$$
D_{i j}^{n+1}=0
$$

is substituted into Bq. (26). But instead of also substituting $D_{i j}=0$ into $\mathrm{Eq}$. (26). this tern is left in the equation, recognizing that certain round off and truncation errors may have been made that will cause this term to be non-zero. In this manner we may produce $D_{i j}=0$ but still account for errors made during the previous time step.

The difference equations must of course be accompanied by difference approxiations to the boundary and initial conditions. The boundary conditions at walls, (solid, flow or symmetry) are given belou. The differential conditions and the difference conditions are shown together. with reference to the particular geometry used. Figure 7 illustrates the two unique geometries which include all possible arrangements of a cell containing fluid wich is adjacent to a boundary cell. and should be used in reference to the following conditions. Once it is determined which cell is the boundary cel1. then these equations nay be used to determine its velocities and pressure, from those of the cell containing fluid. In the following equations a) refers to a vertical wall and b) refers to a horizontal wall. 

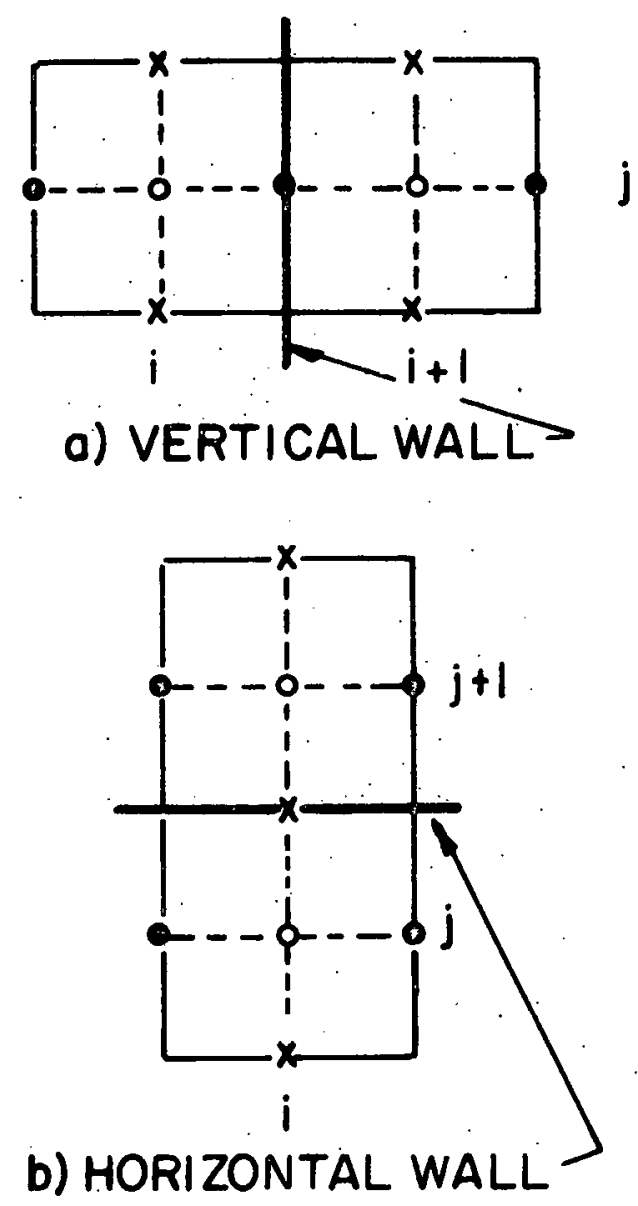

$$
\begin{aligned}
& x \quad v \text { VELOCITY } \\
& \text { - u VELOCITY } \\
& \text { - } \phi, Q, D \text { VALUES }
\end{aligned}
$$

Pigure 7. Illustration of the locations of variables adjacent to horizontal and vertical boundary valls. Such walls may simulate inlets, outlets, solid material or lines of symmetry. 
Free slip:

$$
\begin{aligned}
& a-1) \quad \frac{\partial V}{\partial r}=0: V_{i j+\frac{1}{2}}=V_{i+1 j+\frac{1}{2}} ; V_{i j-\frac{1}{2}}=V_{i+1 j-\frac{1}{2}} \\
& a-2, \quad u=0: u_{i+\frac{1}{2} j}=0 \\
& \text { a-3) } \frac{\partial \phi}{\partial r}=g_{r}: \frac{\phi_{i+1 i}-\phi_{i j}}{8 r}=g_{r}
\end{aligned}
$$

$b-1) \quad \frac{\partial U}{\partial z}=0: u_{i-\frac{1}{2} j+1}=u_{i-\frac{1}{2} j} ; u_{i+\frac{1}{2} j+1}=u_{i+\frac{1}{2} j}$

b-2) $\quad V=0: V_{i j+\frac{1}{2}}=0$

b-3) $\frac{\partial \phi}{\partial z}=g_{z}: \frac{\phi_{i j+1}-\phi_{i j}}{8 z}=g_{z}$

No slip:

$$
\begin{aligned}
& a-1) \quad v=0: v_{i j+\frac{1}{2}}=-v_{i+1 j+\frac{1}{2}} ; v_{i j-\frac{1}{2}}=-v_{i+1 j-\frac{1}{2}} \\
& a-2) \quad u=0 \quad: \quad u_{i+\frac{1}{2} j}=0 \\
& a-3) \frac{\partial \phi}{\partial r}=-\nu \frac{\partial}{\partial z}\left(\frac{\partial V}{\partial r}\right)+g_{r}: \frac{\phi_{i+1 j}-\phi_{i j}}{8 r}=\frac{2 \nu}{8 r \delta z}\left(v_{i j+\frac{1}{2}}-v_{i j-\frac{1}{2}}\right)+g_{r}
\end{aligned}
$$


$b-1) \quad V=0: V_{i j+\frac{1}{2}}=0$

b-2) $u=0: u_{i-\frac{1}{2} j}=-u_{i-\frac{1}{2} j+1} ; u_{i+\frac{1}{2} j}=-u_{i+\frac{1}{2} j+1}$

b-3) $\frac{\partial \phi}{\partial z}=-\nu \frac{\partial}{\partial z}\left(\frac{1}{r} \frac{\partial(r u)}{\partial r}\right)+g_{z}: \frac{\phi_{i j+1}-\phi_{i i}}{\delta z}=$

$$
-\frac{2 \nu}{r_{i} 8 r 8 z}\left[r_{i+\frac{1}{2}} u_{i+\frac{1}{2} j}-r_{i-\frac{1}{2}} u_{i-\frac{1}{2} j}\right]
$$

In: As in No slip condition except,

a-2) $u=$ const $: u_{i}+\frac{1}{2} j=$ const

b-1) $V=$ const $: V_{i j}+\frac{1}{2}=$ const

Out: As in Free slip condition except,

a-3) $\frac{\partial \phi}{\partial r}=\frac{\partial(U V)}{\partial Z}: \frac{\phi_{i+1 j}-\phi_{i j}}{8 r}=\frac{(U V)_{i+\frac{1}{d j}-\frac{1}{2}}-(U V)_{i+\frac{1}{2} j+\frac{1}{2}}}{8 Z}$

b-3) $\frac{\partial \phi}{\partial z}=-\frac{1}{r} \frac{\partial(r u V)}{\partial r}: \frac{\phi_{i j+1}-\phi_{i j}}{8 z}=\frac{(r u V)_{i-\frac{1}{2} j+\frac{1}{2}}-\left(r u V_{i+\frac{1}{2} j}+\frac{1}{2}\right.}{8 r}$

In the oriqinal MAC method, the free surface boundary conditions vere qreatly simplified. The conditions on velocity vere replaced with the numerical equivalents of $\frac{1}{r} \frac{\partial(r u)}{\partial r}=0$ and $\frac{\partial V}{\partial Z}=0$, which are

$$
r_{i+\frac{1}{2}} u_{i+\frac{1}{2} j}=r_{i-\frac{1}{2}} u_{i-\frac{1}{2} j}
$$


and

$$
v_{i j+t}=v_{i j-t}
$$

for cellif.

The pressure boundary condition Eq. (15) uas reduced to

$$
\phi_{i j}=\phi_{\text {applied }}
$$

because surface tension forces vere ignored. Further, usual-

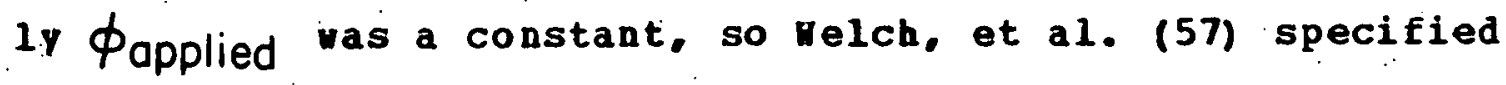
that $\phi_{\text {applied }}=0$ for lack of other motivation. In addition. since the location of the free surface vas only resolved within a cell width, the condition

$$
\phi_{i j}=0
$$

was put in all surface cells (see cell flagging illustrated in Fig. 8) at their centers. Thus the boundary condition for pressure and the velocities were at best guesses at the correct free surface boundary conditions because of resolution difficulties and partiy because of simulation complexities.

The initial conditions are handled well by the original MaC nethod. Aside from the more easily specified initial velocity conditions, such as u=constant, v=constant, it is possible to start the MaC nethod with an arbitrary initial condition. This is done by specifying the desired conditions and letting the solution be calculated for several very small time steps. In this vay initial discontinuities are smoothed or allowed to decay and the solution from this point on will 


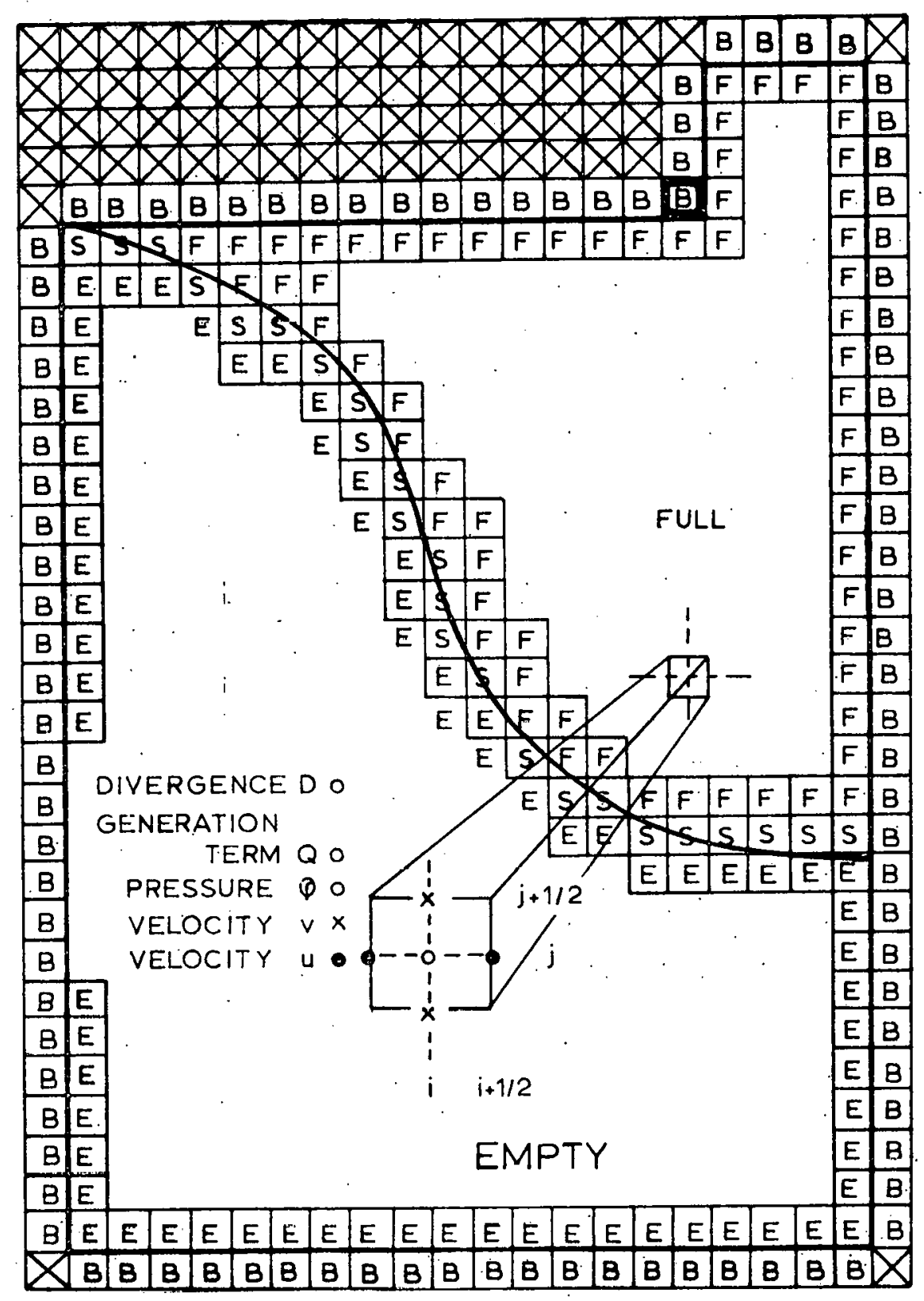

Rigure 8. A typical drop shape uith the computation grid superimposed. The flagging scheme indicates the relative 10cation of the fluid. ( $F=F U L L, S=S U R, B=B \& D$ and $X$ cells are unused boundary cells.) 
satisfy the equations of motion, continuity and the boundary conditions, whereas the actual original distributions may not have. There are no difference approximations used in specifying the 1nitlal conditions, unless the short time solution approach is used. In that case the full difference equations are used subject to

$$
u_{i+t j}^{0}=f\left(r_{i+\frac{1}{2}}, z_{j}\right) ; v_{i j+\frac{1}{2}}^{0}=g\left(r_{i}, z_{j+\frac{1}{2}}\right)
$$

initially, which is fust Eqs. (16) evaluated at each velocity location. From this point on, the full solution technique is used with $\delta t$ taken to be rery small." one of the solutions at some small $\delta t$ avay from $t=0$ is then chosen as the actual initial condition.

\section{The Computation scheme}

The general method of solution is as follows:

1. Cells are flagged according to their particie contents and those of their neighbors, as follows:

There are three types of interior cells FULI, SUR and EMP and they are defined as

FULL: a cell containing particles which has no immediately adjacent EMP cell neighbors

SUR: a cell which contains particles, but has at least one Ell cell neighbor

EHP: a cell which contains no particles

It is also convenient to keep track of which of these cells is on the boundary so ve reguire any one of the above, in ad- 
dition to its type flaq, to carry the flag $O B$ if it has an immediately adjacent boundary cell neighbor.

There a re five types of boundary cells FRSLP, NOSLP, IH, OOT, and EMPBHD and they are defined as

FRSLP: a free slip cell

NoSLP: a no slip cell

Ir: an input cell

our: an output cell

BUPBND: an unused boundary cell

The PRSLP and rosLP cells may also appear as corners of obstacles or wails as indicated by the dark cell in Pig. 8. These cells are also flagged $\cos$ in addition to their boundary type.

2. Given the initial velocity distribution, or the results of the previous iteration, the $D_{i j}$ and $Q_{i j}$ values may be calculated for each full cell, from Eqs. (21) and (25), respectivel.

3. The $\phi$ distribution is nov relayed using

$$
\begin{array}{r}
\phi_{i j}^{h+1}=\frac{8 r^{2} 8 r^{2}}{2\left(8 r^{2}+8 z^{2}\right)}\left[\frac{\left(r_{i+1} \phi_{i+1 j}^{h}+r_{i-\frac{1}{2}} \phi_{i-1)}^{h+1}\right)}{r_{i} 8 r^{2}}+\frac{\phi_{i j+1}^{h}+\phi_{i j-1}^{h+1}}{\delta z^{2}}\right. \\
\left.-Q_{i j}-D_{i j} / 8 t\right]
\end{array}
$$

subject to the convergence criteria 


$$
\operatorname{mox}_{i j}\left\{\left|\phi_{i j}^{h+1}-\phi_{i j}^{n}\right|\right\} / \phi_{r o f}<\epsilon
$$

Here $\epsilon$ is adjustable subject to the waxiaun nagnitude of tolerable error or computer tine per cycle, which ever is the most stringent requirenent. A practical value of $\epsilon$ was found by Welch, et al. (57) to be 0.0002 . The superscript $h$ refers to the iteration number on Bq. (49), and is not to be confused with the superscript which indicates the current time crole.

4. Velocities $u_{i+\frac{1}{2} j}^{n+1}$ and $v_{i j+\frac{1}{2}}^{n+1}$ are calculated fron Eqs. (22) and (23).

5. The marker particles are moved at the local average velocity. Time is advanced one $\delta t$ increment, and any desired values are stored or printed. If further calculations are desired the process is continued by returning to item 1 . This process is expanded to inclade some of the individual steps needed in the following flow diagran, Pig.,9. From the diagram several features of the input and output are indicated as are the provisions for updating $D_{i j}=0$ in surface cells and resetting tanqential velocities at boundaries. otherwise this is just the procedure outlined above. The actual details of the algorithms used, flor sheets and other practical computing advice are found in the uAC manual (57). These will not be presented except where essential details differ from the original uac method or it is 


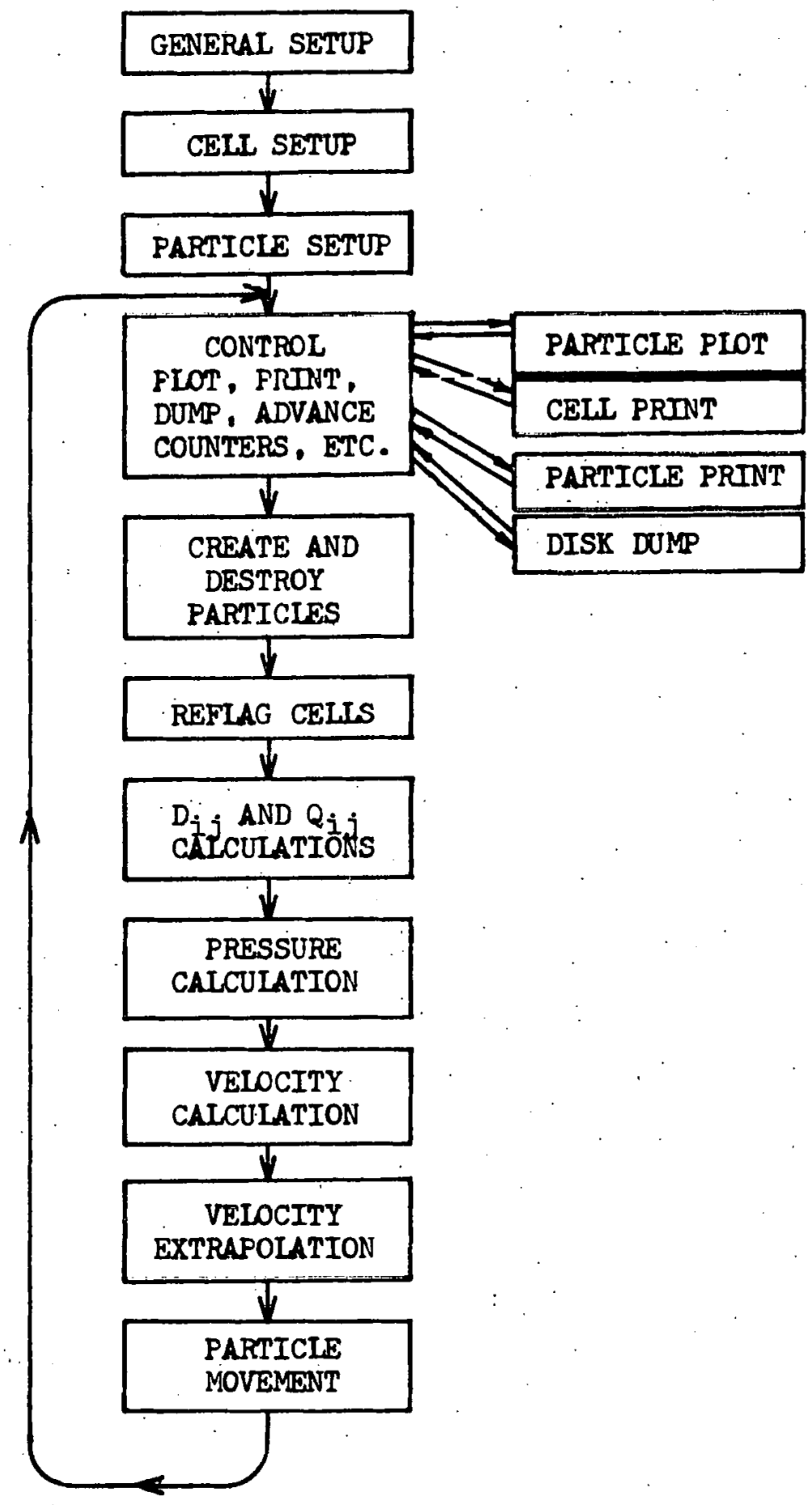

Pigure 9. A flov diagram of the BAC nethod, shouing general calculation areas. 
advantageous to explain an alqorithm graphically.

The difference equations and the flow sheet contain the basic information necessary to implement the mac method. Dhat remains to be shown are the types of solutions it has produced and some estimates of the stability and accuracy of the technigues. Several examples of the technique's capabilities ay be found in the ac manul (57) and the nany publications by the oriqinal authors which followed $110,9,11$. 28. 30, 31, 32). Reproduction of most of those solutions was not attempted here as Dr. F. H. Harlow was kind enough to. furnish a listing of his sLosh computer progra in ForTain lanquage and a detailed list of results of the "breaking dam" problem (31, 57). A new code based on the original sLosH code was then witten which contained the capabilities of the Slosh code, but was generalized to include all the capabilities of the original Mac method. The new code vas then given the "breaking dam" problem to solve and reproduced Harlow's solution. With the only differences being attributable to roundoff error. Thus the capabilities of the nev code vere considered conparable vith the codes used by Melch, et al. (57) and their other solutions were not duplicated, as not enough detailed results vere arailable for comparison. 


\section{Stability and Mccuracy}

The original uac nethod gave very sketchy and incomplete details as to the reguirements on the size of the tine step. 8t, for stability. Nelch, et al. (57), hovever, do present some restrictions, which vere not explained but are reasonable conditions. Rirst the speed of waves in a tank influenced by gravity simuitaneously linits the size of the cells and the time step. The condition according to Nelch, et al. (57) is analogous to the courant condition for compressible flow problews. This condition is

$$
\operatorname{cor}<\frac{28 r 8 z}{8 r+8 z}
$$

where

$$
c=[(g / k) \tan h(k h)]^{\frac{1}{2}}
$$

Here, $c$ is the vave speed, $k$ is the wave nuber and $h$ is the height of fluid in the tank. For square cells of width $\delta r$ this condition says that the wave may not move nore than one cell width in one time step.

The other stability consideration they present is

$$
2 v 8 t<\frac{8 r^{2} 8 z^{2}}{8 r^{2}+8 z^{2}}
$$

which again for square cells reduces to

$$
8 t<\frac{8 r^{2}}{4 \nu}
$$

This condition is referred to as the "diffusional" stability criterion, and it arises from treating Eqs. (8) and (9) as linear equations, ignoring terns of order less than two in the space variables and applying Fourier analysis to 
the remaining terms (31). These conditions did agree vith their experimental observations about the stability. of the technique.

Hirt (35) gives nore detail as to the origins of the stability critieria just presented, and gives some useful rules of thumb for judging the stability of a calculated f10:.
As a useful rule of thumb the mac method is considered stable if $\nu$ is qreater than $\delta t u^{2} / 2$. where u is the average maximum fluid speed, and if $\nu$ is qreater than $\left(\delta x^{2} \partial u / \partial x\right) / 2$. vhere $\partial u / \partial x$ is the averaqe maximum velocity gradient in the direction of flow. The first condition is needed for linear. stability. The second condition is a non-linear stability requi rement.

While these results apply strictly only to the cartesian form of the Mavier-stokes equations, similar results may be derived using the heuristic approach of Hirt (35) f for the cylindrically symetric form used in this work. Hovever, it was found that the solutions obtained osing only Bg. (54) as a restriction on $\delta t$ shoved no signs of instability. Thus further investigation of the stability requirements was not necessary.

The accuracy of the nethod is not precisely stated in the aAC manual. The primary reason for this is that the error analysis of the entire problei is extremely difficult, and rould take more time and effort than the generation of the method in the first place. Thus the complete analysis of the method remains to be done. Nelch, et al. (57) do specify 
some useful and helpful empirical results that are only briefly outlined here:

a) Cells wust be small enough that no field variable $\phi$. $D$, or Q changes by uch across any cell (nuch is not defined in the HAC manual).

b) Cells ust also be small enough to resolve the nost interesting and useful features of the flow (defined by the probleng.

c) The time step nust be small enough to prevent instability. but large enough to include meaningful problems. welch, et al. (57) take the time step as large as the stability requirements will allow at any point in the solution. d) The number of particles in a calculation is relatively unimportant as they do not enter the calculations directly (this is not true for those particles wich designate the free surface, bot remains true for the bulk of the particles within the fluid region when the MAC wethod is aodified). e) The conservation of momentu is most important, and can be observed during the calculation as the nagnitude of the $D_{i j}$ terms. To the extent that the $D_{i j}$ terms do not vanish, the system is not conserving mass properly. (The error comitted here is bounded by the accuracy with which the boundary conditions on the pressure distribution are knoun and applied): If none of the above conditions are seriously violated during 
a calculation it is fairiy certain that the solution is valid, though a quantitative description of the errors incurred will have to avait a more complete analysis.

\section{Becent Modifications}

Several authors $(7,36,46)$ have recently reported the need for increased accuracy in the method of incorporating the free surface boundary conditions in the mac method. These authors are concerned vith more accurate approxination of the tanqential stress condition Eq. (13), and nore precise location of the pressure (normal stress) boundary condition, Bq. (12). While these improvenents bear directly on the problem considered here, they fall short of the ability to include surface tension at the interface as a part of the normal stress boundary condition.

Mormal stress values have usually been incorporated at the centers of the surface cells, as in the original MaC method. This'approximation is stable provided that the values used as boundary conditions and the cell size are sma11. However, there may be large errors associated with the choice of location of the normal stress boundary values. Consider the following argument. In the approximation of

$$
\nabla^{2} \phi=\frac{1}{\gamma} \frac{\partial}{\partial r}\left(r \frac{\partial \phi}{\partial r}\right)+\frac{\partial^{2} \phi}{\partial z^{2}}
$$

the difference approximations nsed by the original wac wethod are

$$
\nabla^{2} \phi \approx \frac{r_{i+1}\left(\phi_{i+1 i}-\phi_{i j}\right)-r_{i-1}\left(\phi_{i j}-\phi_{i-j i}\right)}{r_{i} 8 r^{2}}+
$$

(Eq. cont'd) 


$$
+\phi_{i j+1}+\phi_{i j-1}-2 \phi_{i j} / 8 z^{2}
$$

considering this as a truncated Taylor series expansion, the approximation plus the first terms dropped is given by

$$
\begin{aligned}
\nabla^{2} \phi= & {\left[r_{i+\frac{1}{2}}\left(\phi_{i+1 j}-\phi_{i j}\right)-r_{i-\frac{1}{2}}\left(\phi_{i j}-\phi_{i-1 j}\right)\right] / r_{i} 8 r^{2}+} \\
& {\left[\phi_{i j+1}+\phi_{i j-1}-2 \phi_{i j}\right] / 8 z^{2}+\left(\left.\frac{\delta r^{2}}{6 r_{i}} \frac{\partial^{3} \phi}{\partial r^{3}}\right|_{i j}+\left.\frac{\delta z^{2}}{12} \frac{\partial^{4} \phi}{\partial z^{4}}\right|_{i j}+\ldots\right) }
\end{aligned}
$$

Equation (56) then has an acceptable error of order $O\left(\delta r^{2}, \delta z^{2}\right)$. provided that the information needed at all the above points is available. However, if the value of $\phi$ vere actually available at the points $i+a j, i j+1, i-1 j$, and $i j-1$. where $0 \leq a \leq 1$, and the assugption rere made that they rould be equally valid when used in Eq. (56), then the approximation to Eg. (56) plus the first terms dropped vould be

$$
\begin{aligned}
\nabla^{2} \phi= & {\left[r_{i+\frac{1}{2}}\left(\phi_{i+1 j}-\phi_{i j}\right)-r_{i-\frac{1}{2}}\left(\phi_{i j}-\phi_{i-i j}\right)\right] / r_{i} \delta r^{2}+} \\
& {\left[\phi_{i j+1}+\phi_{i j-1}-2 \phi_{i j}\right] / \delta z^{2}+\left(\left.\frac{r_{i+\frac{1}{2}}(\alpha-1)}{r_{i} \delta r} \frac{\partial \phi}{\delta r}\right|_{i j}\right.} \\
& \left.+\left.\frac{\delta r^{2}}{6 r_{i}} \frac{\partial^{3} \phi}{\partial r^{3}}\right|_{i j}+\frac{\delta z^{2}}{12} \frac{\partial^{4} \phi}{\partial z^{4}}+\cdots\right)
\end{aligned}
$$

Here the error term may be as large as the boundary value itself $(0(1 / \delta x))$, and so the approximation is much less desirable.

This approximation introduces errors into the pressure equation wich; if allowed to grow unchecked, will eventually 
cause the surface shape to becone irregular and meaningless if resolution less than a few cell widths is desired. This type of result is shown in Fig. 10, here a drop of yater subjected to a reduced surface tension force at the centers of its surface cells is allowed to fall under the influence of gravity. The severity of the instability introduced by shifting the pressure boundary conditions only slightly from their actual points of application is evident.

Chan and street (7). used a more accurate approximation to the pressure equation, based on the locations at which the free surface intersected the pressure grid. By using the unequal interval data, the order of the error introduced by the incorporation of the free surface boundary pressures may be reduced considerably. an example is shown in Fig. 11.

If a Taylor series expansion based on unequally spaced points is used then Eg. (55) is approximated by

$$
\begin{aligned}
& \nabla^{2} \phi=\frac{2 r_{i}+a_{3} 8 r}{r_{i} a_{1}\left(a_{1}+a_{3}\right) 8 r^{2}} \phi_{i+a_{1} j}+\frac{2 r_{j}-a_{1} 8 r}{r_{i} a_{3}\left(a_{1}+a_{3}\right) 8 r^{2}} \phi_{i-a_{3}} \\
& +\frac{2}{a_{2}\left(a_{2}+a_{4}\right) 8 z^{2}} \phi_{i j+a_{2}}+\frac{2}{a_{4}\left(a_{2}+a_{4}\right) 8 z^{2}} \phi_{i j-a_{4}}-\left(\frac{2 r_{i}\left(a_{3}-a_{1}\right) 8 r}{r_{i} a_{1} a_{3} 8 r^{2}}\right. \\
& \left.+\frac{2}{a_{2} a_{8} \delta z^{2}}\right) \phi_{i j}+\left(\left.\frac{\left(a_{1}-a_{8} \delta r\right)}{3} \frac{\partial^{3} \phi}{\partial r^{3}}\right|_{i j}+\left.\frac{\left(a_{2}-a_{4}\right) 8 z}{3} \frac{\partial^{3} \phi}{\partial z^{3}}\right|_{i j}+\cdots\right)
\end{aligned}
$$

which has a uch lover error term $(0(\delta, \delta z))$ associated with it than did Eq. (58). 


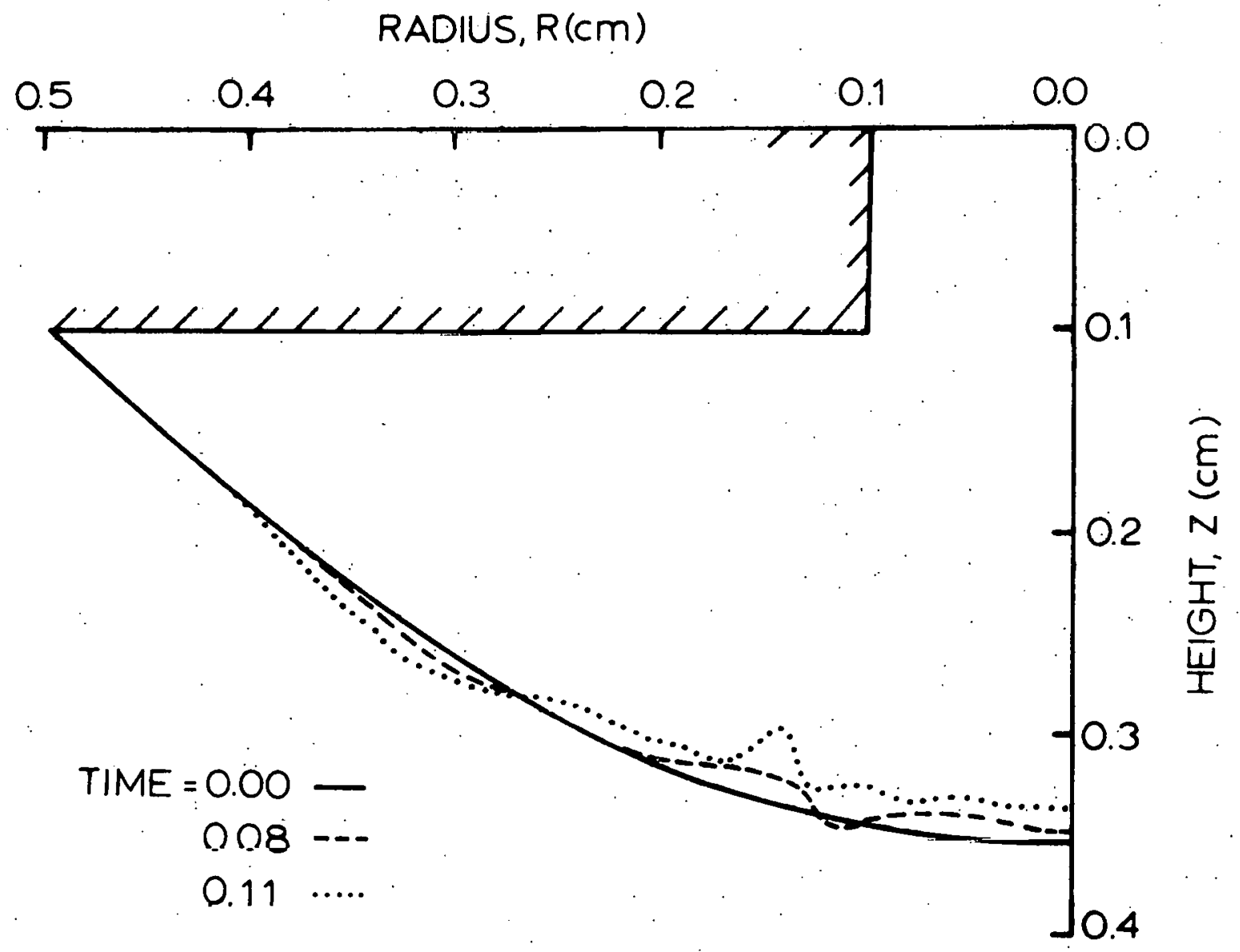

Pigure 10. Illustration of the effect of boundary pressures calculated at the interface, but applied at noarby cell centers. 


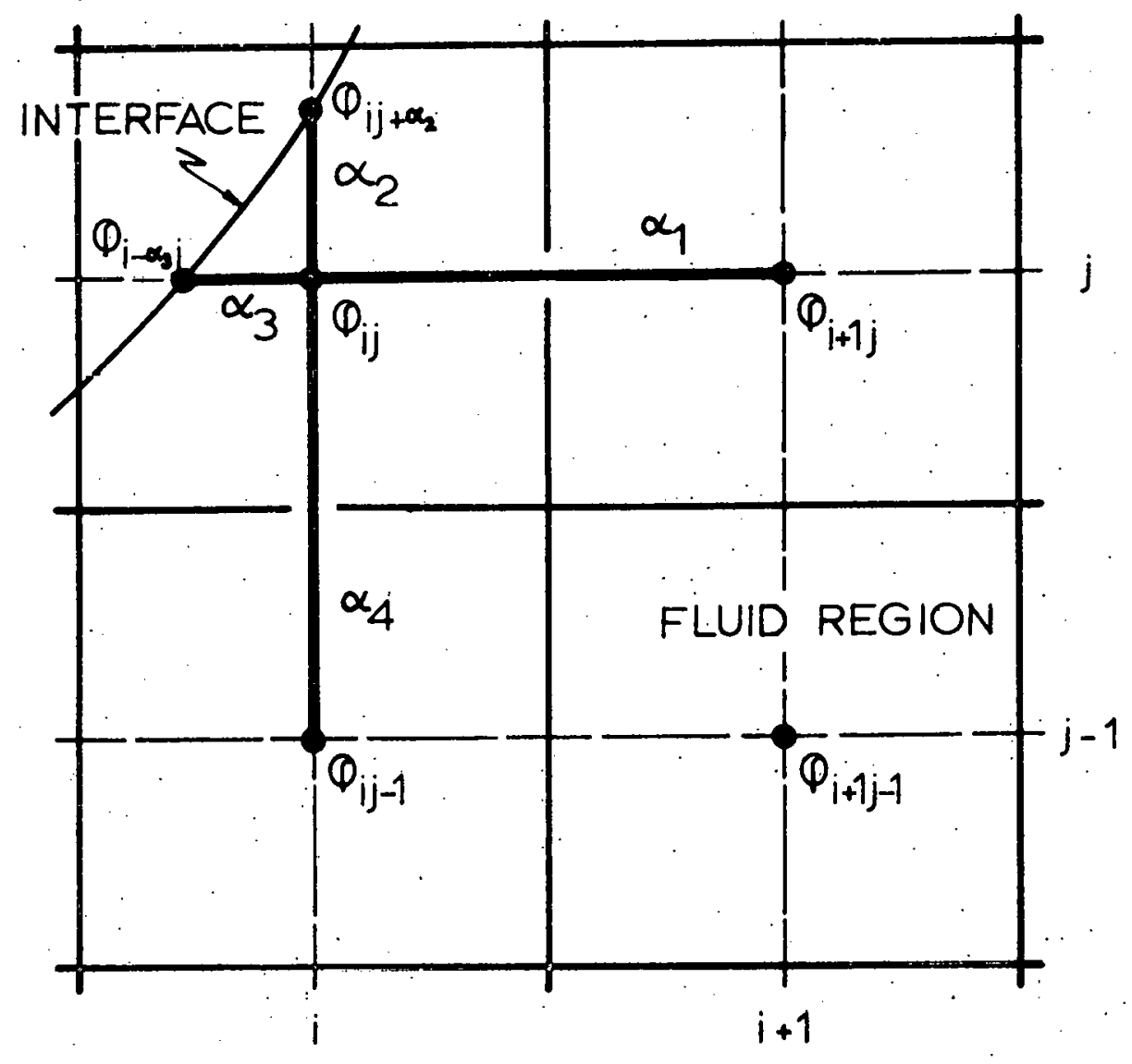

- CELL CENTERS OR BOUNDARY DATA (LOCATION OF. MAC BOUNDARY DATA IS

AT CELL CENTERS ONLY)

$\alpha_{j}$ FRACTIONAL CELL WIDTHS

$$
O \leq \alpha_{1} \leq 1 ; i=1, \ldots, 4 \text {. }
$$

BETWEEN DATA POINTS

OF THE "IRREGULAR STAR"

CELL ij ABOVE

Figure 11. Illustration of the location of variables about the "irregular star". cell ij. 
The method has some difficulties. The difference approximation Eq. (59) is not algebraically consistent with the four velocity equations which supposedily produced it. As stated previously, the way to preserve the algebraic consistency of the finite difference approximations relating velocity and pressure, is to start with the velocity equations and combine them in a form that reduces to Eq. (55). However, if this is not done, then the time rate of change of divergence will not agree with the velocity equations, and as a consequence, the adranced time divergences will not be zero as desired. This result is unacceptable because it allous error to accumulate in the solutions and permits instabilities to develop.

although Chan and street (7) did not allow velocity calculations to be made if the location of the velocity was outside the fluid region, they made no mention of the fact that the velocity and pressure equations do not agree if special treatment is not given to the "irregular star" cells. Nevertheless, their results show considerable improvement over the original Hac technique in the smoothness of the free surface and velocity profiles.

They also used a Newton-Gregory four-point backvard difference approximation to the derivatives of the velocities in order to extrapolate them across the interface. This technique alleviated the problem of deciding which boundary 
condition to apply to the velocities at the free surface. The method requires that the first derivative of the velocit be continuous, which satisfies neither the conservation of volune nor the tangential stress conditions. Hovever, it does produce smoothly varying velocities as the transition into empty space is made, something that the original MaC method did not do. The free surface can thus be used as a reference boundary because it is no longer irregular. These results are of considerable importance to the solution of the forming and separating drop problem.

In the previous discussion, it has been assumed that a technique is available to accurately determine the location and shape of the free surface. This is necessary for the calculation of the fractional cell widths seen in Fig. 11. and for the calculation of surface tension forces. Hovever, the MAC method provides no weans of resolving the fluid interface more accurately than a cell width. Also, none of the articles just reviewed resolved the interface more accurately than the chords that connect the interface particles. Thile the latter resolution. is enough to incorporate accurate boundary data into pressure calculations, it is not sufficient to compute surface tension forces. For the computation of surface tension forces it is necessary to know accurately the first and second derivatives of the function representing the free surface, from which $B_{1}$ and $B_{2}$ may be 
calculated.

Daly $(9,10)$ and Daly and Pracht (11) incorporated surface tension forces in tro fluid calculations by using interface particles to designate the location of the free surface, and spline interpolating functions to represent it betveen particles. This technique allows the calculation of both the location of the interface and the surface tension force at any point, within the accuracy of the interpolating polynonials.

In a subsequent paper Daly (12) denonstrated how the surface may be resolved by piecew ise cubic splines to interpolate the monotonic segments of the interface. Where the particles are not.monotone for more than five successive particles, he suggests using circular segments to approximate the surface and taking the radii of curvature to be the radius of the circle and the distance along the radius to the zaxis respectively. The process described is complete in that it allows for folding of the surface upon itself. It also permits particles to be added to or deleted from the interface when the density becomes irregular. In addition, smoothing can be done in those places where the surface becomes too peaked for proper resolution by splines.

The scheme does have some drawbacks. The surface tension forces are treated as components of the velocity equations. Since the velocities do not always fall on the 
interface, the forces are applied at those velocity locations closest to the interface. This introduces errors due to the differences in location, similar to those discussed for pressure.

Also, Daly's technique is difficult to implement in the general case where the surface curvature may vary idely. The fitting procedures are not difficult to implenent, but sensing were the curve should be broken into segments is very difficult to formulate with generality. Thus while the overall scheme presented by. Daly (12) could have been used in this work, important modifications have been made. 


\section{RESULTS}

\section{Drop Modifications}

The first modification that was incorporated into the MAC method for this work was the addition of the interface fitting program just discussed. It was not possible to inplement Daly's (12) techniques for interfaces wich becane double valued. The reason for this was the complexity of the routines needed to split up the interface particies into monotonically varying sequences.

after some experimenting with the Daly approach, it was found that the accuracy near functional discontinuities ras unacceptable. This is illustrated in Table I for the interface configuration shown in Pig. 12. In addition, when an attempt was made to fit the same interface as a piecerise function of $z$, the method failed completely. This motivated a search for a more easily implemented, accurate technique. Ahlberg. Nilson and Walsh (1) have suggested that a general curve fitting technique using parametric equations would significantly ease the programing problem and provide accurate results as well.

The parameter chosen for this work was the cumulative chord length between interface particles, which is approximately equal to arc length for closely spaced particles. Cumulative chord length is a monotonically increasing indepen- 


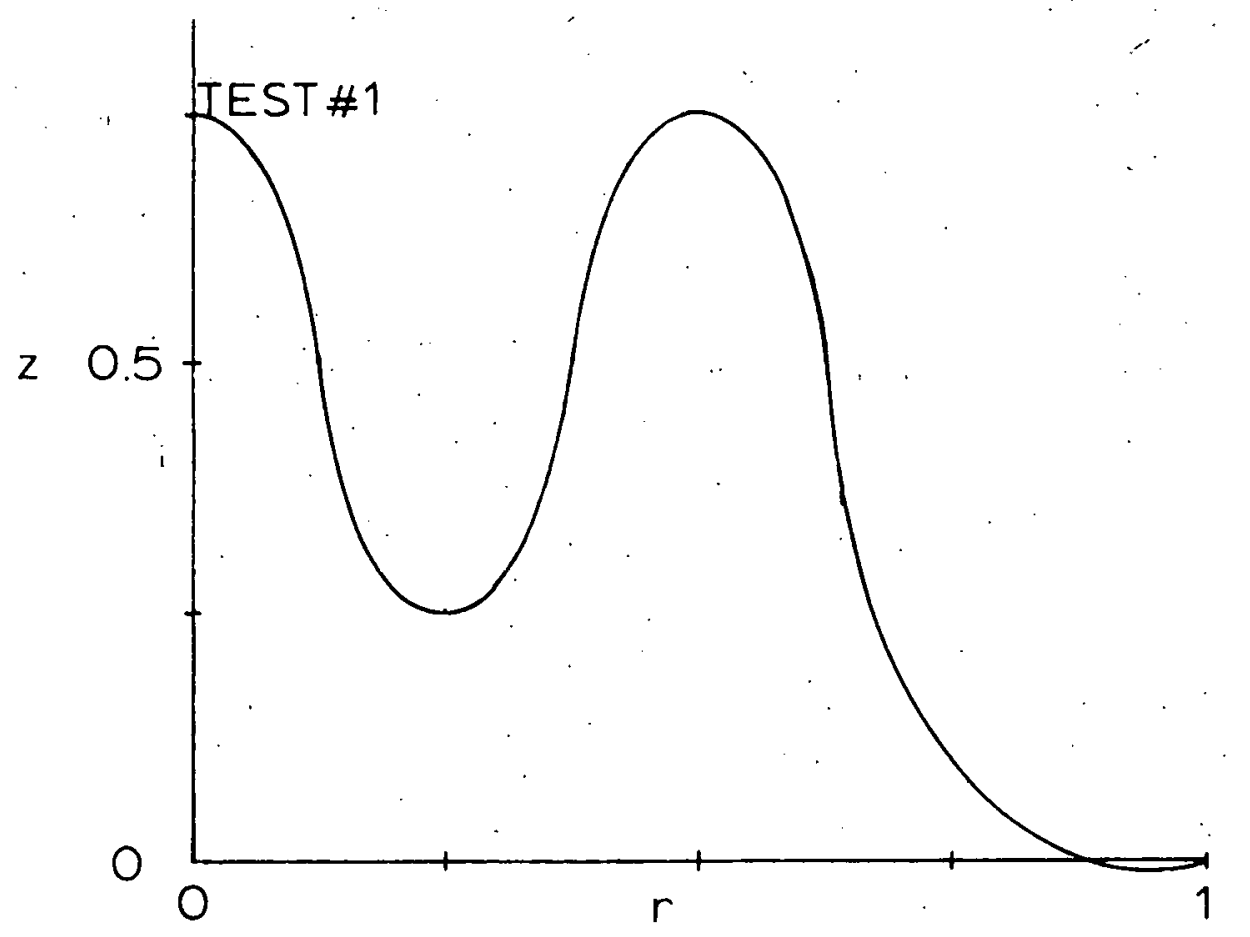

interface function

$$
\begin{aligned}
z=1 / 2+(1 / 4) \cos (4 \pi r), 0 \leqslant r \leqslant 0.625 \\
z=a+b r+c r^{2}, \quad 0.625 \leqslant r \leqslant 1 \\
a=4.347099 \quad b=-9.169124 \quad c=4.822025
\end{aligned}
$$

fluid data

$$
\begin{aligned}
& \rho_{A V}=0.5 \mathrm{gm} / \mathrm{cc} \\
& T_{i}=71.97 \text { dynes } / \mathrm{cm} \\
& \delta x=0.1 \mathrm{~cm} \\
& \delta t=0.001 \mathrm{sec}
\end{aligned}
$$

71 particles were used to describe the interface

Pigure 12. A function used to test the Daly (12) technique for interface fitting. 
Table I. Approximate and known velocity components due to surface tension, for the function shoun in rig. 12.

\begin{tabular}{|c|c|c|c|c|}
\hline$c e 11$ & $\begin{array}{l}\text { coaputed } \\
\text { velocity } \\
\text { (ca/sec) }\end{array}$ & $\begin{array}{l}\text { known } \\
\text { velocity } \\
\text { (rem/sers) }\end{array}$ & error & $\%$ error \\
\hline 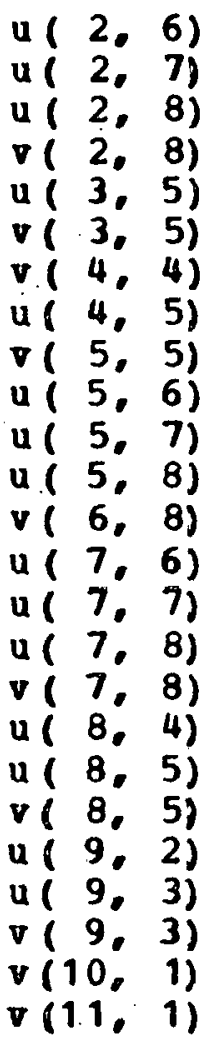 & $\begin{array}{r}-8.914 \\
-12.266 \\
-18.440 \\
-14.418 \\
-5.452 \\
-2.710 \\
56.215 \\
-5.437 \\
1.416 \\
-3.946 \\
-3.011 \\
-1.317 \\
-1.024 \\
-1.582 \\
-2.479 \\
-3.766 \\
-3.455 \\
-0.821 \\
-1.283 \\
-0.525 \\
2.224 \\
0.026 \\
-0.167 \\
2.827 \\
13.877\end{array}$ & $\begin{array}{r}-8.914 \\
-12.266 \\
-18.441 \\
-14.419 \\
-5.452 \\
-2.710 \\
56.825 \\
-5.439 \\
1.416 \\
-3.946 \\
-3.011 \\
-1.315 \\
-1.025 \\
-1.712 \\
-2.457 \\
-3.766 \\
-3.460 \\
-0.821 \\
-1.284 \\
-0.526 \\
2.224 \\
0.025 \\
-0.167 \\
2.826 \\
13.869\end{array}$ & $\begin{array}{l}0.000 \\
0.000 \\
0.001 \\
0.001 \\
0.000 \\
0.000 \\
0.610 \\
0.002 \\
0.000 \\
0.000 \\
0.000 \\
0.002 \\
0.001 \\
0.1130 \\
0.023 \\
0.000 \\
0.005 \\
0.000 \\
0.001 \\
0.001 \\
0.000 \\
0.001 \\
0.000 \\
0.001 \\
0.008\end{array}$ & $\begin{array}{l}0.003 \\
0.002 \\
0.003 \\
0.005 \\
0.006 \\
0.000 \\
1.0732 \\
0.033 \\
0.012 \\
0.005 \\
0.006 \\
0.144 \\
0.012 \\
7.6202 \\
0.9222 \\
0.020 \\
0.156 \\
0.021 \\
0.017 \\
0.055 \\
0.007 \\
1.445 \\
0.077 \\
0.027 \\
0.054\end{array}$ \\
\hline
\end{tabular}

1 Large error due to local maximum in $z$

2 Large error due to curvature discontinuity 
dent variable which can be used for any interface configuration. Thus it is possible to fit radius and height separate1y versus cumulative chord length, for the entire length of the interface, in a simple one step process.

A comparison of the two processes used in the computation of surface tension forces is shown in Table II, for the interface configuration seen in Fig. 13. From Table II it can be seen that the nev scheme sacrifices some accuracy because two fits must be made. In some places fitting errors vill add and in others they will cancel. However, nowhere in the nev method does the large error due to mismatched fits occur as it did using Daly's technique. The new method also uses less storage for the computer code necessary to process the interfaces.

The fitting of the interface proceeds as follows: 1. A single rou of particles is designated as the interface. These particles are always numbered consecutively beginning at the $z$-axis, $k=1 \ldots \ldots k^{\star}$, and the numbering is maintained consecutive whether or not particles are added or removed. The particles string begins and ends vith fictitious particles numbered 0 and $k^{*}+1$ vhich lie outside of and on the physical boundaries of the fluid, respectively. 2. The fitting scheme is the simple piecewise cubic polynomial presented by Daly (12) and by Ahlberg. Nilson and Walsh (1). The parametric function $I(x)$ and its first and 


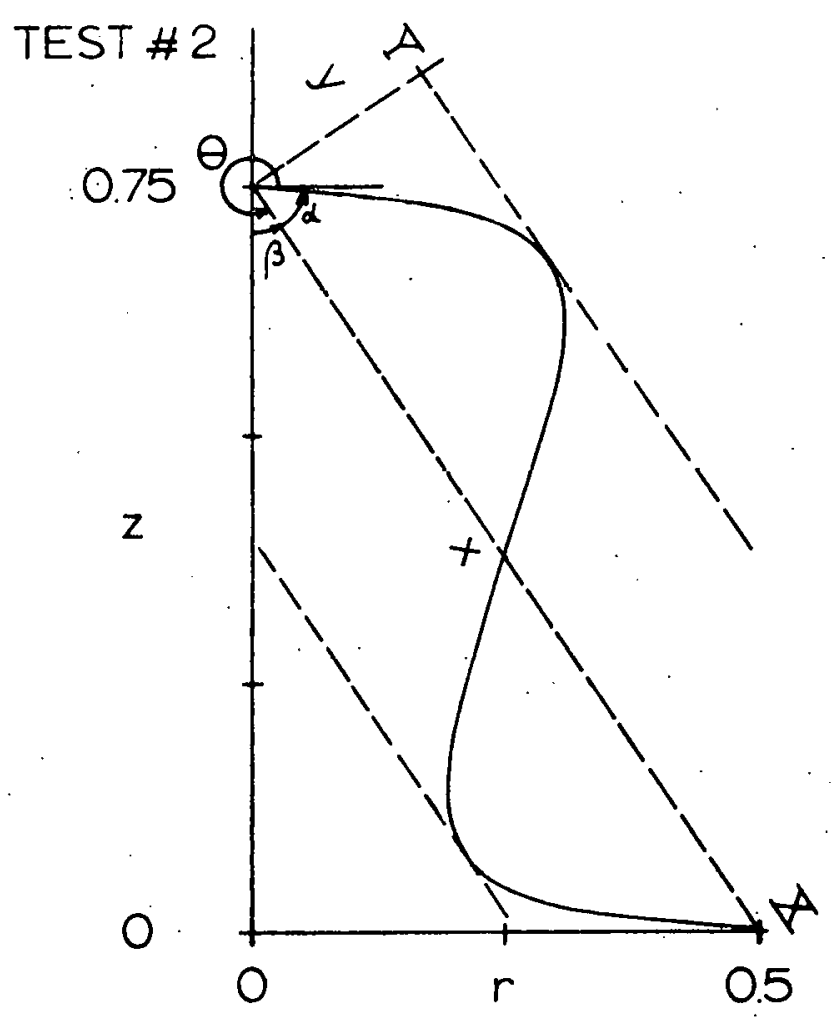

interface function

$$
\begin{aligned}
& y=Y \sin (2 \pi x / X) \quad 0 \leqslant x \leqslant X \\
& r=x \cos \theta-y \sin \theta \\
& z=x \sin \theta+y \cos \theta+0.75 \\
&Z=0.9013879 \quad Y=0.25 \quad \theta=5.442117 \text { (rad) }) \\
& Y^{\prime}(O)=2 \pi Y / X=\tan \alpha=1.5
\end{aligned}
$$

fluid data

$$
\begin{aligned}
& \rho_{k v}=0.5 \mathrm{gm} / \mathrm{cc} \\
& T_{i}=71.97 \text { dynes } / \mathrm{cm} \\
& \delta x=0.1 \mathrm{~cm} \\
& \delta t=0.001 \mathrm{sec}
\end{aligned}
$$

41 particles were used to describe the interface

Figure 13. A function used to test both the Daly (12) interface fitting scheme and that used in this vork. 
Table II. Approximate and known velocity components due to surface tension for the function seen in Fig. 13.

$\begin{array}{cccc}\text { known } & \text { velocity } \\ \text { velocity } & \text { Daly (12) } \\ (\mathrm{cm} / \mathrm{sec}) & (\mathrm{cm} / \mathrm{sec}) & \begin{array}{l}\text { velocity } \\ \text { this vork } \\ (\mathrm{cm} / \mathrm{sec})\end{array}\end{array}$

$(\mathrm{cm} / \mathrm{sec}) \quad(\mathrm{cm} / \mathrm{sec}) \quad(\mathrm{cm} / \mathrm{sec})$

\begin{tabular}{lrrrrr}
\hline & \multicolumn{7}{c}{} \\
$u(1.9)$ & 0.000 & 0.000 & 0.03 & 0.000 & 0.00 \\
$v(2.8)$ & -0.768 & -0.777 & 1.17 & -0.777 & 1.16 \\
$u(3.2)$ & 6.065 & 5.264 & 13.212 & 5.995 & 1.15 \\
$u(3.3)$ & -1.667 & -1.690 & 1.34 & -1.696 & 1.75 \\
$u(3.4)$ & -4.755 & -4.772 & 0.37 & -4.780 & 0.54 \\
$u(3.5)$ & -4.878 & -4.877 & 0.02 & -4.877 & 0.03 \\
$v(3.8)$ & -3.017 & -3.013 & 0.15 & -3.023 & 0.19 \\
$v(4.1)$ & 5.207 & 5.417 & 4.05 & 5.414 & 3.99 \\
$v(4.5)$ & 2.044 & 2.044 & 0.00 & 2.044 & 0.01 \\
$u(4.6)$ & -5.284 & -5.288 & 0.08 & -5.289 & 0.11 \\
$u(4.7)$ & -7.556 & -7.560 & 0.05 & -7.517 & 0.52 \\
$u(4.8)$ & -16.127 & -15.177 & 5.88 & -16.216 & 0.55 \\
$v(4.8)$ & -9.355 & -6.531 & 30.191 & -9.343 & 0.12 \\
$v(5.1)$ & 1.747 & 1.716 & 1.77 & 1.720 & 1.58 \\
$v(6.1)$ & 0.487 & 0.475 & 2.56 & 0.475 & 2.58 \\
& & & & & \\
\hline
\end{tabular}

1 Large errors due to breaks in spline sequences 
second derivatives $I^{\prime}(x)$ and $I^{\prime \prime}(x)$ are,

$$
\begin{aligned}
& r^{\prime \prime}(\dot{x})=M_{k-1}^{r} \frac{\left(x_{k}-x\right)}{l_{k}}+M_{k}^{r} \frac{\left(x-x_{k-1}\right)}{l_{k}} \\
& r^{\prime}(x)=-M_{k-1}^{r} \frac{\left(x_{k}-x\right)^{2}}{2 l_{k}}+M_{k}^{r} \frac{\left(x-x_{k-1}\right)^{2}}{2 l_{k}}+\frac{\left(r_{k}-r_{k-1}\right)}{l_{k}}-\frac{\left(M_{k}^{r}-M_{k-1}^{r}\right) l_{k}}{6} \\
& r(x)=M_{k-1}^{r} \frac{\left(x_{k}-x\right)^{3}}{6 l_{k}}+M_{k}^{r} \frac{\left(x-x_{k-1}\right)^{3}}{6 l_{k}}+\left(\frac{r_{k}}{l_{k}}-\frac{M_{k} l_{k}}{6}\right)\left(x-x_{k-1}\right) \\
& +\left(\frac{r_{k-1}}{l_{k}}-\frac{M_{k-1} l_{k}}{6}\right)\left(x_{k}-x\right) \\
& l_{k}=x_{k}-x_{k-1} \quad ; x_{j}=\sum_{l=1}^{j} \sqrt{\left(r_{l}-r_{l-l}\right)^{2}+\left(z_{l}-z_{l-l}\right)^{2}}
\end{aligned}
$$

where $l_{k}$ is the chord length between particles $k$ and $k-1$, and $X_{j}$ is the cumulative chord length to particle $j$.

4. The end point constants $M_{0}^{r}$ and $M_{K+1}^{r}$ must be specified. They may be obtained in the following manner

$$
M_{0}^{r}=\lambda_{0} M_{1}^{r} ; M_{k+1}^{r}=\lambda_{k+1}^{*} M_{k}^{r}
$$

where the $\lambda$ 's are constants chosen for the best fit. 5. The constants $M_{k}^{r}$ and their companions $q_{k}^{Z}$ in the corresponding 2 formulae are related to their neighbors $\|_{k-1}^{r}$ and $M_{k+1}^{r}$ by

$$
\frac{l_{k}}{6} M_{k-1}^{r}+\frac{\left(l_{k}+l_{k+1}\right)}{3} M_{k}^{r}+\frac{l_{k+1}}{6} M_{k+1}^{r}=\frac{r_{k+1}-r_{k}}{l_{k+1}}-\frac{r_{k}-r_{k-1}}{l_{k}}
$$

which can be witten as the tridiagonal system of equations, 


$$
\begin{aligned}
& {\left[\begin{array}{ccccc}
\left(l_{1}+l_{2}\right) / 3 & l_{2} / 6 & 0 & \cdot & 0 \\
l_{2} / 6 & \left(l_{2}+l_{3}\right) / 3 & l_{3} / 6 & 0 \\
\cdots & \cdots \cdots & \cdots \cdots & 0 \\
0 & 0 & l_{k} / 6 & \left(l_{k}+l_{k+1}\right) / 3
\end{array}\right]\left[\begin{array}{c}
M_{1}^{r} \\
M_{2}^{r} \\
\cdots \\
M_{k}^{r}
\end{array}\right]} \\
& \therefore\left[\begin{array}{l}
\left(r_{2}-r_{1}\right) / l_{2}-\left(r_{1}-r_{0}\right) / l_{1}-l_{1} M_{0}^{r} / 6 \\
\left(r_{3}-r_{2}\right) / l_{3}-\left(r_{2}-r_{1}\right) / l_{2} \\
\cdots \cdots \\
\left(r_{k^{k}+1}-r_{k}\right) / l_{k^{*}+1}-\left(r_{k}^{*}-r_{k+1}\right) / l_{k^{k}}-l_{k} M_{k} / 6
\end{array}\right]
\end{aligned}
$$

The above systen can be solved for the $a_{k}^{r}$ by the method of

Thomas uhich is a simple recursive routine for the inversion of tridiagonal matrices and the simultaneous solution of their associated systems.

6. A similar procedure is used to determine $z(x)$.

7. Hith the spline fits conpleted, one each for $r$ and $z_{\text {. }}$ the interfacial tension force at any point $(x(x), z(x))$ on the interface ay be calculated from the relation

$$
\frac{T_{i}}{\rho} k=\frac{T_{i}}{\rho}\left\{\frac{r^{\prime} z^{\prime \prime}-z^{\prime} r^{\prime \prime}}{\left[\left(r^{\prime}\right)^{2}+\left(z^{\prime}\right)^{2}\right]^{3 / 2}}+\frac{z^{\prime}}{r\left[\left(r^{\prime}\right)^{2}+\left(z^{\prime}\right)^{2}\right]^{1 / 2}}\right\}
$$

where the primes indicate differentiation with respect to $x$.

Figure 14 shous a flow diagram of the interface fitting program. Adjustments to the particle density along the interface are made first, with continuity of the numbering scheme maintained. The interface particles are then splinefitted by the method outlined above, and a check of the 
Master. Flowsheet

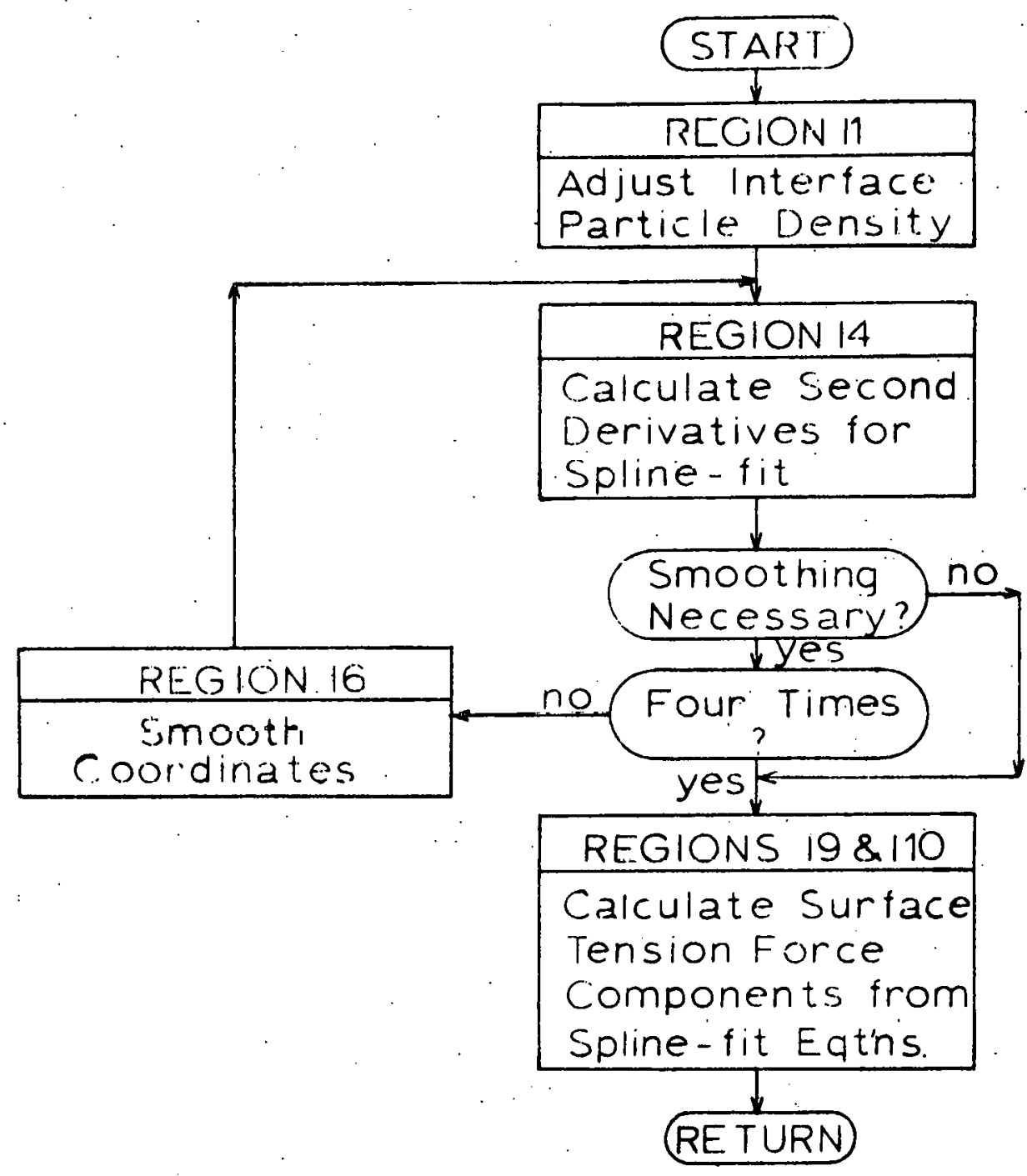

Figure 14. Alowsheet of the fitting schene used in this work: 
curvature at each particle is made, subject to the restriction that

$$
|k|<\frac{\rho}{T_{i}} \frac{8 r^{2}}{8 t^{2}}
$$

as stated by Daly (12). This restricts the fluid wotion due to surface tension to distances less than a cell width in one time step. Particles in violation of Bq. (68) are subjected to a smoothing by a least squares parabolic fit of their nearest neighbors and a subsequent readjustment of their ordinate values. If a particle needs smoothing more than four consecutive times it is ignored, because further smoothing would most likely not reduce its curvature. When this approach is compared with the interface fitting technique of Daly (12) (Fig. 15) it can be seen that some reduction of logic has occurred. What is not apparent from such a comparison is that Daly's "subdivision of interface" subroutine accounted for one third of the total code required for the program.

With the addition of the interface fitting capability. it was believed that the MAC method would produce accurate droplet profiles, given the correct initial conditions. This vas not the case. The errors incurred by the use of surface forces at locations different frow those that actually gave rise to then caused more distortion of the interface than had been experienced before. There was also distortion due to 


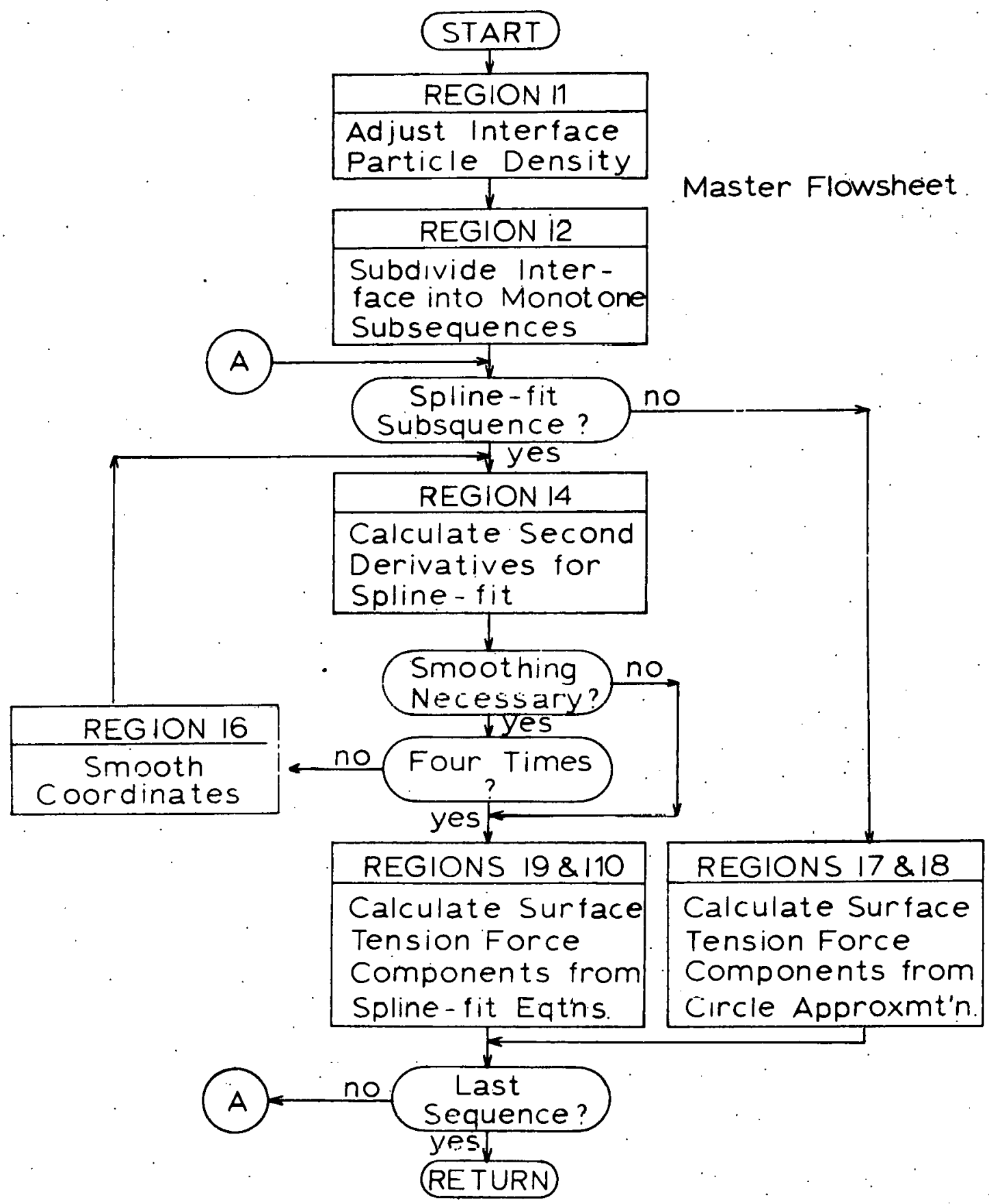

Pigure 15. A flousheet of the fitting scheme proposed by Daly (12). 
the velocity extrapolations of the unmodified MAC method.

The modifications of $\mathrm{Chan}$ and street (7) may be applied to correct these problems. By adjusting the pressure equation, Eq. (56), to accept irregularly spaced boundary data, and using the interface fitting scheme just discussed, it is possible to apply pressure forces at their correct locations.

The following approximation to Eq. (18) displays the adjustments to Eq. (56) which were necessary to introduce irregularly spaced pressure data.

$$
\begin{aligned}
\frac{D_{i j}^{n+1}-D_{i j}}{81}= & -Q_{i j}+\frac{a_{3} r_{i+\frac{1}{2}}\left(\phi_{i j}-\phi_{i+a_{j j}}\right)-a_{1} r_{i-\frac{1}{2}}\left(\phi_{i-a_{3} j}-\phi_{i j}\right)}{r_{i} 8 r^{2} \alpha_{1} \alpha_{3}} \\
& +\frac{\alpha_{4}\left(\phi_{i j}-\phi_{i j+a_{2}}\right)-\alpha_{2}\left(\phi_{i j-a_{4}}-\phi_{i j}\right)}{8 z^{2} \alpha_{2} \alpha_{4}}
\end{aligned}
$$

where

$$
Q_{i j}=\frac{1}{r_{i} 8 r}\left(r_{i+\frac{1}{2}} \xi_{i+\frac{1}{2} j}-r_{i-\frac{1}{2}} \xi_{i-\frac{i}{2} j}\right)-\frac{1}{8 z}\left(\zeta_{i j+\frac{1}{2}}-\zeta_{i j-\frac{1}{2}}\right)
$$

Here $\xi_{i+\frac{1}{2} j}$ and $\zeta_{i j+\frac{1}{2}}$ represent all the terms except for pressure on the right hand sides of Egs. (22) and (23), respectively, and are used for notational convenience. Equation (70) is shown to emphasize the fact that the velocity locations are unchanged from the original MAC method, and only the locations of the pressure boundary data at the free surface have been altered. 
Thus Eq. (18) may nou be approxinated by Eq. (69) in a manner consistent with the velocity equations. The accuracy of this approximation is $0(\delta r, \delta z)$ as may be seen from the last terw of Eq. (71).

$$
\begin{aligned}
& \frac{\partial Q}{\partial t}+Q+\nabla^{2} \phi=\frac{D_{i j}^{n+1}-D_{i j}}{\delta t}+Q_{i j}+\frac{1}{r_{i} \delta r^{2} a_{1} \alpha_{3}}\left[a_{3} r_{i+\frac{1}{2}}\left(\phi_{i j}-\phi_{i+a_{j} j}\right)\right. \\
& \left.-\alpha_{1} r_{i-\frac{1}{2}}\left(\phi_{i-a_{3 j}} \phi_{i j}\right)\right]+\frac{1}{\delta z^{2} \alpha_{2} \alpha_{4}}\left[\alpha_{4}\left(\phi_{i j}-\phi_{i j+a_{2}}-\alpha_{2}\left(\phi_{i j-\bar{a}_{4}} \phi_{i j}\right)\right]\right. \\
& +\left(\left.\frac{1}{2 r_{i}}\left[r_{i+\frac{1}{2}}\left(\alpha_{1}-1\right)+r_{i-\frac{1}{2}}\left(\alpha_{3}-1\right)\right] \frac{\partial^{2} \phi}{\partial r^{2}}\right|_{i j}+\left.\frac{1}{2}\left[\left(\alpha_{2}-1\right)+\left(\alpha_{i}-1\right)\right]_{\frac{\partial^{2}}{\partial Z^{2}}}\right|_{i j}+\cdots\right)_{(71)}
\end{aligned}
$$

This particular arrangement of the velocity and pressure equations together with linear extrapolation of the velocities near the free surface produced a solution to the following hypothetical problen proposed as a test of the technique.

A quiescent water arop is hanging from a flat surface. Its shape is initially given by the Laplace equation and its initial pressure distribution is hydrostatic. At time $t=0$ the surface tension force restraining the drop is remored and the drop is allowed to fall under the influence of gravity subject only to $\phi=0$ at the free surface.

The initial interface and the cell geometry are shown in Fig. 16. The solutions are represented by the sequence of interface profiles shoun at later. times in Fig. 17. At times $t>1.0$ the interface begins to develop lumps which can be 
RADIUS, R $(\mathrm{cm})$

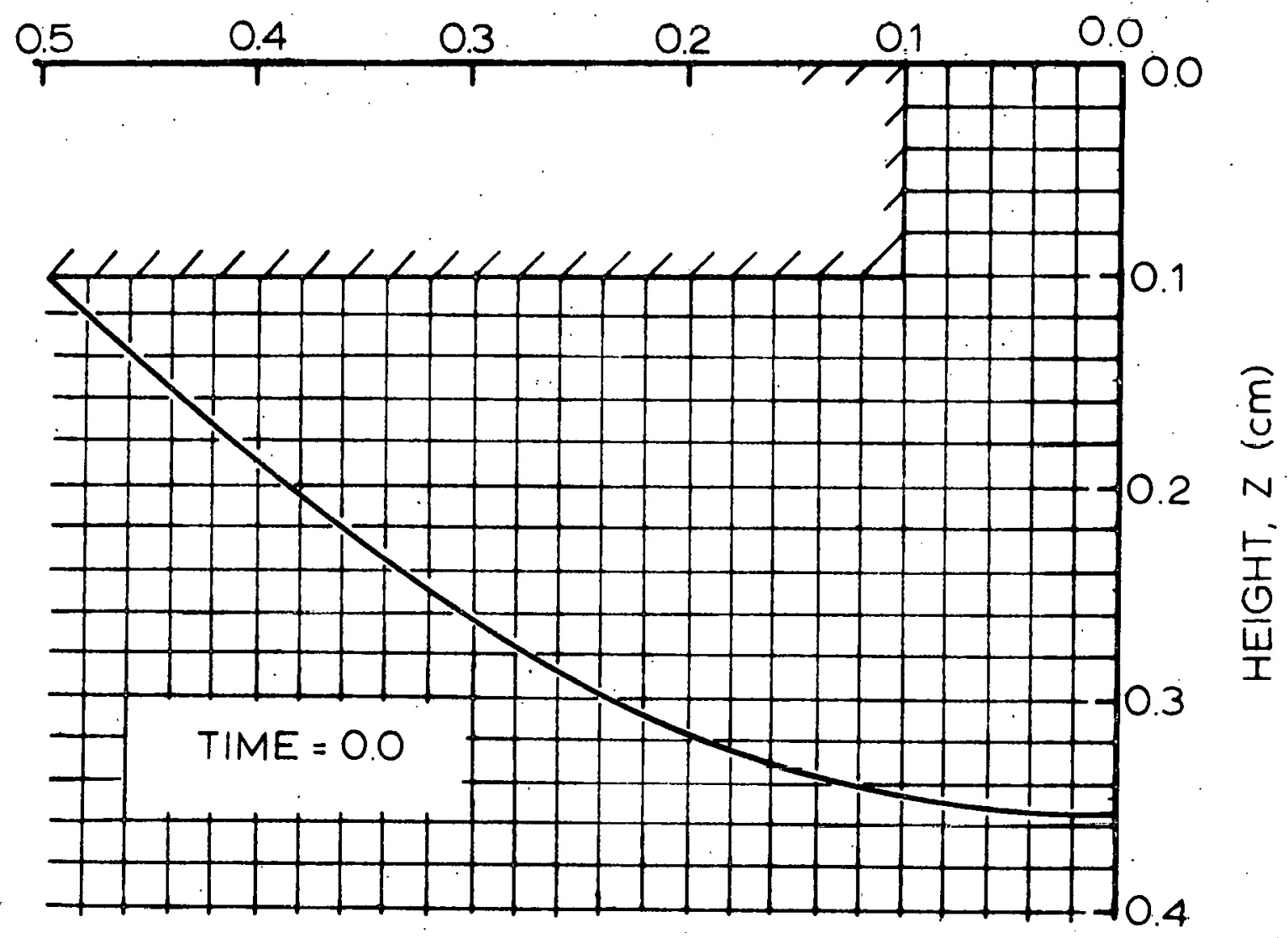

Pigure 16. The initial interface and computation mesh used to simulate the fall of a water drop. 


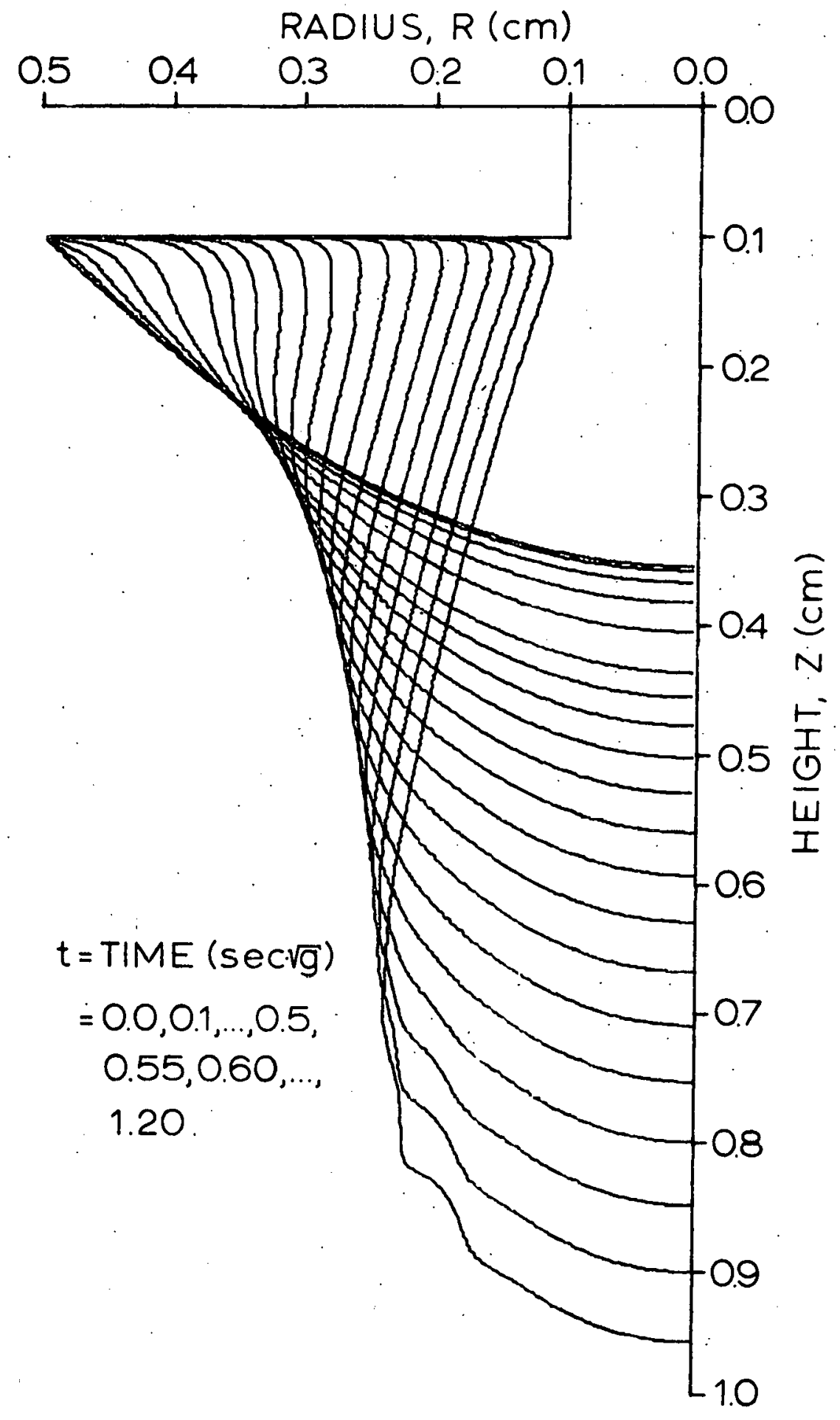

Pigure 17. The profiles of a drop of ater separating ithout surface tension. The lumps appear later in the separation and are due to volume conservation errors. 
traced back to the velocity extrapolation procedure. Due to the independent extrapolation of $u$ and the divergence in cells outside the fluid is not necessarily zero. This is unimportant until a cell which has not been used in the pressure calculations becomes an "irregular star", because of movement of fluid into the cell. At this time its value of $D_{i j}$ is incorporated into the pressure calculation. since there is no way to control the size of $D_{i j}$ for cells outside the fluid region, these values may be large. In the case presented here they are large enough to produce the lumps in the interface: The velocity equations respond to the tenporary loss of momentum by imparting momentum in the opposite direction, causing the lumps.

The problem of lumps due to the incorporation of $D_{i j}$ errors into the pressure solution was eliminated by forcing $D_{i j}=0$ into the cells surrounding the fluid region. This was acconplished by first linearly extrapolating the v velocity values as before, approximately three cell widths avay from the interface. Then, using the u velocities inside the fluid at the interface as boundary data for the u velocities outside the Elaid, the difference approximation to $D_{i j}=0$ was used to determine the remaining u velocity in each cell adjacent to the fluid region. This process was used to extend $u$ to the next row of cells and so on until all needed outside velocities, both $u$ and $v$, were specified and the di- 
vergences vanished at the cell centers.

When the above extrapolation technique ras applied to the problem of the falling drop, the interface profiles in Fig. 18 resulted. As can be clearly seen, the lumps have disappeared and the interface is smooth and accelerating at the gravitational rate. Thus wile slightly less accurate than other possible schemes, Eq. (69) together vith linear velocity extrapolation provides the needed accuracy for the solution of this particular falling drop problem.

other pertinent information about the drop besides its profile may be gathered in this process. Figure 19 presents the rate of surface area production for the drop. This information along with the velocity distributions permits studies of mass transfer within the arop. However, since the velocity distributions are generated in tabular form it is not convenient to present the time variations of each of : these distributions. A typical vertical velocity distribution is shown in Fig. 20 to illustrate the quantity of information which is available in each digtribution. Thus, to save space and and make meaningful assessment of the flov easier, the velocity distributions are presented in the form of vector fields, which will be explained later. The marker particle plots are included where they indicate some useful Elow property, such as the amount of surface stretching in the falling drop problen. The pressure distributions are not 


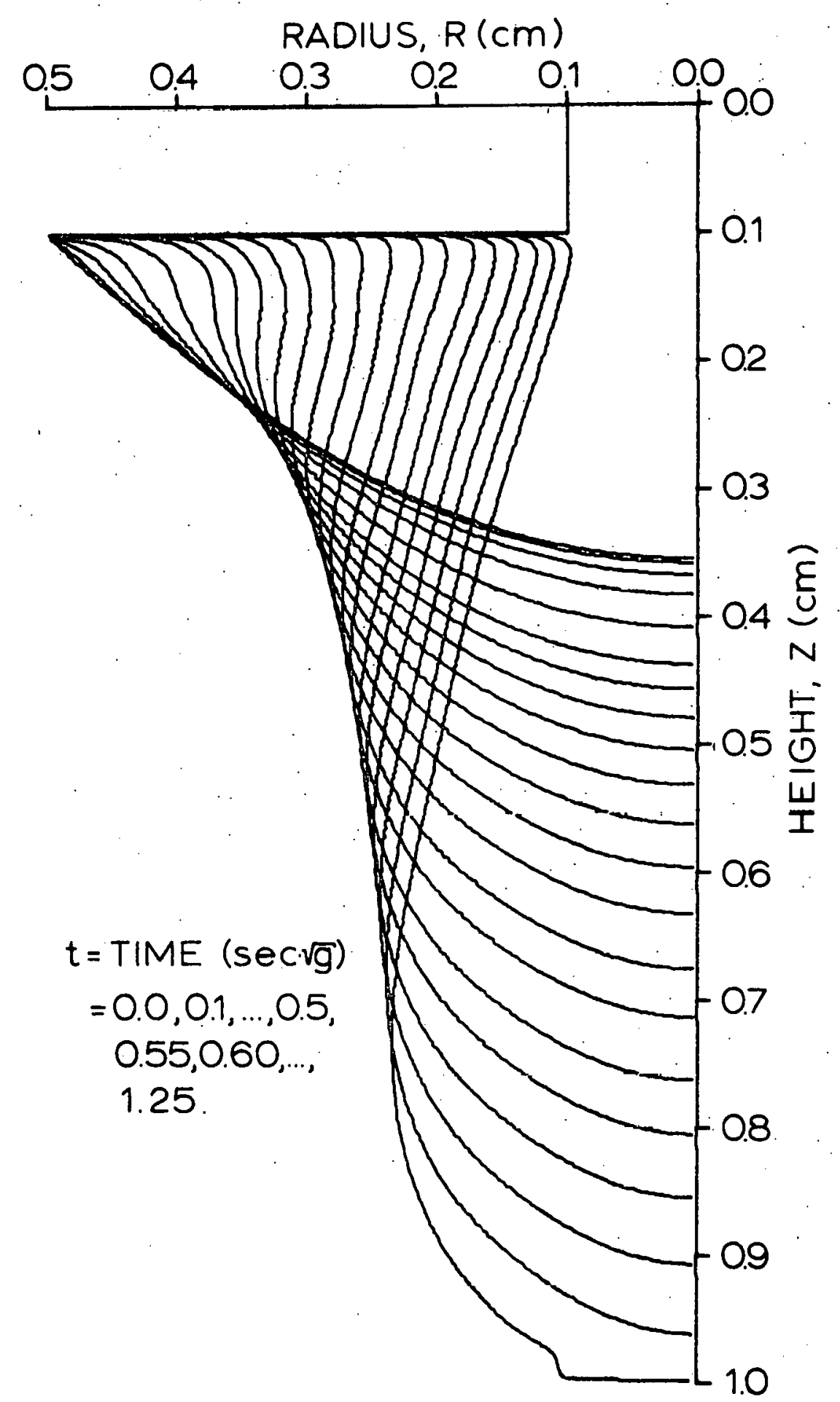

Piqure 18. The profiles of a drop of vater separating vithout surface tension. The smoothness of the profiles indicates a lack of rolume conservation errors. 


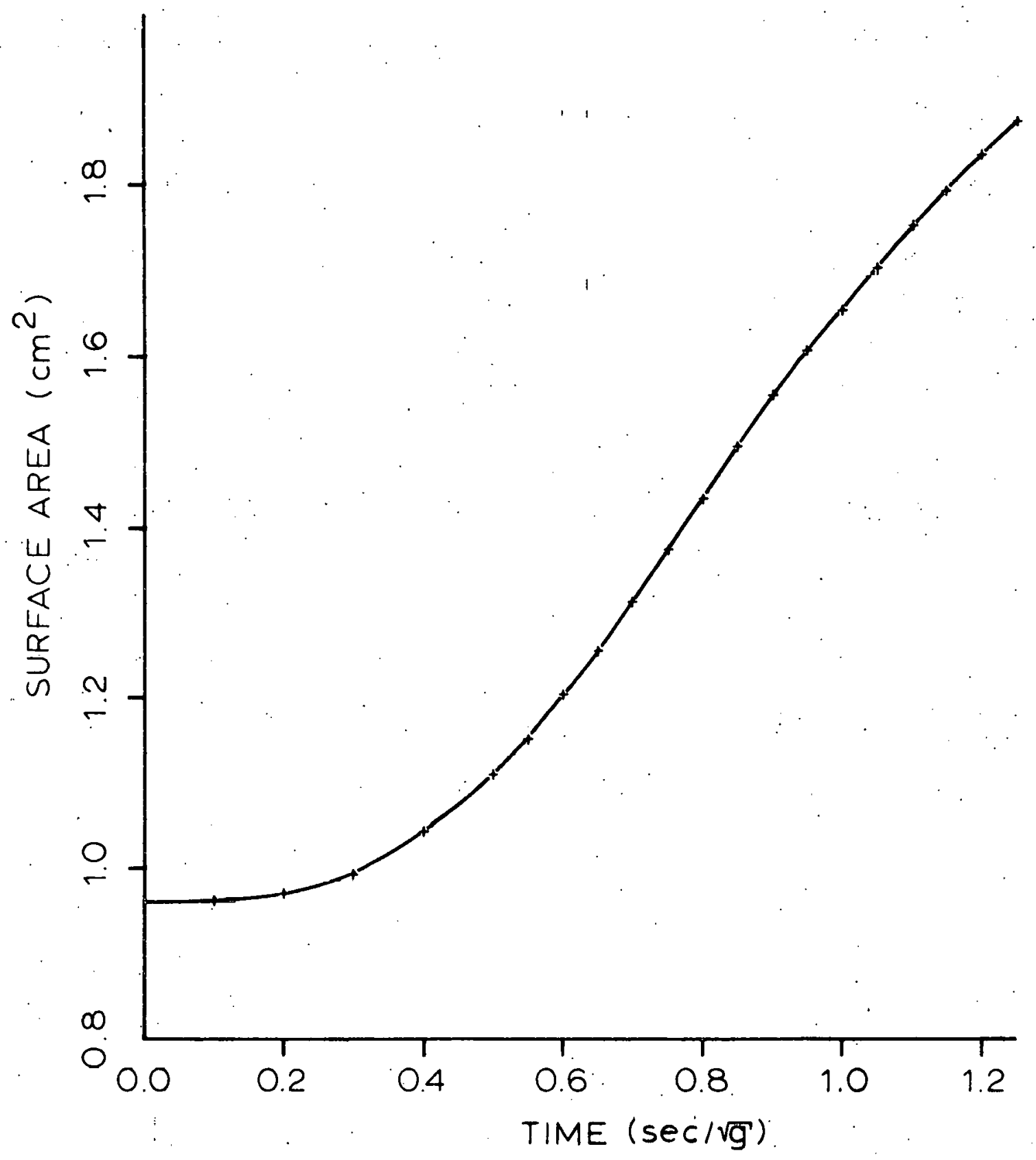

Figure 19. The surtace area of the drop seen in Fig. 18 as a function of time. 


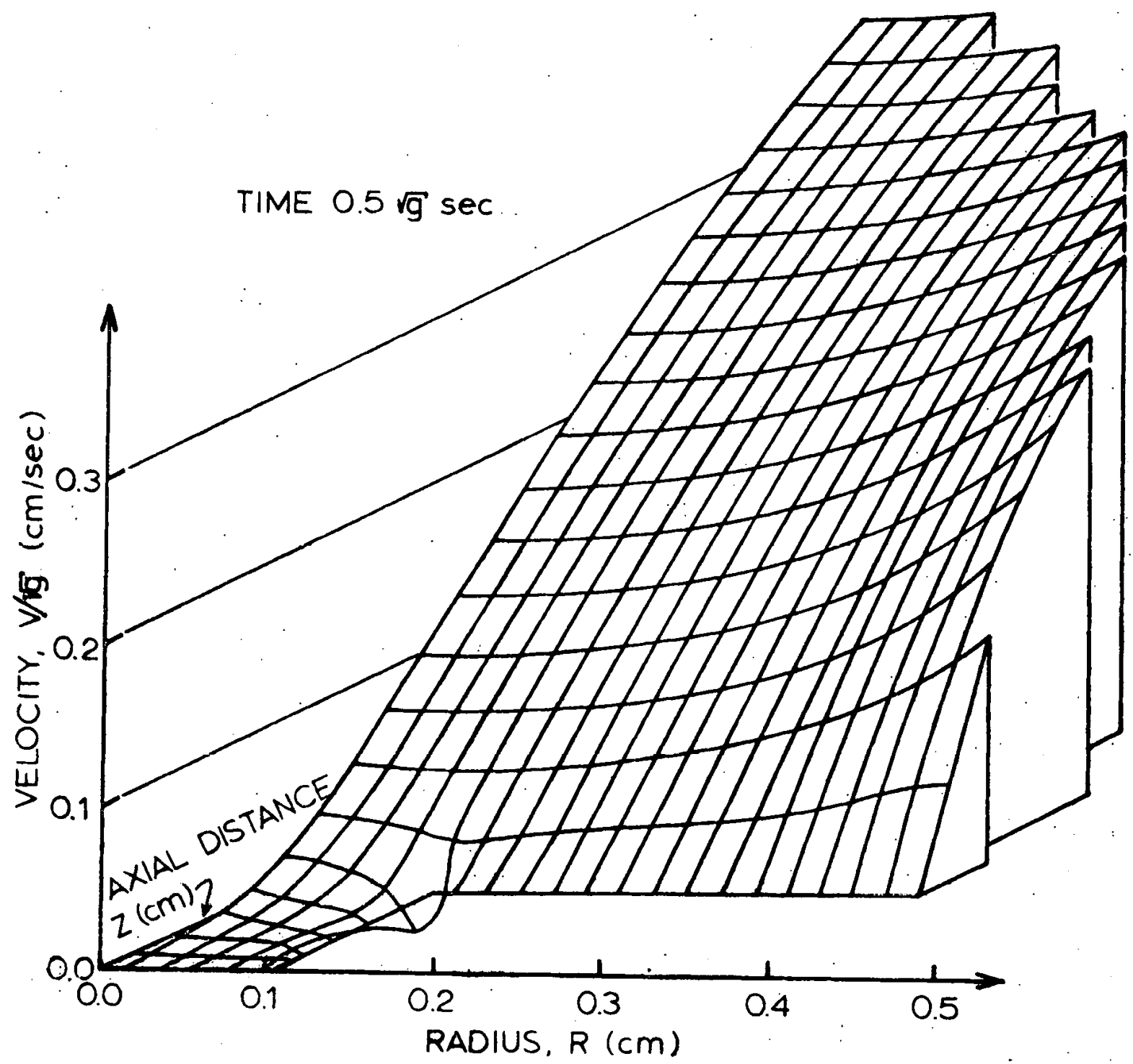

Pigure 20. The v velocity function shown as a function of $r$ and $z$. The velocity scale should be multiplied by $\sqrt{980}$ to convert the values to ca/sec. These velocities a re taken from the run whose profiles are seen in Fig. 18, at tine 0.5 $\sec / \sqrt{980}$. 
presented because of the difficulty in presenting them in a manner which would contribute to the understanding of the basic flow.

Most recently, the falling drop problen uas again solved by a technique somewhat different from that just presented. In this technique Eq. (69) is used to approxinate Eq. (55). This equation was only used to predict the pressure distribution. Once the pressure distribution was properly relaxed. the pressures vere extrapolated to cell centers outside the fluid. This vas done in such a manner as to preserve the accuracy of the approximation to Eq. (69). but to relocate the pressures for more accurate use in the velocity equations.

The extrapolation was ade in the following manner. For any "irregular star" cell, the approximation to $\frac{\partial^{2} \phi}{\partial Z^{2}}$ is

$$
\begin{aligned}
& \frac{\partial \phi}{\partial \alpha^{2}} \approx \frac{2}{a_{2}\left(\alpha_{2}+\alpha_{4}\right) \& z} \phi_{i j+\alpha_{2}}+\frac{2}{\alpha_{4}\left(a_{2}+a_{4}\right) \& Z^{2}} \phi_{i j-\alpha_{4}} \\
& -\frac{2}{a_{2} a_{4} 8 Z^{2}} \phi_{i j}
\end{aligned}
$$

where the data are assuined to be unequally spaced. Hovever, equally spaced data could have given rise to the same value of the second derivative from the following approximation,

$$
\frac{\partial^{2} \phi}{\partial z^{2}} \cong \frac{\phi_{i j+1}+\phi_{i j-i}-2 \phi_{i j}}{8 z^{2}}
$$

If $a_{4}=1$, these tuo approximations way be set equal to give $\frac{2}{a_{2}\left(\alpha_{2}+1\right)} \phi_{i j+a_{2}}+\frac{2}{\left(\alpha_{2}+1\right)} \phi_{i j-1}-\frac{2}{\alpha_{2}} \phi_{i j}=$ (Eq. cont'd.) 


$$
=\phi_{i j+i}+\phi_{i j-1}-2 \phi_{i j}
$$

uhich may be subsequently rearranged to solve for $\phi_{i j+1}$. If the extrapolated values of $\phi$ are used in place of the free surface values in the velocity equations then it is possible to write velocity and pressure equations which are algebraically consistent and have error terms of order $0\left(\delta r^{2} \cdot \delta z^{2}\right)$. This may be shown as follows. With the extrapolated pressure data arailable at equally spaced points, it is possible to use the original velocity equations, Eqs. (22) and (23). The pressure derivatives in these equations are accurate to terms of order $0\left(\delta r^{2}\right)$, as opposed to the errors of order $O(\delta r)$ incurred by using the border values and Eqs. (69) and (70). The error incurred in extrapolating the pressures is of order $O\left(\delta r^{2}\right)$ as may be seen from comparing the truncation errors of the two second derivative approximations. Thus the accuracy of the pressure derivative terms in the velocity equations may be increased by one order of magnitude, and at the same time the velocity and pressure equations are nade consistent with one another.

These two changes alone have accounted for a large reduction in the error introduced at the free surface. The resulting interface profiles are shown in Fig. 21. As can be seen from a comparison with those of Fig. 18, the new profiles are not that auch different from the old profiles, however, the greatest improvement is in the smoother 


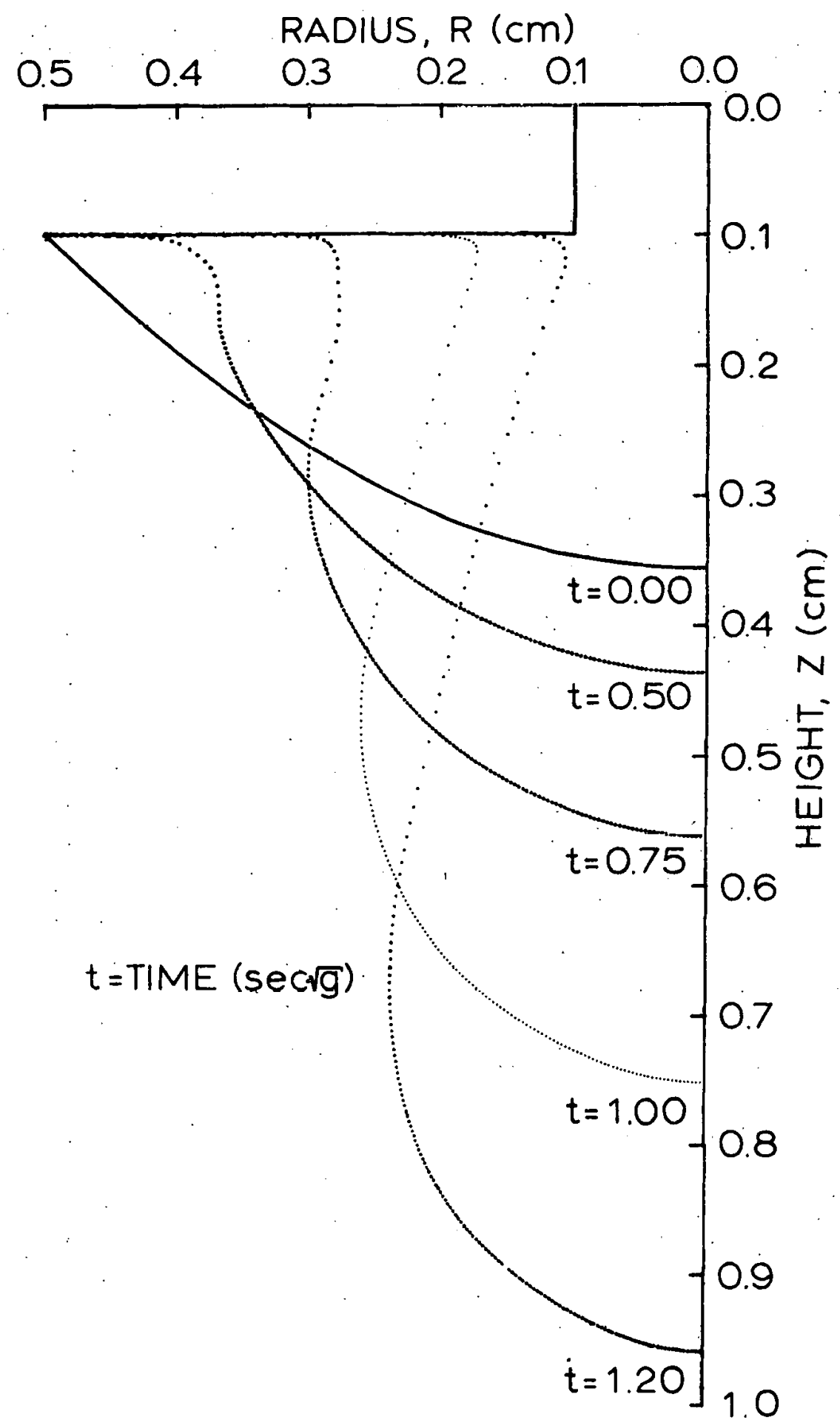

Pigure 21. The profiles of a drop of vater separating without surface tension. This calculation was perforied using surface pressures extrapolated to cell centers. 
velocities at the interface.

\section{The Falling Drop problen}

osing the latest methods presented in the previous section, the uncestrained or partially restrained fall of a drop vas considered. In this problem, there is no flow into or out of the drop, but its shape changes with time as it falls under the influence of gravity. The drops considered used the following fluid parameters: density. $1 \mathrm{gm} / \mathrm{cm}^{3}$, viscosity, 10 centipoise, initial surface tension, $12.26 \mathrm{dynes} / \mathrm{cm}$, initial fluid velocity $0 \mathrm{~cm} / \mathrm{sec}$ and a gravitational acceleration of $980.662 \mathrm{~cm} / \mathrm{sec}^{2}$. The surface tension was chosen to give a drop shape which could be followed for at least 1 centimeter as it stretched out. Thus the most deformation could be observed within the region, which was limited by the amount of computer storage available. At the start of calculation, the surface tension vas reduced to some fraction of its original value.

In the first example, Fig. 22, the profiles and marker particles are presented for a drop uhose surface tension was reduced to zero. As can be seen from the vector velocity plots in Fig. 23 the flow is dominanty vertical at the apex and approximates the flow pattern of an inviscid jet impinging on a flat plate near the base. This is seen in the figure as downward directed line segments near the drop apex and short lines which approximate the tangents of a 
THIS PAGE

\section{WAS INTENTIONALLY \\ LEFT BLANK}


Pigure 22. warker particle plots for Brample 1 . Here a free slip velocity boundary condition was applied at the base of the drop. No surface tenision was applied. 


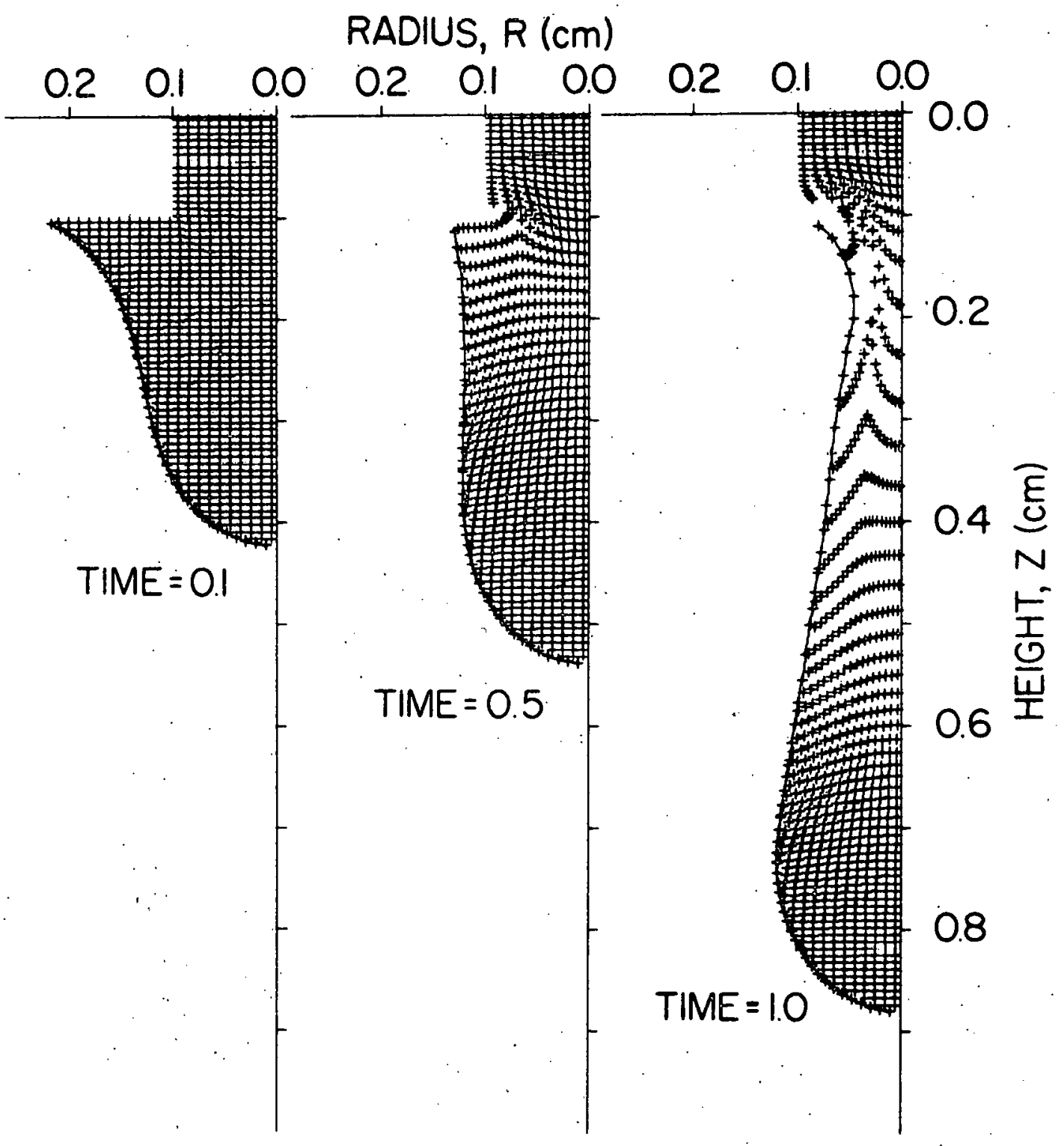


THIS PAGE

\section{WAS INTENTIONALLY \\ LEFT BLANK}


Plgure 23. Velocity rector plots for Example 1. At each time the vectors are scaled so that the longest vector has length $0.01 \mathrm{~cm}$ and corcesponds to the maximum velocity in the field. At times $0.1,0.5$, and 1.0 sec $\sqrt{9}$ the maxinum velocities are $0.097,0.493$, and $0.914 \mathrm{~cm} / \mathrm{sec} \sqrt{\mathrm{g}}$. 


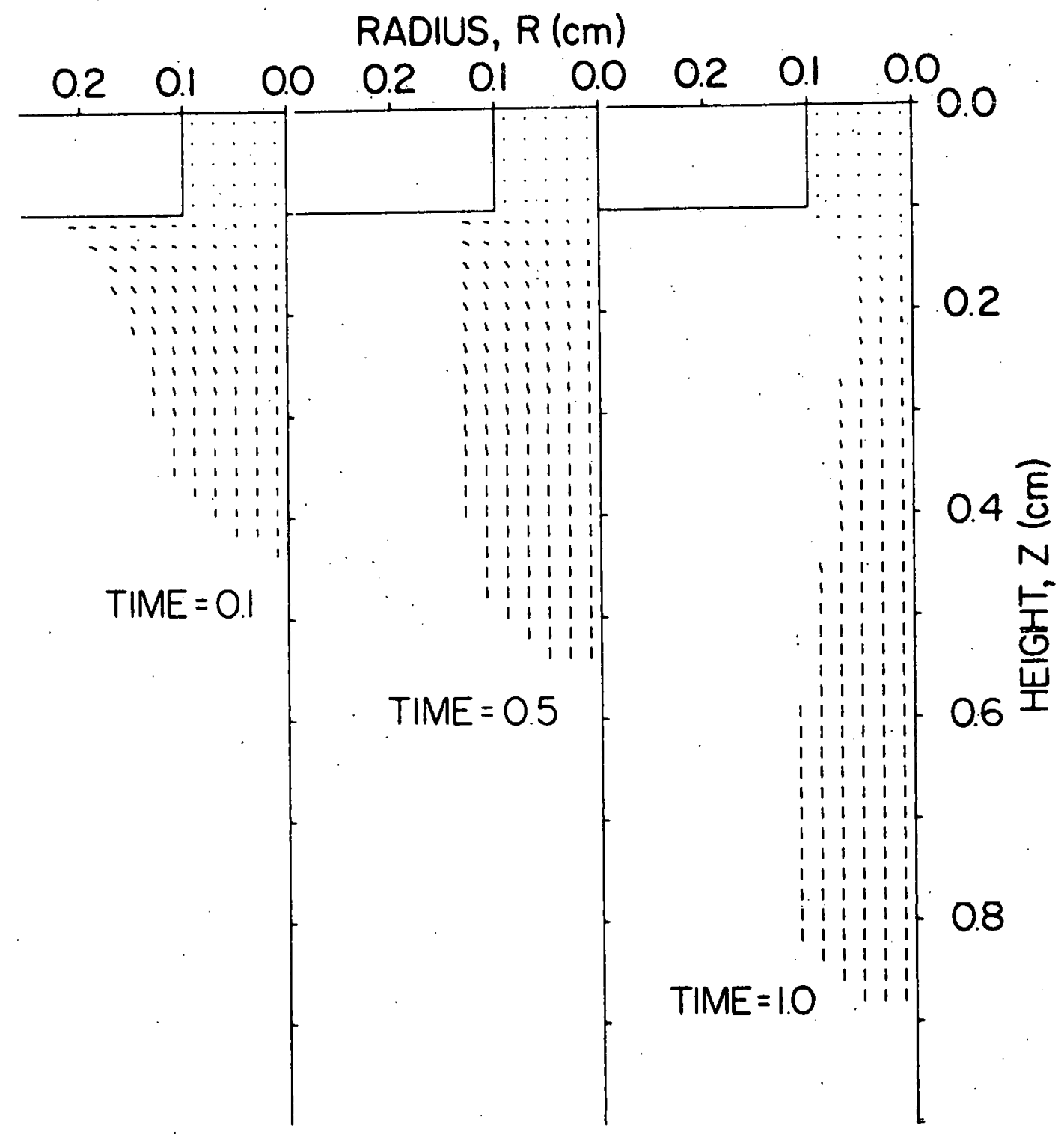


hyperbolic family near the base.

A principal feature of this calculation is the free slip boundary condition applied at the base of the drop. This was as much a test of the boundary condition as a determination of the flow pattern, and it reveals that the free slip condition does not adequately represent the flow near the base. The calculation extends over the time period from 0 to 0.032 seconds, indicating the magnitude of the accelerations involved. of primary interest is the fact that the fluid within the arop does not rotate because of the vertical flow, but rather approaches plug flow. This type of motion causes the fluid near the surface of the drop to remain near the same surface elements as time passes, and there is no transport of material from the center of the drop to its surface by convection.

The second example calculation uses the same initial conditions and fluid parameters as Example 1, but in this case the boundary condition at the base of the drop is restricted to no slip. The marker particle plots and the free surface are indicated in Fig. 24 and the vector velocity fields in Fig. 25. The basic flow pattern is the same as that of Exaple 1, but the apex of the drop is slightly retarded by the initial resistance to flow exerted by the base. This can be seen by comparing the apex heights of the drops in Pigs. 22 and 24 at time $t=1(\sec \sqrt{9})$. Also as $t i$ ae 
THIS PAGE

\section{WAS INTENTIONALLY \\ LEFT BLANK}


Figure 24. Uarker particle plots for Example 2. Here a no slip velocity boundary condition was applied at the base of the drop. Mo surface tension was applied. 


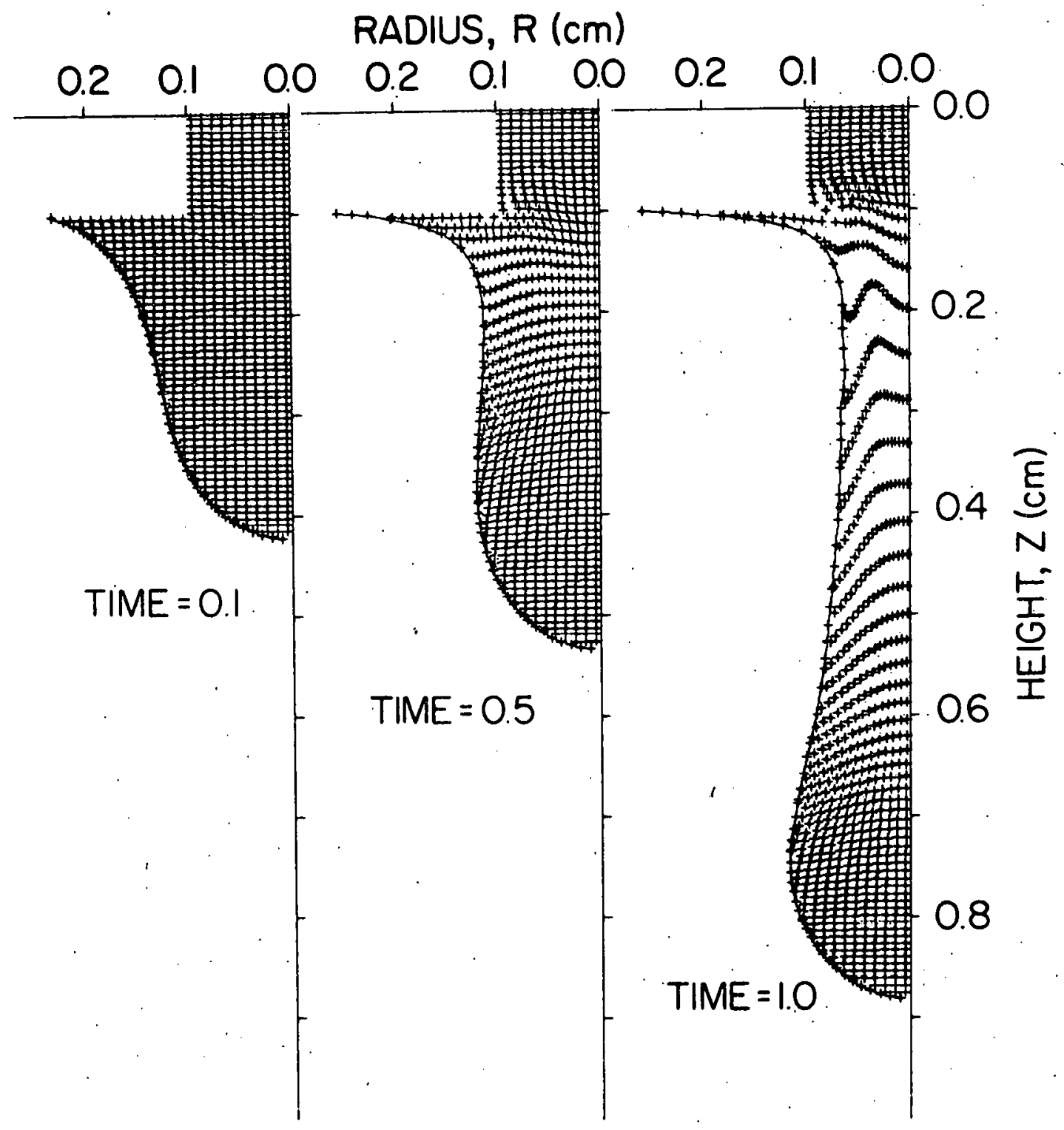




\section{THIS PAGE}

\section{WAS INTENTIONALLY \\ LEFT BLANK}


Pigure 25. Vector velocity plots for Example 2. At each time the vectors are scaled so that the longest vector has length $0.01 \mathrm{ca}$ and corresponds to the naximun velocity in the field. At times $0.1,0.5$, and 1.0 sec $\sqrt{g}$ the maximun velocities are $0.101,0.455$, and $0.919 \mathrm{ca} / \mathrm{sec} \sqrt{\mathrm{g}}$. 
RADIUS, $R(\mathrm{~cm})$

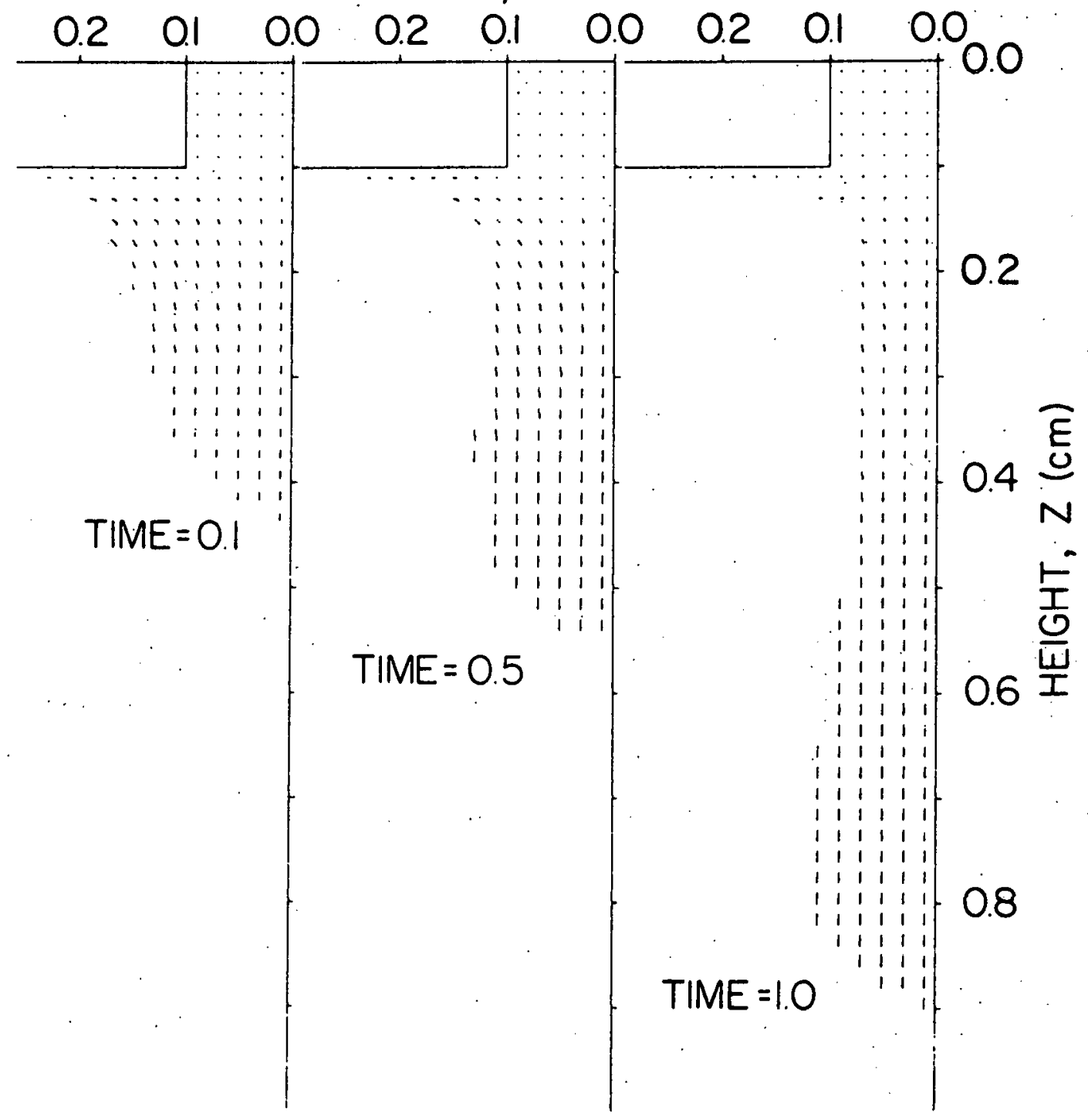


passes, the fluid stretches out into a thin film over the base, in a maner resembling the way in which real drops separate. Again the flow pattern is similar to that of an inviscid jet, and the fluid elements within the drop remain virtually static with respect to the surface elements they are adjacent to.

one effect not yet mentioned is the drag exerted on the fluid elements about midway between the centerline and the interface. This can be seen in the marker particle plots by following a single horizontal row of particles from the centerline to the interface, at a given time. clearly the particles about miduay along the row are not accelerating as rapidly as those along either the centerline or the free surface. Here, fluid from the edge of the drop whose momentua is nostly horizontally directed is merging with fluid which is mostly moving vertically. As these two flows werge, the horizontally soving fluid is accelerated in the rertical direction, and as it changes direction, there is a local decrease in the vertical momentum of the fluid which mixed vith it. This is indicated by the change in direction of the velocity vectors in Pig. 25. This effect rould be present even if fluid vere entering through the nozzle, as the fluid resting near the base must be accelerated horizontally before it can be accelerated vertically. Some daming of any circulation patterns due to incoming fluid would necessarily 
result.

As can be seen by inspection of the marker particles, there is a great deal of stretching at the interface. comparison of successive time plots reveals that most of the interface stretching takes place on the sides of the drop near the base. while very little stretching takes place near the apex. The non-uniformity of this type of stretching would produce locally high mass transfer rates because new surface area is being created and material from inside the drop is thus drayn to the interface. This result would correspond with the experimental observation that most of the disturbance of drops due to mass transfer takes place along the sides wile yery little disturbance takes place at the a pex.

The third example calculation again uses the same boundary and initial conditions and fluid parameters as in Example 2. However, in this calculation a surface tension force equal to one half of the initial value was applied at the free surface. When this was first attempted, the drop became very unstable, and the surface wis distorted. Thus, additional modifications to the calculation technique vere necessary.

It was found in test calculations in which the surface tension was not zero that the spline fitting technique was not capable of producing smooth pressure boundary conditions 
(curvatures) at the interface. The errors appear to be due to slight fluctuations in the positions of the interface particles which produced large fluctuations in the curvatures of the splines. This problem vas remedied by least squares fitting the curvatures produced by the splines and applying these swoothed curvatures as pressure boundary conditions. The resulting drop shapes and marker particle plots are shown in Fig. 26 and the vector velocity plots in Fig. 27.

As can be seen from the marker particle plots; Figs. 24 and 26. the drop motion is initially restrained by the surface tension forces. Hovever, the shape of the drops does not vary significantly. This result indicates that the surface tension forces are not yet significant in determining the shape of the drop compared with the accelerations of the ruld and gravity.

At later times the drop surface becomes somewhat ragged as the smoothing function used in the surface tension calculation is affected by strong variations in the curvatures calculated by the splines. These results show the inherent limitations in the smoothing approach. Whereas the curvature of the surface is actually calculated by splines passing through the interface particles uhich may contain errors due to particle fluctuations, the smoothing function nust follow the curvature data regardless of how bad the data might be. Thus, as the calculation proceeds and the particles becone 


\section{THIS PAGE}

\section{WAS INTENTIONALLY \\ LEFT BLANK}


Piqure 26. Marker particle plots for Example 3. A no slip velocity boundary condition vas applied at the base of the drop and a surface tension force equal to one half the initial value was applied at the free surface. 


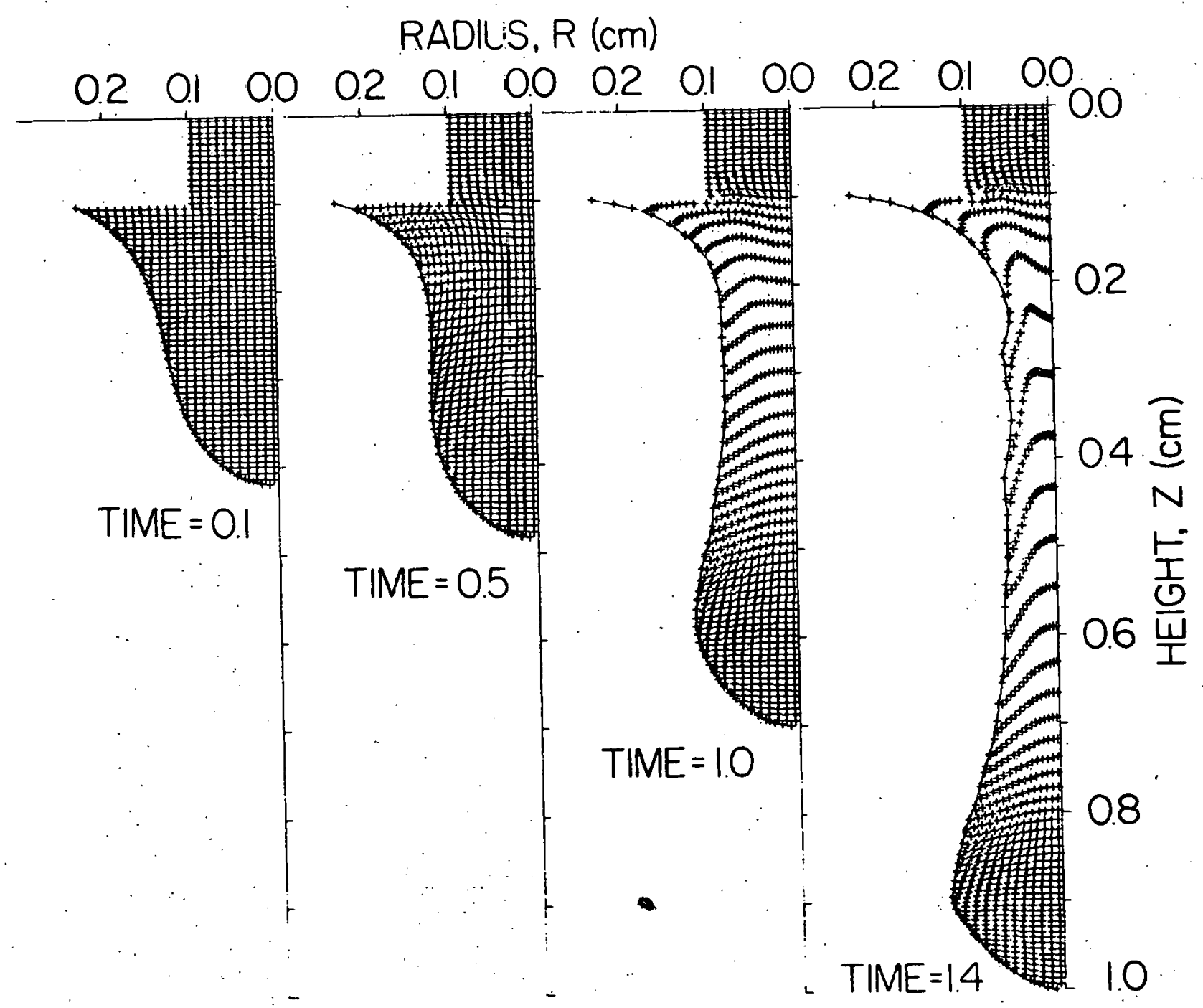

$\vec{\omega}$ 
THIS PAGE

WAS INTENTIONALLY

LEFT BLANK 
Pigure 27. Velocity vector plots for Braaple 3. at each tive the vectors are scaled so that the longest rector has

length $0.02 \mathrm{~cm}$ and corresponds to the aximum velocity in the

field. At times $0.1 ; 0.5,1.0$, and $1.4 \mathrm{sec} \sqrt{\mathrm{g}}$ the maximum

velocities are $0.056,0.276,0.626$, and $1.034 \mathrm{cmisec} \sqrt{\mathrm{g}}$. 


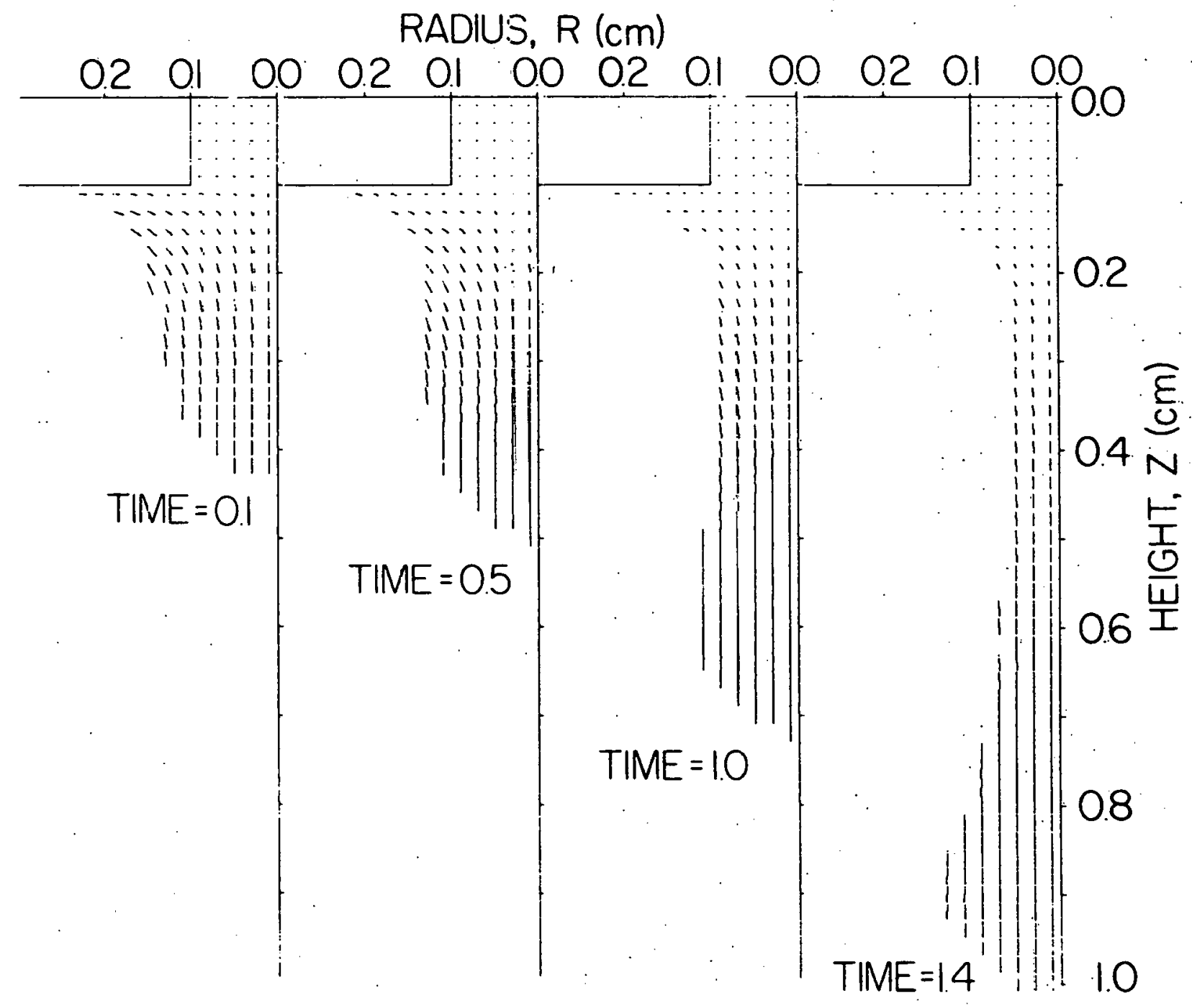


more and more irregularly spaced, the splines begin to oscillate rapidy in order to pass through the particles. This results in extraneous curvatures which the least squares function ast fit. Is these data are then used as pressure boundary conditions, the entire calculation must eventually become unstable. The first signs of this type of instability are the lumps at the free surface seen in Fig. 26 .

Before the instability becomes large, howerer, it is interesting to note the siailarity of the flows of Example 2 and this example. clearly the shapes are nearly identical. but at different times. Also the flov patterns are ver similar. These results would indicate that initially the effect of surface tension on the basic flov pattern is very slight. however; the surface tension is swall also.

The solution at late times indicates that the effect of surface tension becomes much greater as the drop stretches out. Comparison of the last times presented in Example 2 and this example (Figs. 24 and 26 , respectively) shows that when Eurface tension is present the arop begins to bulge more at the top and constrict more along the stem than it does when surface tension is not present. Also, the velocity vector field of Fig. 27, indicates that the fluid in the stem is beginning to accelerate more rapidly than that near the apex. This is seen in the figure as longer vectors near the botton of the stea than in the bulk fluid in the drop. Figure 28 is 
included to shou the effect of surface tension in retarding the acceleration of a falling drop. In this figure drops with and whout surface tension are compared at the same time. clearly the arop without surface tension is accelerating more rapidly as indicated by its greater length.

It is interesting to note that even with surface tension present, the same patterns of surface stretch and particle position relative to surface elements is preserved. This would indicate that the basic flow pattern within the drop is not greatly altered by the application of a small surface tension force, and that surface tension serves mainiy to change the shape of the drop.

The previous three examples of falling drop problems all show that there:is no internal rotation induced by the separation motion. In fact, the opposite effect is indicated by the marker particle plots. The basic flow pattern appears to be plug flow in the vertical direction ( $u=0, \nabla=$ constant) near the top of the drop. Near the base, the flow appears to be the same as that of a jet impinging on a flat plat, but in the opposite direction. This flow is given by (u=-Ar. $v=2 A z$ ), where A is an arbitrary constant.

The three calculations also reveal a marked similarity in the regions where the surface begins to stretch. In each case the side or stem of the drop shows the most stretching between particles and at the same time a stretching of the 


\section{THIS PAGE}

WAS INTENTIONALLY

LEFT BLANK 
Figure 28: Marker particle plots at the sane time, for drops with and without surface tension, taken from $E x a m p l e s ~ 2$ and 3. The shorter drop has surface tension restraining it, and indicates the magnitude of this effect. 


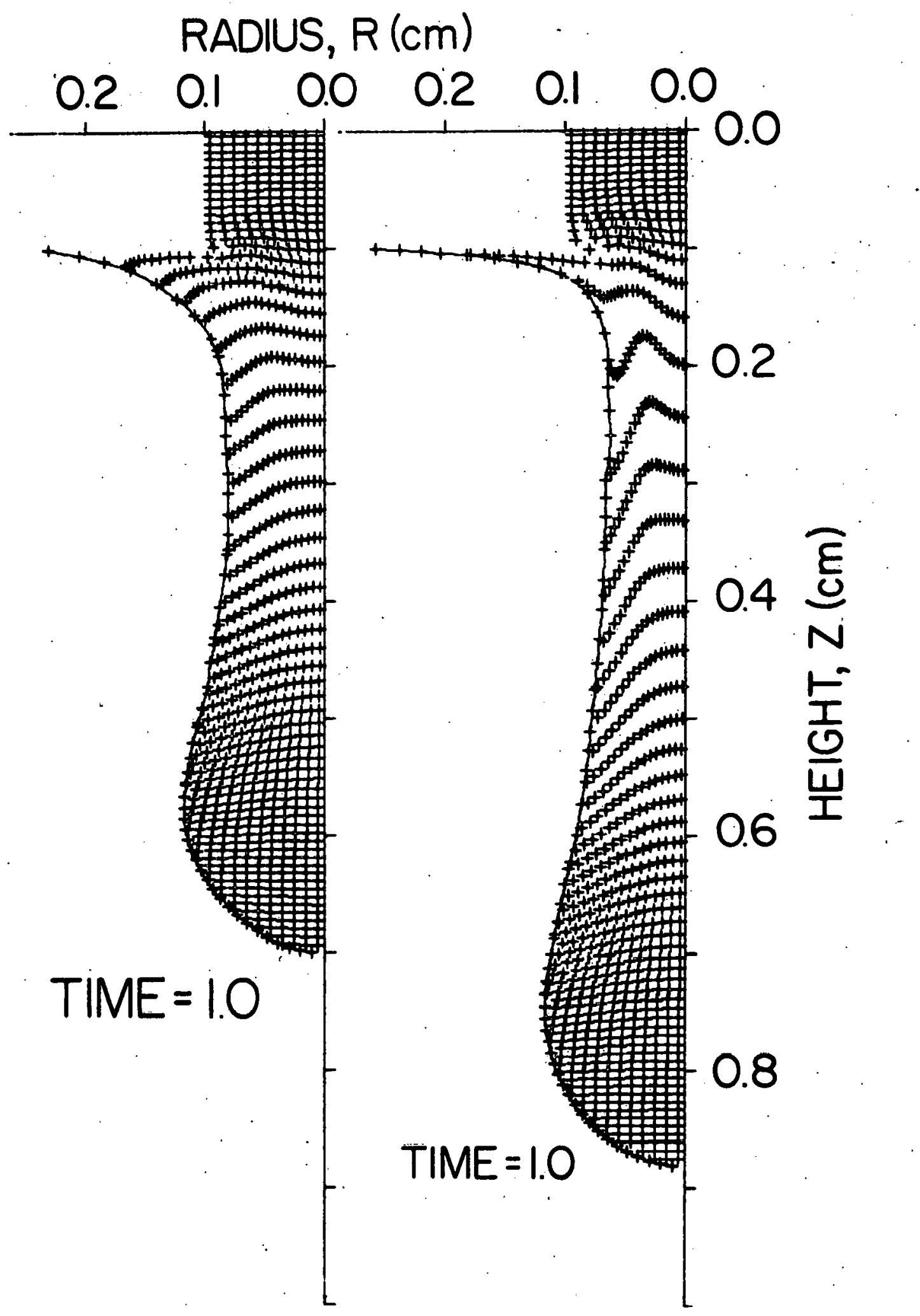


fluid within the drop near the surface. Near the top of the drop very little stretching is apparent, and the fluid within the drop is virtually undisturbed fron its original arrangement.

The following information pertains to the calculation parameters used in the previously discussed falling drop problems. Square cells rere used in all of the falling drop calculations, thus $\delta \mathrm{r}=\delta \mathrm{z}=0.02 \mathrm{~cm}$. The cells were arranged into a rectangle 39 cells wide and 52 cells high. The entire height of the mesh was used by the fluid as the drop stretched out, and ore height could have been added, but at the expense of increased computer storage.

The time step. $\delta t$, used in all of these calculations was $0.02 \sec \sqrt{9}$. This was the largest value which could be used without distorting the interface or causing instabilities. Smaller values of $\delta t$ vere tried but no improvement in the interface resulted. Also decreasing the tine step produced onli slight improvements in the accuracy of the solutions. The initial inleiface was approxinated by 41 particles, but due to the stretching of the interface, particles had to be added as the calculation proceeded. Thus by the end of the calculation as many as 20 particles might have been added, though the exact number is not the same for each of the runs presented here. No particles vere added or deleted from any other part of the fluid region. 
The computation times required were approximately 15 minutes for Examples 1 and 2 , and 52 minutes for Example 3 . The computations vere carried out on an IBM 360 nodel 65 computer, and each computation required 352,000 bytes of storage.

\section{The Eorced Internal circulation prop problem}

In an atteapt to sinulate the flow vithin slowly growing drops, the problem of forced internal circulation within a constant volume drop was considered. In this situation, fluid is added to and uthdrawn from the drop at the same rate. The flow within the drop will become steady once initial transient flows have died away, and the resulting flow patterns should resemble those within a slouly growing drop (56).

In order to study this problem, the MAC method was again modified to incorporate the appropriate boundary conditions. The pressure boundary condition at the interface consists of three components: applied or atmospheric pressure, surface tension, and normal stress due to fluid uotion. The first term is constant and is taken to be zero. The second term is directly proportional to the curvature of the drop. The drop shape was that of a static drop and the surface tension component reduces to a hydrostatic term wich does not vary with time. The third term is proportional to the amount of momentum trying to cross the interface. At steady state, the 
fluid flows tangential to the interface, thus this term must eventually vanish. This is equivalent to a free slip velocity boundary condition and a hydrostatic pressure boundary condition.

The pressure boundary condition at the interface may thus be vitten

$$
\phi=\phi_{a}+g z+c(\vec{u} \cdot \vec{n})
$$

where

$$
\begin{aligned}
\phi_{a}= & \text { applied pressure } \\
g Z= & \text { hydrostatic term } \\
c(\vec{u} \cdot \vec{n})= & \text { dynanic pressure opposed to the normal momentua } \\
& \text { trying to cross the interface. }
\end{aligned}
$$

This approach originated with viecelli (55). who first applied it to the calculation of flows in geometries uith arbitrarily curved boundaries by the MAC method. His technique requires the simultaneous iteration of both pressure and velocity, but has the advantage of the following pressure boundary conditiou, which conserves volume and allows no momentum to cross the interface:

Here $\vec{u}$ is the local velocity vector, $\vec{n}$ is the local surface normal and $\delta$ is the width of the cell. $\beta$ is an iteration parameter used to relax the pressure and velocity equations. 
Viecelli's approach differs from that used here. He iterated pressure and velocity simultaneously between time steps in order to conserve volume and force tangential flow. His schene is, however, closely analogous to that used here when the solution sought is steady state. In that case his iteration parameter closely resembles the tine parameter of this work. The two approaches differ in the manner in which volume conservation is forced in the surface cells, and how the interface position is determined. Viecelli used the original Mac nethod to force volume conservation. In this work, velocities are extrapolated from within the fluid in a manner which insures both continuity of the velocities at the interface and conservation of volume. In the approximation of the boundary position. Viecelli used short straight line segments, while in this work the spline fitting wethod discussed previously was used.

In this maner it was possible to apply the pressure Force at a location nearer to the correct location of the free surface and at the same time conserve volume. viecelli (55) gives more detail concerning the divergence theorem analogy on wich this boundary condition approximation is based, and shows how it may be correctly incorporated into dynamic calculations.

The previously discussed boundary conditions, while somewhat enpirical, indeed produced flous tangential to the 
interface. The flous shov circulation patterns similar to those observed in nature (56), and are approximately what one yould expect. There does appear to be some discrepancy in the flow pattern very near the free surface, which allows the escape of some normal momentum. Hovever, it cannot be attributed entirely to the approximate boundary condition discussed above. Part of the problem in this region of the calculation is the lack of resolution due to finite cell size. Because the grid is composed of square cells and the interface does not lie on a $45^{\circ}$ slope, the grid ust have several "steps" in it to approximately match the true interface position. At these "steps", there is a possibility of discontinuity in the relocity boundary conditions, which are based on extrapolations from within the fluid region. However, as will be seen in the following figures, the error is not large, and the basic flow pattern is not significantly effected.

Forced internal flow of fluid uthin drops as studied by varying fluid viscosity and inlet velocity independently and observing the steady state flow patterns. viscosities in the range of 1 to 80 centipoise (cp) and inlet velocities of 0.2 to 5 centineters per second (co/sec), respectively. were used. Two orthogonal sets of experiments vere conducted, one holding inlet velocity constant at $1 \mathrm{~cm} / \mathrm{sec}$ and varying viscosity $(1,10,20,50$, and $80 \mathrm{cp})$ and the other holding 
viscosity constant at $1 \mathrm{cp}$ and varying inlet velocity, 10.2 , 0.4 . 0.5 , and $1.0 \mathrm{~cm} / \mathrm{sec})$. In this maner any transitions in the flow pattern could be detected and bracketed vithout depending on dynamic similarity.

The first set of experiments, holding viscosity constant and yarying velocity, are presented in pigs, 29, 30 and 31. Figures 29 and 30 present the steady state particle paths and Pig. 31 presents the vector velocity plots corresponding to the highest and lowest inlet relocities. The first experiment was conducted at an inlet velocity of $1 \mathrm{~cm} / \mathrm{sec}$. The striking circulation pattern reveals that a large portion of the fluid within the rortex never passes out of the region that it occupies in Fig. 29. This can be seen by following any pathline of the vortex beginning with the third pathline doin from the base.

Each of these 1 ines eventually retraces itself, indicating a lack of mixing, even in the presence of a strong vortex. The outer pathlines of the vortex do not retrace one another, indicating the extént of mixing. lihe two outer pathlines which terminate near the base of the drop were actually crossing the interface near this point. The program which computed the paths from the steady state velocity distribution was instructed to terminate such paths because it has been found that once a particle crosses the interface. for watever reason, the velocity field is not generally ac- 
THIS PAGE

WAS INTENTIONALLY

LEFT BLANK 
Figure 29. Steady state particle paths for drops uith forced internal circulation. The upper drop has an inlet velocity of $1 \mathrm{ca} / \mathrm{sec}$ and a viscosity of $1 \mathrm{cp}$. The lover drop has an inlet velocity of $0.5 \mathrm{~cm} / \mathrm{sec}$ and a viscosity of $1 \mathrm{cp}$. 


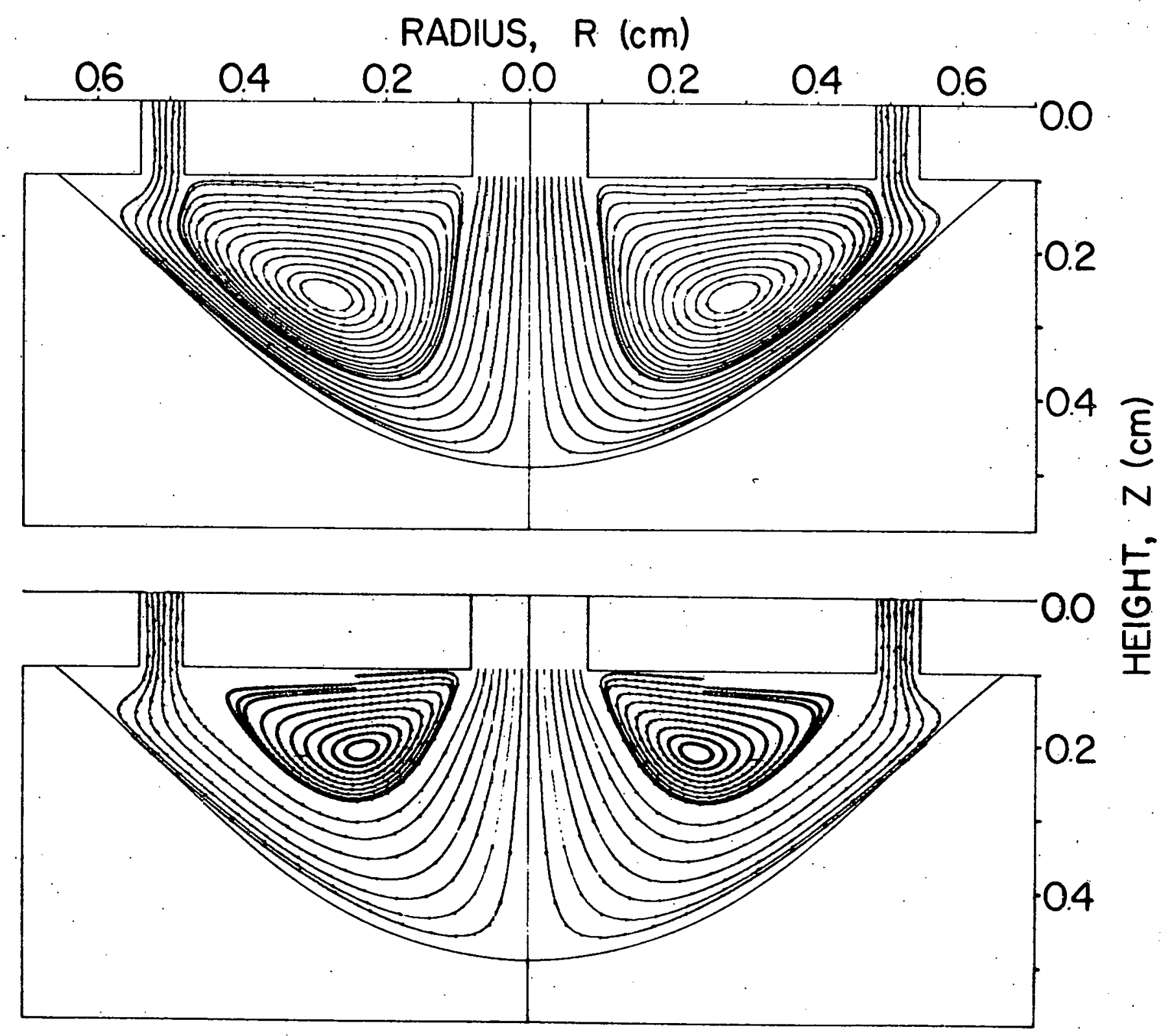


THIS PAGE

WAS INTENTIONALLY

LEFT BLANK 
Figure 30. Steady state particle paths for drops with forced internal circulation. The opper drop has an iniet velocity of $0.4 \mathrm{ca} / \mathrm{sec}$ and a viscosity of $1 \mathrm{cp}$. The louer drop has an inlet velocity of $0.2 \mathrm{ct} / \mathrm{sec}$ and a viscosity of $1 \mathrm{cp}$. 


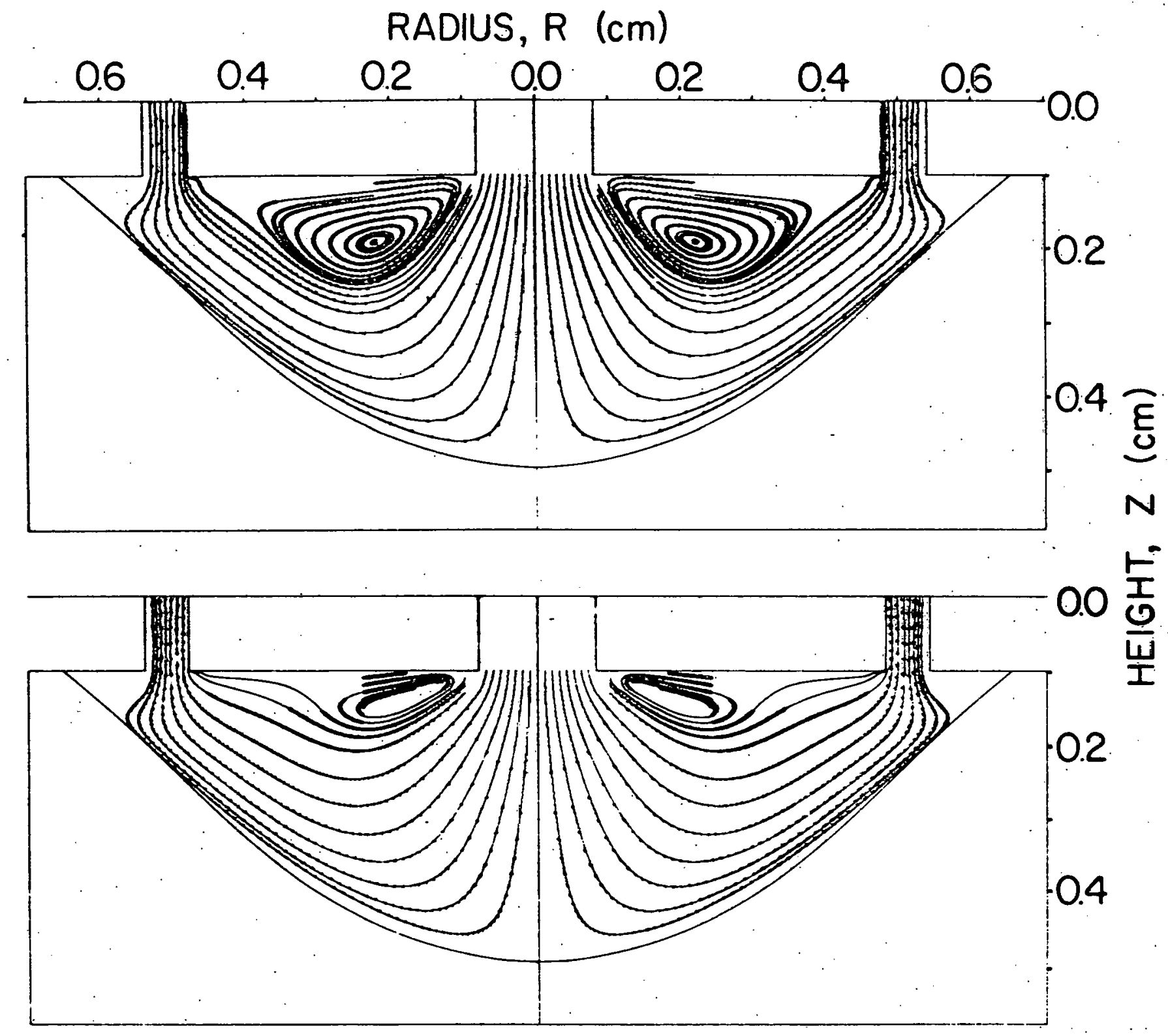


THIS PAGE WAS INTENTIONALLY
LEFT BLANK 
Figure 31. Vector velocity plots for drops with forced internal circulation. The upper drop has an inlet velocity of $1 \mathrm{~cm} / \mathrm{sec}$ and a viscosity of $1 \mathrm{cp}$. The lover drop has an

inlet velocitp of $0.2 \mathrm{cn} / \mathrm{sec}$ and a viscosity of $1 \mathrm{cp}$. 


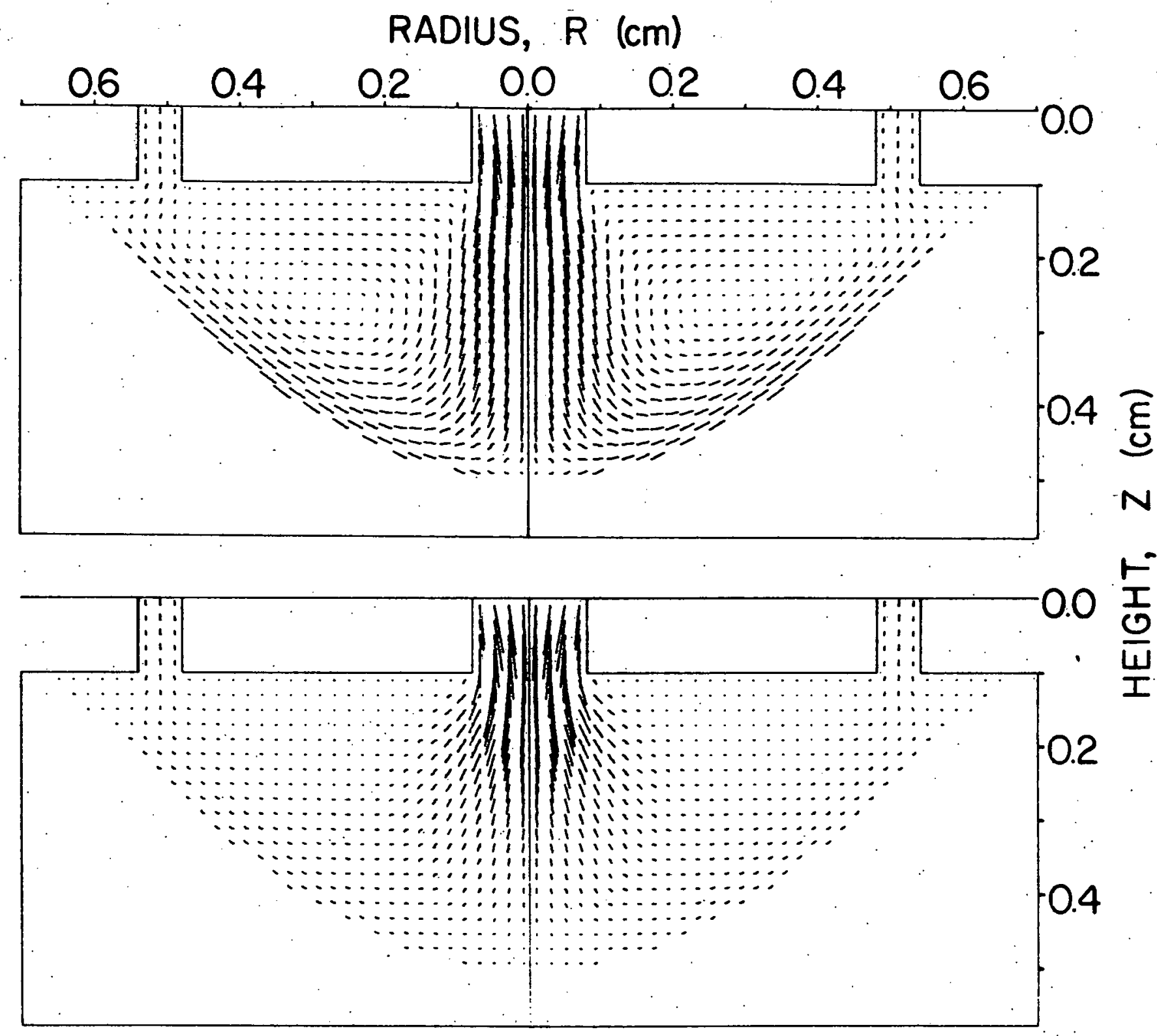

$\vec{\omega}$ 
curate enough to return the particle to the fluid region. The pathlines of those particles which enter the computing region throngh the nozzle mouth ultimately all pass within $0.05 \mathrm{~cm}$ of the interface and achieve the largest linear velocity of any path. This pattern also shows that the maximug gelocity down the interface is achieged in the region uhere the most surface area is present. This means that these particles are in an ideal position for mass transfer, and the model they suggest is the penetration theory model.

It should also be noted that the vector velocity plots in all the following results are scaled so that the raximum velocity vector has a length of $0.1 \mathrm{ca}$. Thus if a vector has a length of $\mathrm{A} \mathrm{cm}$, then the velocity it represents corresponds to $10 \mathrm{AVmax} \mathrm{cm} / \mathrm{sec}$. BI representing the velocity fields in this manner the relative magnitudes of the entire flow nay be seen at a glance.

These plots are also useful in determining velocity profiles ( $u(z) \mid r=$ constant, or $v(r) \mid z=c o n s t a n t)$. The profiles way be seen by sighting down the figure holding it nearly edgeuise to the eye. As an example, Fig. 31, if viewed edgewise at a radius of about $0.15 \mathrm{~cm}$ shows a horizontal velocity profile which is positive at the apex and negative at the base of the drop. This is one method of determining if rotation is present in a flow. Hovever, it 
should be pointed out that the vector components are actually averages of the velocities which border a given cell. Thus in. the case of a very small vortex, the rotation is rasked by the averaging process.

Comparison of the drops shown in Fig 29 reveals the change in circulation pattern as the inlet velocity is decreased from $1 \mathrm{~cm} / \mathrm{sec}$ to $0.5 \mathrm{~cm} / \mathrm{sec}$, while viscosity is held constant at $1 \mathrm{cp}$. The vortex center has changed, and the particles which previously passed within $0.05 \mathrm{~cm}$ of the interface now pass within $0.1 \mathrm{~cm}$. Also by comparison of the relative spacing of the + marks on the pathlines it can be seen that when the inlet velocity is $1 \mathrm{~cm} / \mathrm{sec}$ the residence time for particles near the interface is much less than when the inlet velocity is $0.5 \mathrm{~cm} / \mathrm{sec}$.

Figure 30 further reveals the trend in the reduction of internal velocities and the increase of residence times at the drop surface. The drops shown in this figure have inlet velocities of 0.4 and $0.2 \mathrm{~cm} / \mathrm{sec}$. Also as the internal velocities decrease, the size of the vortex tends to diminish and its center tends toward the corner of the inlet nozzle. In this study, the inlet velocity was not reduced far enough to eliminate vortex motion altogether, howerer, the lovest velocity calculated shoved a vortex that is the smallest resolvable by this technique, one cell widh at its narrowest point. This leads to the conclusion that at some inlet 
velocity less than $0.2 \mathrm{~cm} / \mathrm{sec}$ the rortex must be eliminated altogether, and that laninar flow throughout the drop. prevails.

When experiments were conducted using a fixed inlet velocity and varying viscosities, a lower limit for vortex flow was established. It was found that above a viscosity of 20 cp circulation did not occur, when the inlet velocity was held at 1 cin/sec. If dynaric similarity is a valid assumption, then the velocity at which this same transition would occur at $1 \mathrm{cp}$ would be between $0.1 \mathrm{~cm} / \mathrm{sec}$ and $0.05 \mathrm{~cm} / \mathrm{sec}$. Hovever, this remains to be shown.

The runs calculated varying viscosity wile holding velocity constant are presented in Figs, 32,33 and 34 . As can be seen by comparing the particle paths of the $20 \mathrm{cp}$ run and the $50 \mathrm{cp}$ run. Figs. 32 and 33, the break in flow pattern is apparent. This is probably caused by the limits of resolution in the calculation scheme as once the limiting vorter vidth has been reached rotation cannot be detected. Hovever, it is safe to say that if there were actually any vortex present beyond the Iimits established here, its overall effect on the flow patterns is insignificant.

One further observation that can be made is that for viscosities greater than $50 \mathrm{cp}$, the particle paths remain virtually unchanged. Thus beyond a certain point, further increases in viscosity no longer effect the flow pattern, but 
THIS PAGE

\section{WAS INTENTIONALLY \\ LEFT BLANK}


Figure 32. Steady state particle paths for drops uith forced internal circulation. The upper drop has a viscosity of 10 cp and the lower drop has a viscosity of $20 \mathrm{cp}$. Both drops. - have inlet velocities of $1, \mathrm{co} / \mathrm{sec}$. 


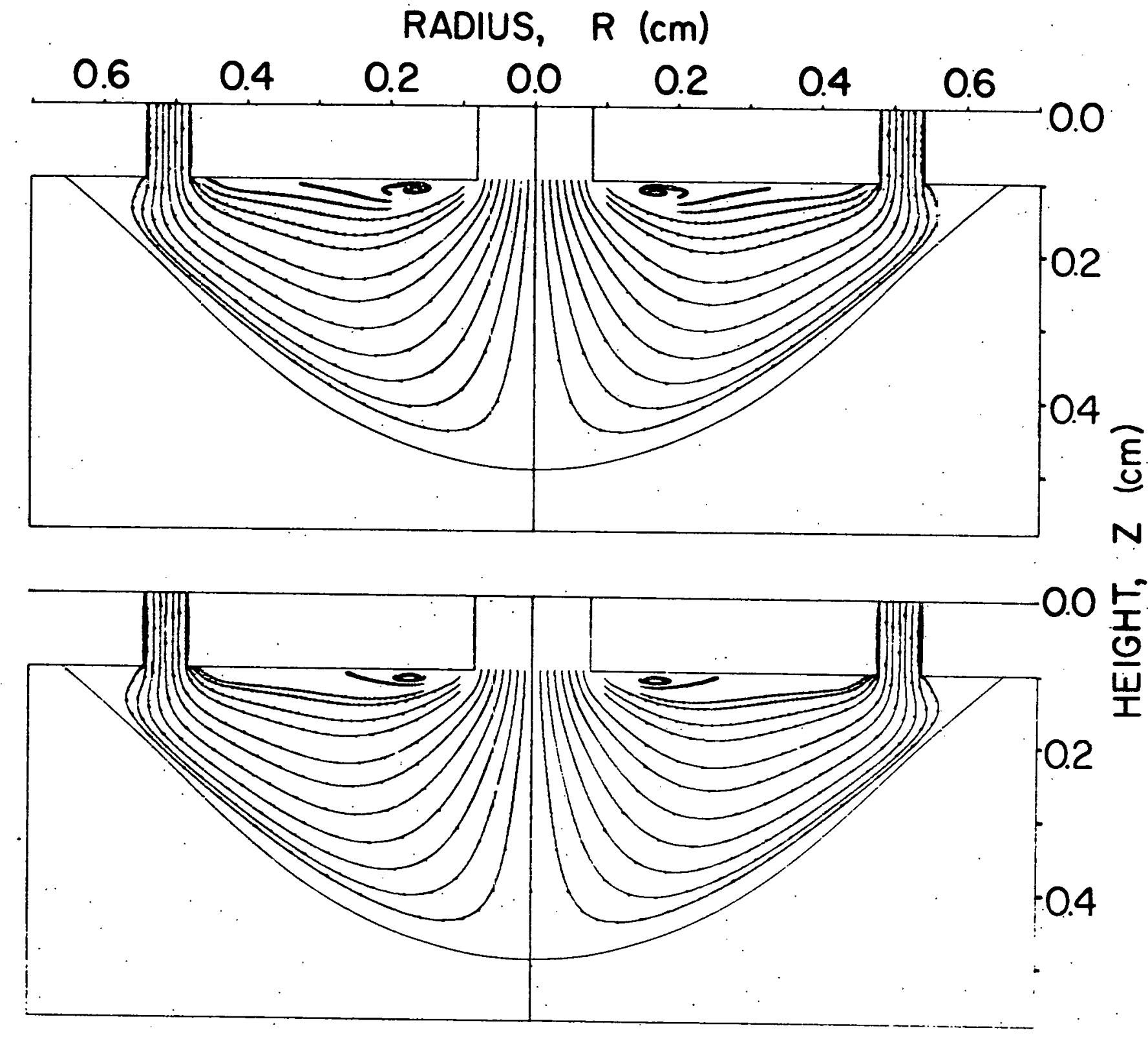

$\vec{\omega}$ 


\section{THIS PAGE}

WAS INTENTIONALLY

LEFT BLANK 
Pignce 33. Steady state particle paths for drops with forced internal circulation. The upper drop has a viscjsity of 50 Cp and the lower drop has a viscosity of $80 \mathrm{cp}$. Both drops have inlet. velocities of $1 \mathrm{ca} / \mathrm{sec}$. 


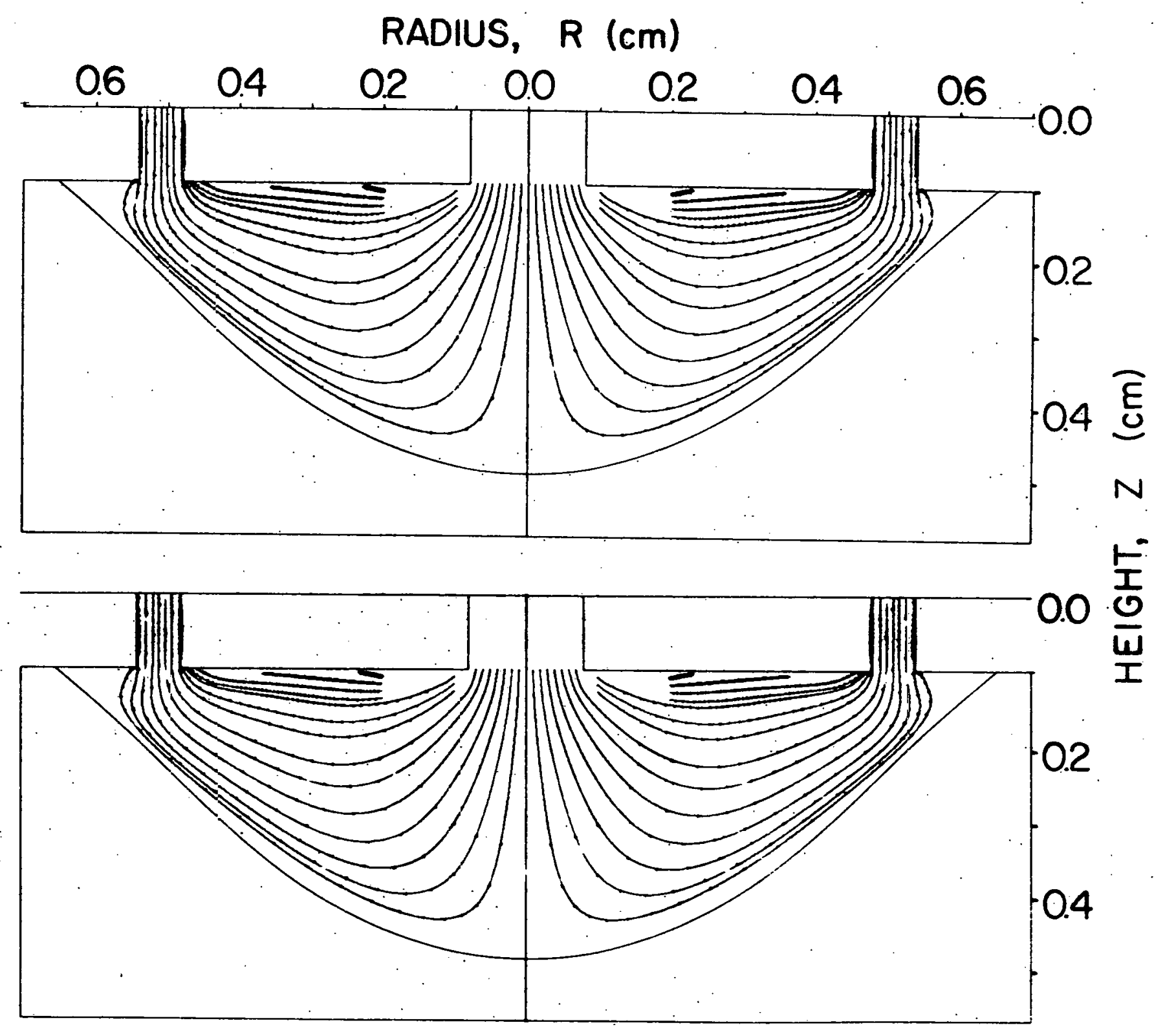

$\vec{\infty}$ 
THIS PAGE

\section{WAS INTENTIONALLY \\ LEFT BLANK}


Figure 34. Vector velocity plots for drops ith forced internal circulation. The upper drop has a viscasity of $10 \mathrm{cp}$ and the lover drop has a viscosity of $80 \mathrm{cp}$. . Eoth drops have inlet velocities of $1 \mathrm{~cm} / \mathrm{sec}$. 


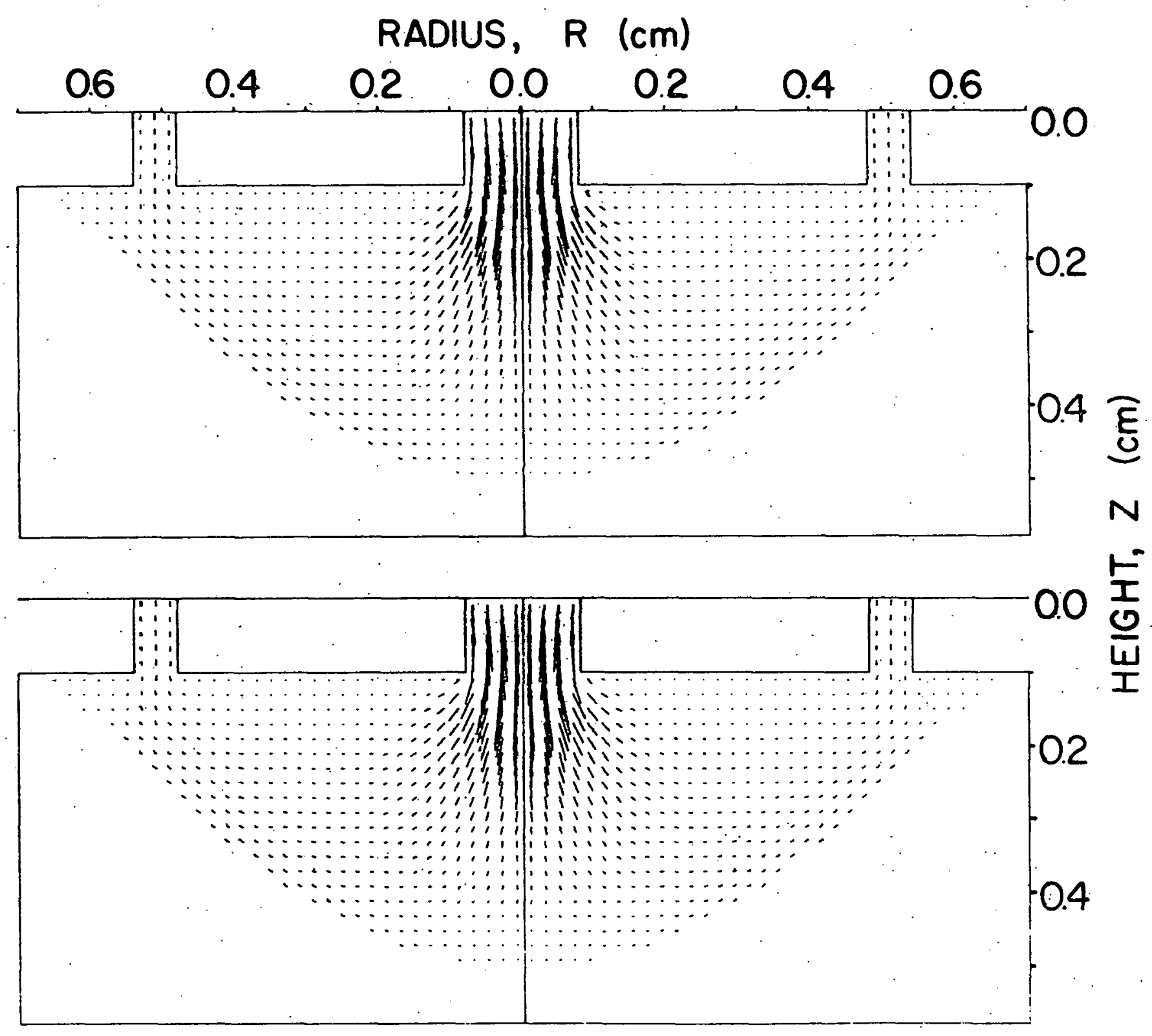

$\vec{E}$ 
rather just slou it down. This can be viewed as the point at which the second order term in the velocity equations is dominant with respect to the the rest of the terms.

Two adational flows were calculated for comparison uth those just presented, one at $10 \mathrm{cp}$ and $5 \mathrm{~cm} / \mathrm{sec}$ inlet velocity, and the other at $50 \mathrm{cp}$ and $1 \mathrm{~cm} / \mathrm{sec}$ inlet relocity, but with a variation in free surface velocity boundary conditions. The first calculation shown in Fig. 35 is an attempt to verify the dynamic similarity concept directiy. Here a drop with the sane Reynolas number as the $1 \mathrm{cp}, 0.5 \mathrm{~cm} / \mathrm{sec}$ run presented in Pig. 29 is shown. It can immediately be seen that while the flow patterns are not identical, they are very similar. When this difference was discovered, a check of the maximum velocities in the nozzle mouth was made. It was found that although the Reynolds number for these two flows based on the inlet velocity was the same, the Regnolds number based on the average velocity at the nozzle wouth were not. The difference in Reynolds number, due to the different rates at wich a parabollc velocity in the nozzle section was established, was significant enough to distinguish the two calculations. Hovever, verification of dynamic similarity is implied by the closeness of the two solutions.

The second additional calculation was made on a drop with a viscosity of $50 \mathrm{cp}$ and an inlet velocity of $1 \mathrm{~cm} / \mathrm{sec}$ and it is also shoun in Fig. 35. Hoverer, the fluid velocity 
THIS PAGE

\section{WAS INTENTIONALLY LEFT BLANK}


Pigure 35. Steady state particle paths for drops with forced internal circulation. The upper drop has a viscosity of 10 cp and an inlet relocity of $5 \mathrm{~cm} / \mathrm{sec}$. This was a test of dynamic similarity. The lower drop has a viscosity of $50 \mathrm{cp}$ and an inlet velocity of $1 \mathrm{~cm} / \mathrm{sec}$. The velocities at the surface of this drop vere set to zero to sigulate drag at the interface. 


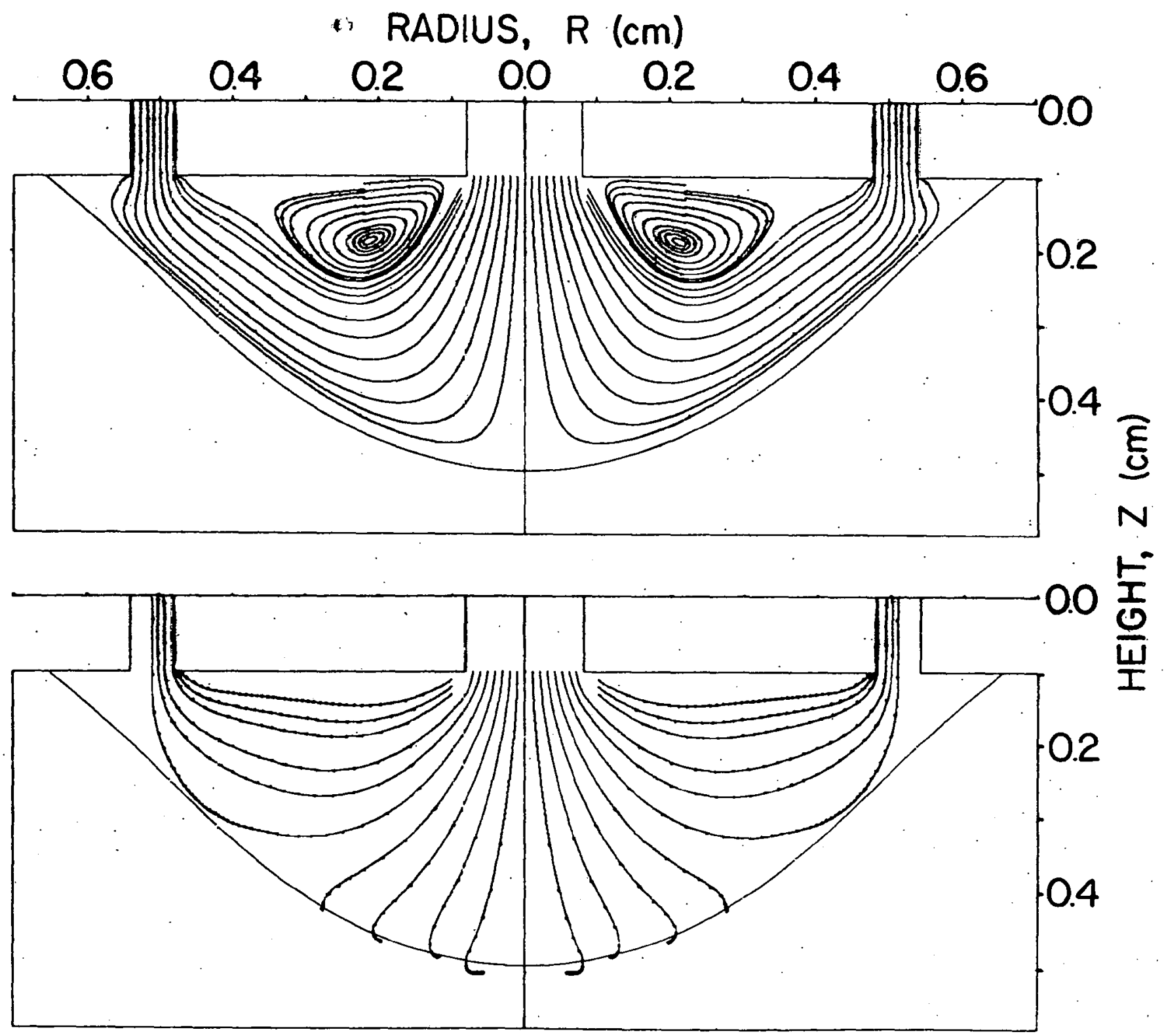


at the surface was restricted to be zero. This vas an attempt to test the effect of a no slip condition at the interface. It was decided that this boundary condition was inappropriate on the basis of the particle paths which resulted. As can be seen from Fig. 35, some of the particles travel to the interface and then stagnate, or drift very slowly toward the centerline. Also only about half of the particle paths that originate in the nozzle mouth terminate in the annulus. This implies that momentum is being lost across the interface.

Pinally, two photographs taken by Neathers (56) of forced internal circulation drops are included for general comparison.: The first is a drop with a viscosity of about 83 cp and an inlet velocity of $2 \mathrm{~cm} / \mathrm{sec}$. shown in Fig.36. A drop of lower viscosity, $1.4 \mathrm{cp}$, and the same inlet relocity is presented in Fig. 37. These photographs were taken during a two fluid experiment in an attempt to establish the flow patterns within groving drops experimentally. For this reason it is remarkable that the flows compare as well as they do with the results of this work. The similarity of the particle paths of Figs. 37 and 29 are obvious, even though the drop in the photograph is of a different viscosity, inlet velocity. interface boundary condition and shape. The same type of comparison can be nade between Figs. 36 and 33 , and again the flows are similar despite the differences in the 


\section{THIS PAGE}

WAS INTENTIONALLY

LEFT BLANK 
Figure 36. Time lapse photograph of a two flaid drop. Alusinue particles vere added to the drop: phase to create the particle paths. This drop has a viscosity of $\varepsilon 3$ cp and an inlet velocity of $2 \mathrm{ca} / \mathrm{sec}$. 


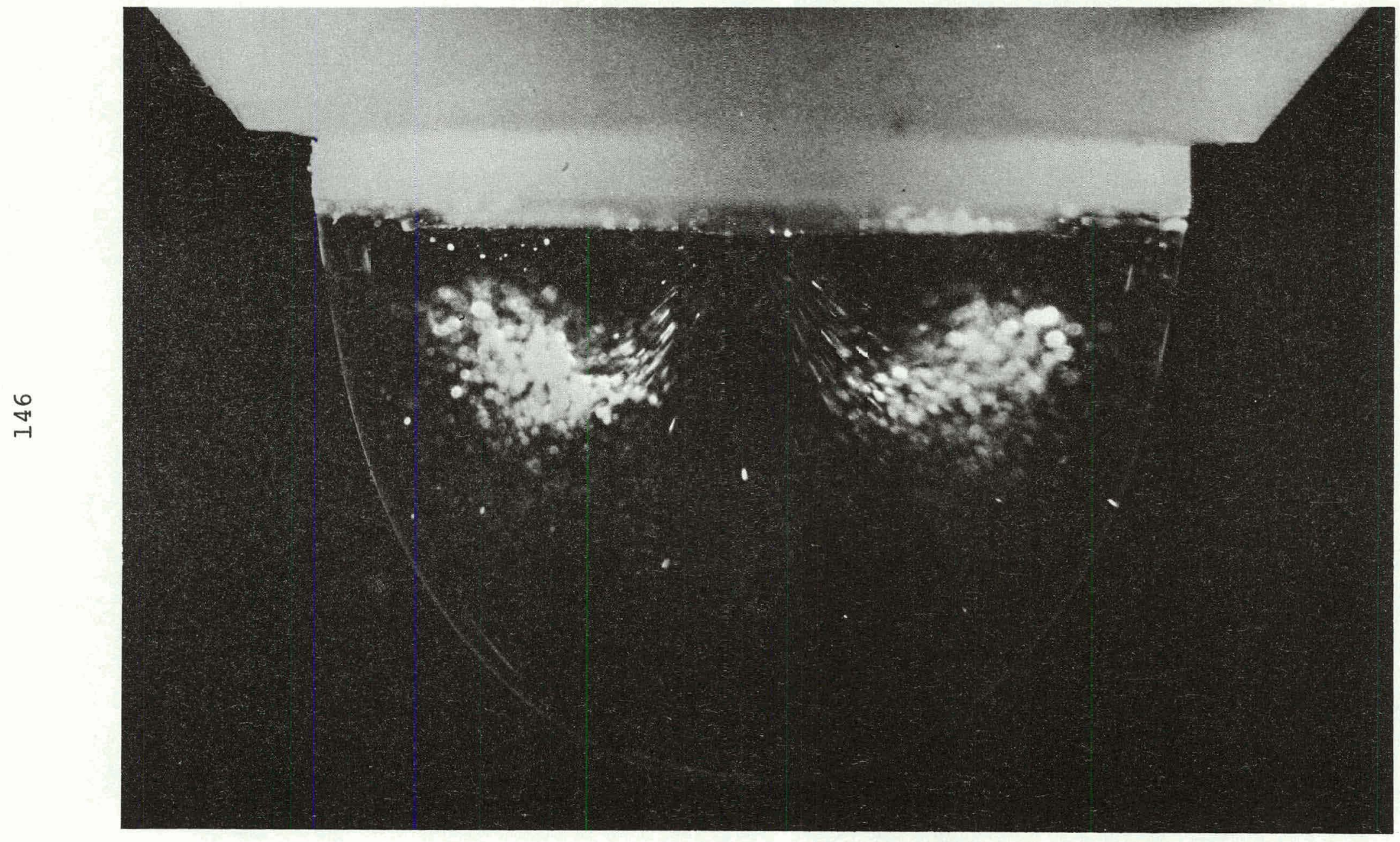




\section{THIS PAGE \\ WAS INTENTIONALLY \\ LEFT BLANK}


Figure 37. Tive lapse photograph of a two fluid drop. Aluminum particles in the drop phase produce the particle paths. This drop has a viscosity of $1.4 \mathrm{cp}$ and an inlet velocity of $2 \mathrm{~cm} / \mathrm{sec}$. 


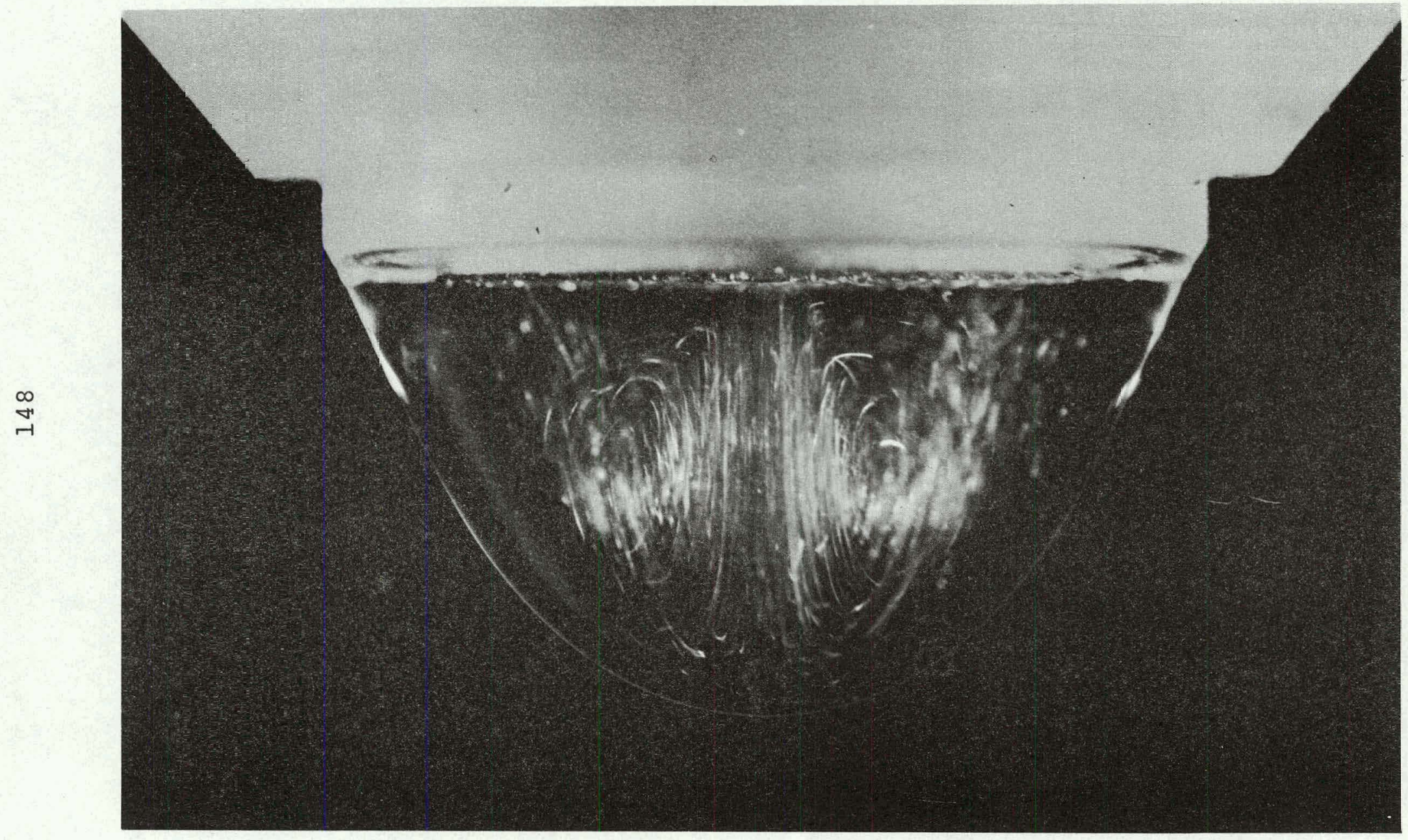


physical situations. Thus it is believed that the flow patterns presented here are valuable guides to the types of flow which is found both in drops with forced internal circulation, and slowly growing drops. Furthermore, it has been demonstrated that the MaC method when appropriately modified can produce solutions to the forced internal circulation drop problem, and that if a specific drop problem solution vere desired, it would be possible to use this technique to obtain it. 


\section{CONCLOSTONS AND RECOHAENDATIONS}

\section{Conclusions}

(1) The flow within a falling drop roughly approximates the flow within a separating drop, and indicates that surface stretch occurs mostly at the sides of the drop. Thus the creation of new surface area is the most likely means of mass transfer in this situation.

(2) The velocity distribution in the falling drop is plug flow in the direction of gravity. No rotation was found in this flow.

(3) The circulation patterns in drops with forced internal circulation obtained by the modified MAC nethod indicate two regimes of flow, rotating and non-rotating. The occurrence of rotation was observed only above Reynolds numbers of 0.8 if the Reynolds number is based on the drop viscosity, the inlet velocity, the nozzle diameter, and the drop density.

(4) The drops with forced internal circulation shoved high velocities at the interface in the region where the surface area is greatest. This suggests that penetration theory would explain the mass transfer process. Recommendations

(1) The MAC method has the potential to solve the conbined problen of a forming and separating drop. Hovever, $a$ means of calculating snooth and accurate surface curvatures 
must be found before this potential can be realized:

(2) Aull two fluid simulation should be made of the forced internal circulation drop problem, in order to determine the effects of a second phase on the flow patterns near the interface. Also the correct normal and tangential stress boundary conditions should be used in any future simulations of drops with forced internal circulation, in order to determine the effect of their onission in this work.

(3) An effort should be made to reduce the a mount of computer code necessary. to implement the modified MAC method, as considerable efficiency could be introduced in future calculations. 
NOM ENCLATURE

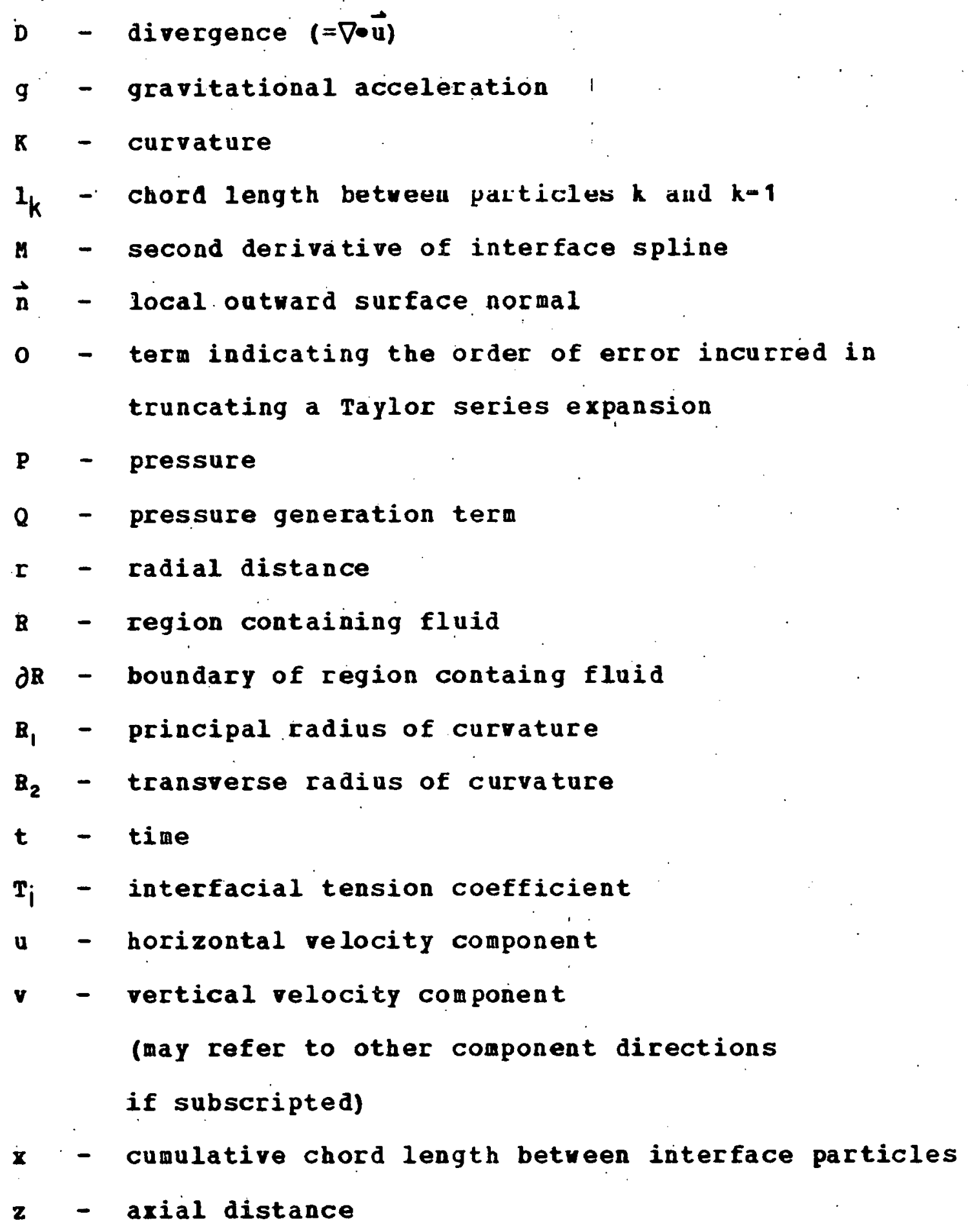


Greek Letters

$\alpha$ - fractional cell width of an "irregular star"

$\beta$ - relaration parameter

or - radial cell width

St - time step

$8 Z$ - axial cell width

$\epsilon \quad-$ convergence criterion

$\eta$ - normal direction

$\lambda$ - arbitrary constant

$\mu-v i s c o s i t y$

$\nu$ - kinematic viscosity

$\rho$ - density

$\tau$ - tangential direction

$\phi$ - pressure to density ratio

Superscripts

r - radial direction

$t \quad-$ time

$z$ - axial direction

- - differentiation with respect to $x$ 
Subscripts

$$
\begin{aligned}
& f \quad \text { - free surface } \\
& \text { i - radial direction index } \\
& \text { j - axial direction index } \\
& k \text { - particle index } \\
& \text { r - radial direction } \\
& \text { - - wall or line of symetry } \\
& z \text { - axial direction } \\
& \theta \quad \text { - angular direction }
\end{aligned}
$$




\section{ACKHOWLEDGEHENTS}

The author would like to thank Dr. L. E. Burkhart for proposing this project and for his continued guidance and encouragement. Special thanks are also due to Dr. F. H. Harlow of the Los alamos Scientific Laboratory for providing the sLosi computer code and output listing wich were the basis for the calculations, and also for providing many invaluable references to MAC calculations. Thanks are also due to Dr. Richard Seemann, Larry Stretz and Bill Frazier for their helpful suggestions and patience in listening to many ideas which were never pursued. Many thanks are also due to the entire Computation Center staff for their endless help in clearing up computation difficulties, and for putting up with my constant presence. Finally I rould like to thank my ufe for patiently enduring the many frustrations of graduate study, for her constant support, and for lettering all the equations and many of the figures used in this thesis. 


\section{BIBL IOGR APEY}

1. Ahlberg, J. H., Nilson, E. N. and Walsh, J. L. The theory of splines and their applications. Academic Press; New York, Y. Y. 1967.

2. Aris, R. Vectors, tensors and the basic equations of fluid mechanics. Prentice-Hall, Inc., Englewood Cliffs, N. J. 1962 .

3. Bashforth, $F$ and dams, J. An attempt to test the theories of capillary action. University press, Carbridge, England. 1883.

4. Bird, B. B., Stewart, H. E. and Lightfoot, E. N. Transport phenomena. John Riley and Sons, Inc., New York, N. Y. 1960 .

5. Brodkey, B. S. The phenowena of fluid motions. AddisonResley publishing Co.. Reading. Mass. 1967.

6. Chandrasekhar, S. Hydrodynamic and hydronagnetic stability. Oxford Oniversity Press, London, England. 1961.

7. Chan, R. K. C. and Street, R. I. A computer study of finite ampitude vater vaves. Journal of Computational Physics 6: 68-94. 1970.

8. Constan, G. L. and Calvert, S. Mass transfer in drops under conditions that promote oscillation and internal circulation. American Institute of Chenical engineers Journal 9: 109-115. 1963.

9. Daly. B. J. Numerical study of the effect of surface tension on interface stability. The Physics of Pluids 12: 1340-1354. 1969 .

10. Daly. B. J. Numerical study of tyo Eluid Rayleigh-Taylor instability. The Physics of Pluids 10: 297-307. 1967.

11. Daly. B. J. and Pracht, B. E. Numerical study of density-current surges. The Physics of Fluids 11: 15-30. 1968 .

12. Daly, B. J. A technique for including surface tension effects in hydrodynamic calculations. Journal of Computational Physics 4: 97-117. 1969. 
13. Dixon, B. B. and Russe11, A. A. A. The absorption of carbon dioxide by Iiquid drops. Journal of the society of Chemical Industry 69: 284-288. 1950 .

14. Freud, B. B. and Harkins, D. D. The shapes of drops and the deternination of surface tension. Journal of cherical Physics 33: 1217-1234. 1929.

15. Fromm, J. The time dependent floy of an inconpressible viscous fluid. In Alder, B.: Fernbach, S, and Rotenberg. 4. eds. Methods in computational physics. Vol. 3. pp. 345-382. Acadenic Press, Inc.. New York, N. Y. 1964.

16. Gal-Or, B., Klinzing, G. E. and Tavlarides, I. L. Bubble and drop phenomena. Industrial and Engineering Chenistry $61: \quad 21-34.1969$.

17. Garner, F. H. and skelland, A. H. P. Liquid-liquid mixing as affected by the internal circulation within droplets. Institute of Chemical Engineers rransactions 29: 315-321. 1951.

18. Gill, N. N., Cole, R., Davis, E. J., Lin, S. P., and Hunge, R. J. Fluid dynamics. Industrial and Engineering Chemistry 62: 108-139. 1970.

19. Gill, H. N., Cole, R., Estrin, J., Nunge R. J. and Littman; H. Fluid dynamics. Industrial and Engineering Chemistry 61: 41-75. 1969.

20. Gonezplata, A. and Regan, T. H. Hass transfer. Industrial and Engineering Chemistry 60: 53-62. 1968.

21. Grigar, K., Jaroslav, P. and Landau, J. Loss in pressure associated with drop formation in liquid-liquid systems. Chemical Engineering science 25: 1773-1783. 1970.

22. Groothuis, H. and Kramers, H. Gas absorption by single drops during formation: Chenical Engineering science 4: 17-25. 1954.

23. Halligan. J. E. and Burkhart, I. E. Determination of the profile of a groving drop. American Institute of Chenical Engineers Journal 14: 411-414. 1968 .

24. Halligan, J. E. and Burkhart, L. E. Flow during droplet separation. Journal of Colloid and Interface science 29: 658-663. 1969. 
25. Halligan, J. E. and Burkhart, L. E. Profile of a separating drop. Journal of Colloid and Interface Science 27: 127-132. 1968.

26. Halligan, J. E. The profile of a liquid droplet during formation and separation. Unpublished $P h . D$. thesis. Ames, Iowa, Library. Iowa State University. 1967.

27. Handlos, A. E. and Baron, T. Mass and heat transfer from drops in liquid-liquid extraction: American Institute of Chemical Bugineers Journal 3: 127-136. 1957.

28. Harlow, F. H. and Ansden, A. A. The sBac method: a numerical technique for calculating incompressible fluid flows. 0.S. Atoric Energy Comnission Report LA-4370 [ Los Alanos Scientific Laboratory. University of California. Los Alamos, N. M. ] 1970.

29. Harlow, F. H. Numerical methods for fluid dynamics, an annotated bibliography. U. S. Atomic Bnerg. Combission Report LA-4281 [ [ os Alamos Scientific Laboratory, University of California. Los Alanos. N. H.] 1969.

30. Harlow, F. H. and Shannon, J. P. The splash of a liquid drop. Journal of Applied Physics 38: 3855-3866. 1967.

31. Harlow. F. H. and Welch, J. E. Numerical calculation of time dependent $v i$ scous incompressible flow of fluid uith a free surface. The Physics of Pluids 8: 2182-2189. 1965.

32. Harlow, F. H. and Melch, J: E. Nunerical study of large anplitude free surface motions. The physics of Pluids 9: 842-851. 1966 .

33. Hayuorth, C. B. and Treybal, R. E. Drop formation in two-liquid-phase systems. Industrial and Bngineering Chemistry 42: 1174-1181. 1950.

34. Hirt, C. H. and Harlow, F. H. A general corrective procedure for the numerical solution of initial value problens. Journal of Computational Physics 2: 114-119. 1967.

35. Hirt. C. H. Heuristic stability theory for finite difference equations. Journal of Computational physics 2: $339=355.1968$. 
36. Hirt, C. H. and shannon, J. P. Free surface stress conditions for incompressible flow calculations. Journal of Computational physics 2: 403-411. 1968.

37. Kunar, R. A unified approach to bubble and drop formation. Chemical engineering Science 26: 177-184. 1971.

38. Lamb, Sir Horace. Hydrodynamics. 6th ed. Dover Publications, Inc.. Nev York, H. I. 1932 .

39. Landau, L. D. and Lifschitz, E. M. Fluid mechanics. Adison-Resley Publishing Co., Inc.. Reading, Hass. 1959.

40. Laplace, P. S. Treatise on capillary action. Mechanique Celeste. Supplement to Book 10. 1806. Original not available: cited in Bashforth, F. and Adams, J. An attempt to test the theories of capillary action. P. 5 . University Press, Cambridge, England. 1883.

41. Magarvey, R. H, and MaclatchY, C. S. Mass transfer and wake phenomena. American Institute of Chemical Bngineers Journal 14: 260-265. 1968.

42. Malvern, I. E. Introduction to the mechanics of a continuous media. Prentice-Hall, Inc.. Englewood cliffs, N. J. 1969.

43. Manfre, G. Rheological aspects of drop formation. Journal of Applied Physics 37: 1955-1962. 1966.

44. Uarsh, B. D. and Heideger, M. J. Uass transfer from free drops. Industrial and Engineering Chenistry Fundanentals $4: 129-133.1965$.

45. Narayanan, S., Basu, A. and BoY. N. K. Prediction of drop diameter during formation. Chemical Bngineering Science 25: 1950-1951. 1970.

46. Hichols, B. D. and Hirt, C. H. Improved free surface boundary conditions for numerical incompressible flow calculations. Journal of Conputational Physics 8: 434-448. 1971.

47. Null, H. R. and Johnson, B. F. Drop formation in liquidliquid systems from single nozzles. American Institute of Chemical Engineers Journal 4: 273-281. 1958. 
48. Panno, A. and Calvert, S. Mass transfer in drops with forced internal circulation. In ostrach, S. and scanlan, R. H.. eds. Developments in Uechanics. vol. 2. Part I. pp. 776-788. Pergaion Press, Ney York, H. Y. 1965.

49. Rao, E. V. I. H., Kumar, R. and Kuloor, H. R. Drop formation studies in liquid-iiquid systens. Chenical Engineering Science 21: 867-880. 1966.

50. Regan, T. H. and Gomezplata, A. Hass transfer. Industrial and Engineering Chemistry 62: 41-53. 1970.

51. Seemann, R. C. Drop separation in a liquid-liquid systen. Unpublished M.S. thesis. Ames, Iowa, Library. Iowa state University. 1970.

52. Sharer, P. C. Mass transfer frow a drop with forced internal circulation. onpublished H.S. thesis. Anes, Iova, Iibrary. Iowa State University. 1972.

53. Tavlarides, L. L., Coulaloglou, C. A., Zeitlin, M. A., Klinzing. G. E. and Gal-or, B. Bubble and drop phenonena. Industrial and Engineering chemistry 62: 6-27. 1970.

54. Viecelli; J. A. A computing nethod for incompressible flows bounded by moving valls. Journal of Conputational Physics 8: 119-143. 1971.

55. Viecelli. J. A. A method for including arbitrary external boundaries in the MAC incompressible fluid compating technique. Journal of Computational Physics 4: 543-551. 1969.

56. Neathers. P. M. Internal flow patterns of forming liquid drops. Onpublished H.S. thesis. Anes, Iowa, Library. Ioua State Oniversity. 1970.

57. Delch, J. E., Harlow, F. H.. Shannon, J. P. and Daly, B. J. The ac nethod: a computing technique for solving iscous, incompressible, transient fluid flow probleas involving free surfaces. U. S. Atonic Energy Conmission Report LA-3425 [Los Alamos Scientific Laboratory, University of California, Los Alamos, U. U.] 1965. 